Aus der Abteilung Kardiologie und Pneumologie

(Prof. Dr. med. G. Hasenfuß)

im Zentrum Innere Medizin

der Medizinischen Fakultät der Universität Göttingen

\title{
Regulation nukleoplasmatischer Kalziumtransienten in Kardiomyozyten
}

\author{
INAUGURAL - DISSERTATION \\ zur Erlangung des Doktorgrades \\ der Medizinischen Fakultät \\ der Georg-August-Universität zu Göttingen \\ vorgelegt von \\ Mojib Ahmad Asgarzoei \\ aus \\ Kabul (Afghanistan)
}

Göttingen 2012 
De k a n: Prof. Dr. Michael P. Schön

I. Berichterstatter: Prof. Dr. rer. nat. J. Kockskämper

II. Berichterstatter/in:

III. Berichterstatter/in:

Tag der mündlichen Prüfung: 


\section{Inhaltsverzeichnis}

1. Einleitung 9

1.1 Anatomie und Funktion des Herzens.................................... 9

1.2 Elektrische Erregung der Herzmuskelzelle............................ 10

1.3 Kalziuminduzierte Kalziumfreisetzung............................... 12

$1.4 \mathrm{Ca}^{2+}$ und seine Regulation im Zellkern.............................. 15

1.5 Zielsetzung der Arbeit.............................................. 19

2. Material und Methoden $\quad 20$

2.1 Isolation der Kaninchenmyozyten................................ 20

2.1.1 Lösungen und Substanzen.................................. 20

2.1.1.1 Pufferlösung..................................... $\quad 20$

2.1.1.2 Kollagenaselösung............................... 20

2.1.1.3 Stopplösung.................................... 21

2.1.1.4 Albuminlösung.................................. 21

2.1.2 Myozytenisolation..................................... 21

2.2 Isolation der Mäusemyozyten..................................... 22

2.2.1 Lösungen und Substanzen................................. 22

2.2.1.1 Pufferlösung................................... 22

2.2.1.2 Kollagenaselösung............................... 22

2.2.2 Myozytenisolation...................................... 22

2.3 Vorbereitung zur Messung....................................... 22

2.3.1 Lösungen und Substanzen............................... 22

2.3.1.1 Fluo-4/AM................................. 22 
2.3.1.2 Laminin

2.3.1.3 Forskolin...................................... 23

2.3.2 Ausplattieren der Zellen und Beladung mit Fluo-4/AM...... 24

2.4 Messapperatur............................................... 24

2.5 Durchführung einer Messung............................... 25

2.6 Auswertung.............................................. 25

2.6.1 Analyse der elektrisch stimulierten $\left[\mathrm{Ca}^{2+}\right]$-Transienten...... 25

2.6.2 Kalibrierung der $\left[\mathrm{Ca}^{2+}\right]-$ Konzentration aus den

Fluoreszenzänderungen.............................. $\quad 26$

2.6.3 Statistik.............................................. 28

3. Ergebnisse 29

3.1 Frequenzabhängige $\mathrm{Ca}^{2+}$-Änderungen in Kaninchenventrikelmyozyten 29

3.1.1 Frequenzabhängige Änderungen des diastolischen $\mathrm{Ca}^{2+} \ldots \ldots .29$

3.1.2 Frequenzabhängige Änderungen des systolischen $\mathrm{Ca}^{2+} \ldots \ldots$.

3.1.3 Zeit bis zum Erreichen des systolischen maximalen $\mathrm{Ca}^{2+} \ldots \quad 32$

3.1.4 Zeitkonstante des Abfalls des $\mathrm{Ca}^{2+}$-Transienten............ 32

3.2 Frequenzabhängige $\mathrm{Ca}^{2+}$-Änderungen in Kaninchenvorhofmyozyten 32

3.2.1 Frequenzanhängige Änderungen des diastolischen $\mathrm{Ca}^{2+} \ldots \ldots$.

3.2.2 Frequenzabhängige Änderungen des systolischen $\mathrm{Ca}^{2+} \ldots \ldots .33$

3.2.3 Zeit bis zum Erreichen des systolischen maximalen $\mathrm{Ca}^{2+} \ldots . \quad 35$

3.2.4 Zeitkonstante des Abfalls des $\mathrm{Ca}^{2+}$-Transienten............. 35

3.3 Frequenzabhängige $\mathrm{Ca}^{2+}$-Änderungen in Mausventrikelmyozyten..... 35

3.3.1 Frequenzabhängige Änderungen des diastolischen $\mathrm{Ca}^{2+} \ldots \ldots . \quad 36$

3.3.2 Frequenzabhängige Änderungen der systolischen Kalziumspiegel 36

3.3.3 Zeit bis zum Erreichen des systolischen $\mathrm{Ca}^{2+} \ldots \ldots \ldots \ldots \ldots . . . . .38$

3.3.4 Abfall des $\mathrm{Ca}^{2+}$ Transienten............................. 38

3.4 $\mathrm{Ca}^{2+}$-Änderungen in Vorhofmyozyten des Kaninchens nach definierter Pause

Stimulation.................................................. 40

3.4.1 Änderung des diastolischen $\mathrm{Ca}^{2+}$ nach der Stimulationspause $\quad 40$

3.4.2 Änderung des systolischen $\mathrm{Ca}^{2+}$ nach der Stimulationspause $\quad 41$

$3.5 \mathrm{Ca}^{2+}$-Änderungen in Ventrikelmyozyten der Maus nach definierter Pause der

Stimulation............................................... 41

3.5.1 Änderung des diastolischen $\mathrm{Ca}^{2+}$ nach der Stimulationspause $\quad 41$ 
3.5.2 Änderung des systolischen $\mathrm{Ca}^{2+}$ nach der Stimulationspause

3.6 Änderung des systolischen und diastolischen $\mathrm{Ca}^{2+}$ in Mäusekardiomyozyten unter pharmakologischer Beeinflussung durch Forskolin............. 45

3.6.1 Veränderungen des diastolischen $\mathrm{Ca}^{2+}$ unter Forskolin....... 46

3.6.2 Veränderungen des systolischen $\mathrm{Ca}^{2+}$ unter Forskolin........ 46

3.6.3 Zeit bis zum Erreichen des systolischen $\mathrm{Ca}^{2+} \ldots \ldots \ldots \ldots \ldots . . . . .49$

3.6.4 Abfall des $\mathrm{Ca}^{2+}$-Transienten............................. 49

3.7 Zellkerne und perinukleäre $\mathrm{Ca}^{2+}$-Speicher in Kardiomyozyten des Kaninchens

3.7.1 Ausmaße des Zellkerns in Ventrikel- und Vorhofmyozyten des Kaninchens. 51

3.7.2 Kerntubuli.

4. Diskussion

4.1 Frequenzabhängige Änderungen des $\mathrm{Ca}^{2+}$-Spiegels................. 54

4.2 Frequenzabhängige Änderung der Kinetik des $\mathrm{Ca}^{2+}$-Transienten..... 56

4.3 Änderungen des $\mathrm{Ca}^{2+}$-Transienten nach Forskolingabe............... 58

4.4 Unterschiedliche Regulation des $\mathrm{Ca}^{2+}$ im Kern und im Zytoplasma... $\quad 59$

4.5 Die Kernhülle und die nukleären Tubuli.......................... 60

5. Zusammenfassung 


\section{Abbildungsverzeichnis}

1.1 Goldman-Hodgkin-Katz-Gleichung............................... 11

1.2 Schema der T-Tubuli des Sarkolemms und der Lokalisation der

L-Typ-Kalzium-Kanäle und Ryanodin-Rezeptoren............................ 13

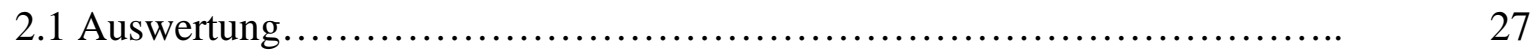

3.1 Frequenzabhängige Änderungen des $\mathrm{Ca}^{2+}$ in Ventrikelmyozyten des Kaninchens 30

3.2 Ergebnisse der frequenzabhängigen Änderungen des $\mathrm{Ca}^{2+}$ in Vorhofmyozyten des

Kaninchens...................................................... 34

3.3 Diastolische und systolische frequenzabhängige $\mathrm{Ca}^{2+}-\ddot{A}$ nderungen in

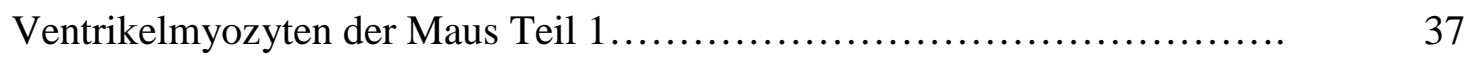

3.4 Diastolische und systolische frequenzabhängige $\mathrm{Ca}^{2+}-$ Änderungen in

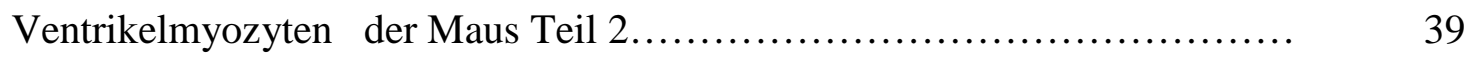

$3.5 \mathrm{Ca}^{2+}$ in Vorhofmyozyten des Kaninchens nach einer Stimulationspause........ 42

3.6 $\mathrm{Ca}^{2+}$ in Ventrikelmyozyten der Maus nach einer Stimulationspause............ 44

$3.7 \mathrm{Ca}^{2+}$ - ̈̈nderungen nach Applikation von Forskolin Teil 1.................... 47

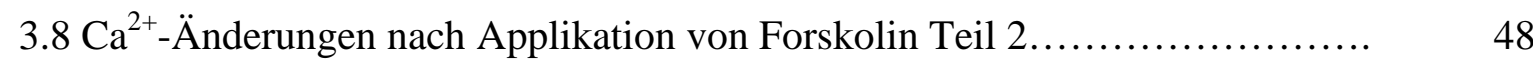

3.9 Färbung der intrazellulären $\mathrm{Ca}^{2+}$-Speicher der Ventrikel- und Vorhofmyozyten des

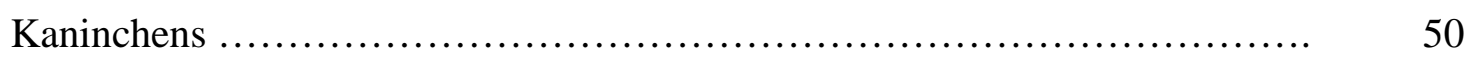

3.10 Anzahl der Kerntubuli.......................................... $\quad 52$ 


\section{Abkürzungsverzeichnis}

AMP

ANOVA.

AP-1

ATF-1

ATP.

BDM

DNA

DREAM.

$[\mathrm{Ca} 2+]$

CaM.

CaMK

cAMP

CREB

CRM1

DAG

DHPR

DMSO

Fluo-4/AM

HDAC

HEPES.

FKBP12.6.

IP3

IP3R

$\mathrm{kDA}$

M.

MEF2

mRNA

MW

NCX
Adenosinmonophosphat

analysis of variance

activation protein-1

activating transcription factor-1

Adenosintriphosphat

2,3-Butandionmonoxim

Desoxyribonukleinsäure

Downstream Regulatory Element Antagonist Modulator

$\mathrm{Ca}^{2+}$-Konzentration

Calmodulin

$\mathrm{Ca}^{2+} / \mathrm{CaM}$-abhängige Proteinkinase

Zyklisches Adenosinmonophosphat

Cyclic-AMP-Response-Element-Binding-Protein

chromosomal region maintenance protein 1

Diacylglycerin

Dihydropyridinrezeptor

Dimethylsulfoxid

Fluo-4/Azetoxymethylester

Histondeacetylasen

2-(4-(2-Hydroxyethyl)-1-piperazin)-Ethansulfonsäure

FK506-Bindungsprotein 12.6

Inositoltrisphosphat

Inositoltrisphosphatrezeptor

Kilo-Dalton

$\mathrm{mol} / \mathrm{l}$

myocyte enhancer factor 2

messenger RNA

molecular weight / Molekulargewicht

$\mathrm{Na}^{+} / \mathrm{Ca}^{2+}$-Austauscher 
NFAT

$\mathrm{pH}$

PIP2

PKA.

PKD.

PLC

RT50

RYR

SEM.

SERCA

SRF.

TTP nuclear factor of activated T-cells

negativer dekadischer Logarithmus der ProtonenKonzentration

Phosphatidylinositol-4,5-bisphosphat

Proteinkinase A

Proteinkinase D

Phospholipase C

relaxation time $50 \%$

Ryanodinrezeptor

Standard error of the mean

$\mathrm{Ca}^{2+}$ ATPase des sarkoplasmatischen/endoplasmatischen Retikulums

serum response factor

Time to peak 


\section{Einleitung}

\subsection{Anatomie und Funktion des Herzens}

Dem Herzen ist im Organismus eine wesentliche Rolle zugeordnet. Sein Gewicht beträgt ca. $300 \mathrm{~g}$, lokalisiert ist es thorakal im mittleren Mediastinum. Es ist ein großer Muskel, welcher durch ein eigenes aus Bindegewebe bestehendes Skelett, das Herzskelett, gestützt wird. Das Herz funktioniert wie eine Pumpe, welche aus verschiedenen Teilen besteht. Diese Pumpe setzt sich aus 4 Hohlräumen zusammen, welche durch 4 Klappen voneinander getrennt werden. Man teilt das Herz ein in ein rechtes und ein linkes Herz. Beide bestehen aus je einem Vorhof, welcher mit einer Kammer verbunden ist. Das sauerstoffarme Blut gelangt aus dem großen Kreislauf, welcher alle Organe bis auf die Lunge umfasst, über die obere und untere Hohlvene (Vv. cavae superior et inferior) in den rechten Vorhof. Von dort aus gelangt es über eine Herzklappe, die Trikuspidalklappe, in die rechte Herzkammer. An die rechte Herzkammer ist der Pulmonalstamm angeschlossen, der sich in zwei Pulmonalarterien aufspaltet, welche in die Lunge ziehen. Zwischen Pulmonalstamm und rechter Herzkammer befindet sich die Pulmonalklappe. Die rechte Kammer pumpt das Blut über die Lungenarterien in die Lunge, wo das Blut mit Sauerstoff angereichert wird und über die Lungenenvenen in den linken Vorhof gelangt. Dieser ist mit der linken Kammer verbunden, wird von dieser allerdings auch durch eine Herzklappe, die Mitralklappe, getrennt. An die linke Kammer ist die Aorta, die Hauptschlagader, angeschlossen. Auch liegt hier, wie zwischen rechter Kammer und Pulmonalarterie, eine Herzklappe, die Aortenklappe. Die linke Kammer pumpt das mit Sauerstoff gesättigte Blut über die Aorta in den großen Kreislauf. Hierbei sorgen die Herzklappen dafür, dass das Blut immer nur in eine Richtung fließt und verhindern einen Rückstrom in die entgegengesetzte Richtung.

Wenn die beiden Kammern kontrahieren, öffnen sich die Pulmonal- und Aortenklappe, um einen Blutfluss in die Richtung des großen Kreislaufs (Körperkreislauf über die Aorta) und des kleinen Kreislaufs (Lungenkreislauf über Pulmonalarterie) zu gewährleisten. Gleichzeitig schließen sich die Herzklappen zwischen den Kammern und den Vorhöfen (Trikuspidal- und Mitralklappe), damit das Blut nicht von den Kammern in die Vorhöfe gelangt. Während dessen füllen sich die Vorhöfe passiv wieder mit Blut, welches jedoch durch die geschlossenen Klappen vorerst nicht in die Kammern gelangt. Diesen Vorgang nennt man die 
Systole. Nachdem das Blut aus den Kammern gepumpt wurde, erschlafft das Herz. Pulmonalund Aortenklappe schließen sich, damit das Blut aus den Gefäßen nicht zurück in das Herz strömt. Gleichzeitig öffnen sich die Klappen zwischen Kammern und Vorhöfen, damit das Blut aus den Vorhöfen in die Kammern gelangt. Hierbei erfolgen nur etwa $20 \%$ bis $30 \%$ der Füllung durch aktive Kontraktion der Vorhöfe, der Rest gelangt passiv in die Kammern. Diesen Vorgang nennt man Diastole.

Modifiziert werden diese Aktionen durch das vegetative Nervensystem. Bei steigender Belastung muss eine Erhöhung des Herzzeitvolumens zur erhöhten Durchblutung der Organe erfolgen. Das vegetative Nervensystem kann in zwei Teile aufgeteilt werden, die als Gegenspieler verstanden werden können. Der Sympathikus erhöht die Herzfrequenz (positivchronotroper Effekt) und steigert die Kraft (positiv-inotroper Effekt), der Parasympathikus wirkt gegenteilig. Die Nervenfasern des Sympathikus, welche das Herz innervieren (Nervi cardiaci), kommen aus den zervikalen Ganglien. Die parasympathischen Fasern entstammen dem Nervus vagus, dem 10. Hirnnerven. Sowohl sympathische als auch parasympathische Fasern innervieren den Sinusknoten, welcher sich in der Wand des rechten Vorhofs in der Nähe der Einmündung der oberen Hohlvene befindet.

\subsection{Elektrische Erregung der Herzmuskelzelle}

Der Herzmuskel besteht aus Muskelzellen, den Kardiomyozyten. Diese arbeiten im Verbund als funktionelle Einheit. Am Beginn jeder Herzmuskelkontraktion steht die elektrische Erregung der Zelle. Zwischen dem Inneren der Zelle und dem Extrazellulärraum herrscht über der Zellmembran eine Ladungsdifferenz, welche durch eine Konzentrationsdifferenz verschiedener Ionen zwischen diesen beiden Kompartimenten und der selektiven Permeabilität für bestimmte Ionenspezies gewährleistet wird. Man spricht hierbei auch vom Ruhemembranpotenzial. Bei Konzentrationsunterschieden über dieser für Ionen permeablen Membran erfolgt eine Diffusion der Ionen durch die Membran entlang des Konzentrationsgefälles. Gleichzeitig wird aber auch eine elektrische Ladung verschoben. Durch diese Ladungsverschiebung entsteht ein elektrisches Feld, dessen Feldstärke von der über die Membran verschobenen Ladungsmenge abhängt. Das elektrische Feld lässt sich durch eine Potentialdifferenz über der Membran nachweisen. In dem elektrischen Feld wirkt auf die Ionen eine Kraft, die in ihrer Richtung dem Konzentrationsgefälle entgegengesetzt ist und dadurch die Ionen in dem Bestreben, die Membran zu durchtreten, behindert. Die wirkende Kraft ist proportional zur elektrischen Feldstärke. Es stellt sich ein stabiles 
elektrische Potential ein, bei dem die auf die Ionen wirkende Kraft gerade so groß ist, dass ein Durchtritt der Ionen durch die Membran entlang des Konzentrationsgefälles verhindert wird. Hier besteht also ein Gleichgewicht eines Konzentrationsgradienten und eines entgegengesetzten elektrischen Gradienten.

Die Permeabilität der Zellmembran ist für die verschiedenen Ionen unterschiedlich groß. Dies wird bei der Berechnung des Membranpotentials nach Goldman, Hodgkin und Katz (Clay 2009) berücksichtigt (Abbildung 1.1). Mit der Goldman-Hodgkin-Katz-Gleichung ergibt sich ein Ruhemembranpotential von ca. $-90 \mathrm{mV}$. Dieser Wert lässt sich auch experimentell nachweisen.

$$
U_{M}=\frac{R T}{F} \cdot \ln \frac{p_{N a} \cdot\left[N a^{+}\right]_{a}+p_{K} \cdot\left[K^{+}\right]_{a}+p_{C l} \cdot\left[C l^{-}\right]_{i}}{p_{N a} \cdot\left[N a^{+}\right]_{i}+p_{K} \cdot\left[K^{+}\right]_{i}+p_{C l} \cdot\left[C l^{-}\right]_{a}}
$$

Abbildung 1.1 - Goldman-Hodgkin-Katz-Gleichung. Hierbei handelt es sich um die Gleichung, welche zur Errechnung des Ruhemembranpotentials verwendet wird. R steht hier für die universelle Gaskonstante, $T$ für die absolute Temperatur in Kelvin, F für die Faradaysche Konstante, $P$ für die Permeabilität (leitet sich aus dem Fickschen Diffusionsgesetz ab und ist der Quotient aus der Diffusionskonstanten und der Membrandicke), K für Kalium, Na für Natrium und Cl für Chlorid. Berechnet wird hierbei die Membranspannung in $m V$.

Vornehmlich verantwortlich ist hierfür das $\mathrm{K}^{+}$, dessen Gleichgewichtspotenzial über der Zellmembran in Ruhe bei ca. $-90 \mathrm{mV}$ liegt und für das die Membran unter Ruhebedingungen die größte Permeabilität besitzt. Das Ruhemembranpotenzial der Zelle liegt, mit beeinflusst durch die anderen Ionen, bei ca. $-85 \mathrm{mV}$. Die Zellmembran ist mit verschiedenen Kanälen durchsetzt, von denen einige für Ionen spezifisch sind und somit einerseits das Ruhemembranpotenzial aufrechterhalten und andererseits die Depolarisation der Zelle ermöglichen. Im Herzen handelt es sich hierbei hauptsächlich um $\mathrm{Na}^{+}-, \mathrm{K}^{+}$- und $\mathrm{Ca}^{2+}-\mathrm{Kanäle}_{\text {. }}$ Trifft die Erregung auf die Zelle, kommt es zur Depolarisation des Membranpotenzials. Ab einem Schwellenwert von ca. $-60 \mathrm{mV}$ öffnen sich die spannungsgesteuerten $\mathrm{Na}^{+}-\mathrm{Kanäle}$, wodurch es entsprechend dem elektrochemischen Gradienten zum Einstrom von $\mathrm{Na}^{+}$-Ionen in die Zelle kommt. Das Membranpotenzial kann nun auf einen Wert von ca. $+30 \mathrm{mV}$ steigen. 
Diese Phase des Aktionspotenzials wird Aufstrich (Phase 0) genannt und dauert ca. 1 Millisekunde (ms). Die $\mathrm{Na}^{+}$-Kanäle werden unmittelbar nach diesem schnellen Aufstrich inaktiviert. Durch eine Zunahme der Permeabilität der Zellmembran für $\mathrm{K}^{+} \mathrm{zu}$ Beginn des Aktionspotenzials(durch die Aktivierung des transienten Auswärtsstroms) wird der $\mathrm{K}^{+}$Ausstrom kurzzeitig gesteigert. Während dieser Zeit fällt das Membranpotential von einer initialen Spitze aus leicht ab, dieser Abschnitt wird Phase 1 genannt. Etwas verzögert gegenüber den $\mathrm{Na}^{+}-$Kanälen öffnen sich die $\mathrm{Ca}^{2+}$-Kanäle und $\mathrm{Ca}^{2+}$-Ionen strömen in die Zelle. Der $\mathrm{Ca}^{2+}$-Einstrom wirkt der Repolarisation der Zelle entgegen. Man nennt diese Phase, in der sich das Membranpotential über einen relativ langen Zeitraum (ca. 200-250 ms) nur wenig repolarisiert, die Plateauphase (Phase 2). Während der Plateauphase steigt die Permeabilität der Zellmembran für $\mathrm{K}^{+}$wieder auf Werte etwas über dem Ruhewert an. Die Permeabilität für $\mathrm{Ca}^{2+}$ nimmt gleichzeitig ab. Durch den jetzt stark zunehmenden $\mathrm{K}^{+}$-Ausstrom repolarisiert sich die Zellmembran (Repolarisationsphase, Phase 3) und es kommt zur Rückkehr zum Ruhemembranpotenzial.

Herzmuskelzellen zeigen eine ausgeprägte Refraktärphase, d. h. eine Phase, in der kein neues Aktionspotential ausgelöst werden kann. Die absolute Refraktärphase beginnt unmittelbar mit dem schnellen Aufstrich des Aktionspotentials. Innerhalb dieser Phase kann, auch durch sehr starke Reize, kein neues Aktionspotential ausgelöst werden. Erst gegen Ende der Repolarisation können in der Amplitude abgeschwächte und zeitlich verkürzte Aktionspotentiale ausgelöst werden. Man nennt diese Phase relative Refraktärphase. Erst nach der relativen Refraktärphase können wieder in Amplitude und Dauer reguläre Aktionspotentiale ausgelöst werden. Ursache für das refraktäre Verhalten der Herzmuskelzelle ist eine anhaltende Inaktivierung des $\mathrm{Na}^{+}$-Kanals während der Depolarisationsphase. Erst nach Repolarisation auf Werte kleiner $-40 \mathrm{mV}$ setzt die Erholung des $\mathrm{Na}^{+}$-Kanals ein.

\subsection{Kalziuminduzierte Kalziumfreisetzung}

Nach Inaktivierung der spannungsabhängigen $\mathrm{Na}^{+}$-Kanäle kommt es zur Öffnung der L-Typ$\mathrm{Ca}^{2+}$-Kanäle (auch Dihydropyridinrezeptoren (DHPRs) genannt). In regelmäßigen Abständen ziehen vom Sarkolemm Einstülpungen in die Tiefe, die sog. T-Tubuli, in diesen befinden sich die DHPRs.

Auf der intrazellulären Seite des Sarkolemms befindet sich nahe den DHPRs das sarkoplasmatische Retikulum, in dessen Membran u.a. die Ryanodinrezeptoren (RyRs) 
lokalisiert sind (siehe Abbildung 1.2). Nach Bindung von $\mathrm{Ca}^{2+}$ an diese Rezeptoren, die $\mathrm{Ca}^{2+}$ permeable Kanäle sind, kommt es zur $\mathrm{Ca}^{2+}$-Freisetzung aus dem sarkoplasmatischem Retikulum, der sog. kalziuminduzierten Kalziumfreisetzung (Bers 2002).

In der Membran des sarkoplasmatischen Retikulums lassen sich Cluster von ca. 100 RyRs finden, denen gegenüber sich Cluster von ca. 10-25 DHPRs befinden (Bers 2002). Diese lokale sarkoplasmatische Kalziumfreisetzungseinheit wird Couplon genannt, jeder Kardiomyozyt besitzt ca. 10.000 dieser Couplons (Franzini-Armstrong et al. 1999).

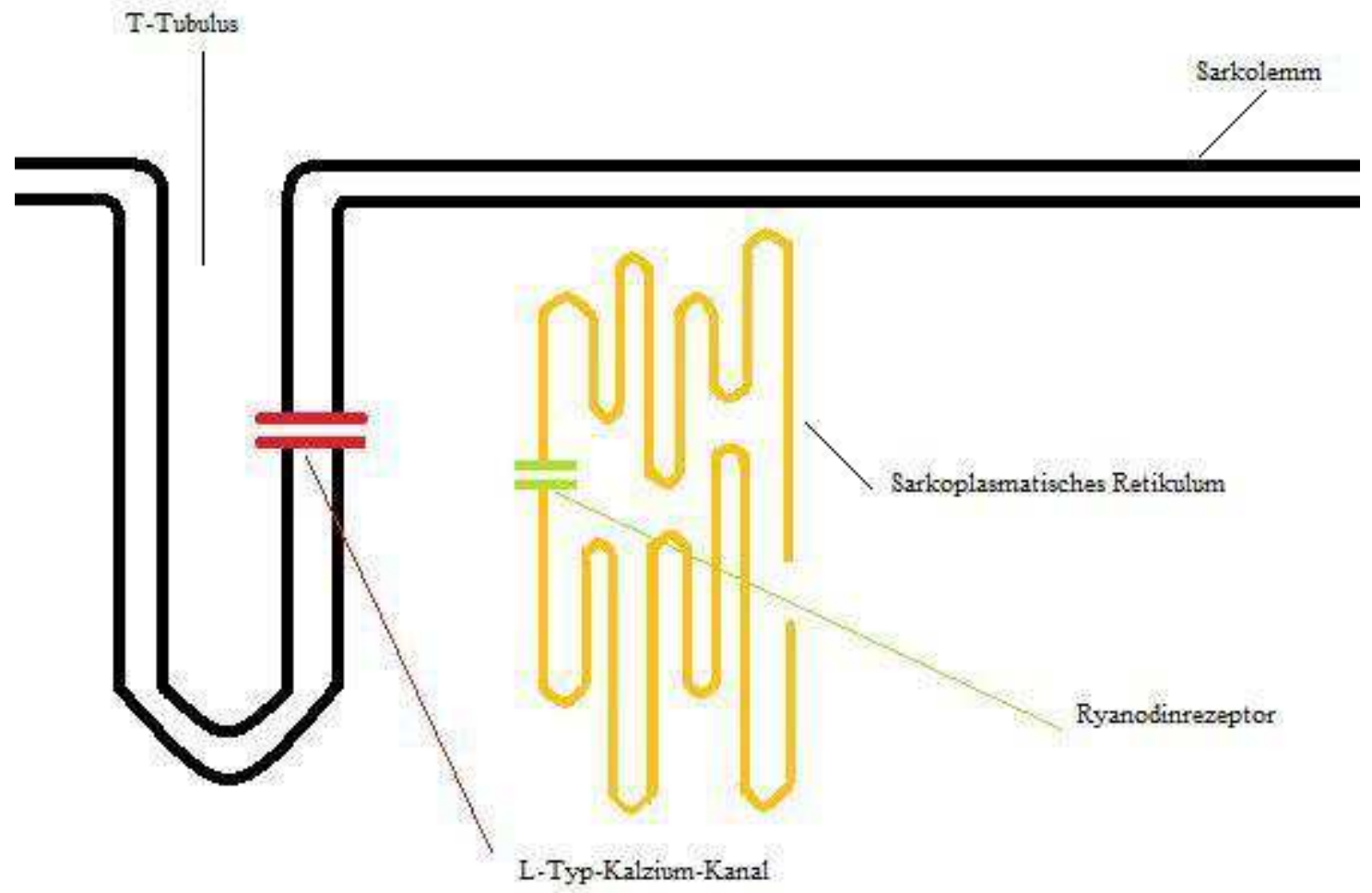

Abbildung 1.2 - Schema der T-Tubuli des Sarkolemms und der Lokalisation der L-TypKalzium-Kanäle und Ryanodin-Rezeptoren: Zu sehen ist die schematische Darstellung eines T-Tubulus des Sarkolemms. Über den L-Typ-Ca $\mathrm{Ca}^{2+}$-Kanal gelangen die $\mathrm{Ca}^{2+}$-Ionen während eines Aktionspotenzials nach intrazellulär, wo sie an den Ryanodinrezeptor in der Membran des sarkoplasmatischen Retikulums binden, zu dessen Öffnung führen und dadurch die Freisetzung des dort gespeicherten $\mathrm{Ca}^{2+}$ bewirken.

Dies ist für die Kontraktion der Zelle essenziell, da während der Kontraktion ein Großteil des benötigten $\mathrm{Ca}^{2+}$ aus den intrazellulären Speichern des sarkoplasmatischen Retikulums stammt, für dessen Freisetzung der RyR hauptsächlich verantwortlich ist (Bers 2002). 
Es kommt jedoch nicht $\mathrm{zu}$ einer vollständigen Entladung der $\mathrm{Ca}^{2+}$-Speicher des sarkoplasmatischen Retikulums, was am ehesten auf eine Inaktivierung der RyRs zurückzuführen ist (Shannon et al. 2003).

Auch in Ruhe besteht eine geringe stochastische Wahrscheinlichkeit einer spontanen Entladung einzelner RyR-Cluster in Form von sog. $\mathrm{Ca}^{2+}$-Sparks (Cheng $\mathrm{H}$ et al. 1993). In vielen Studien konnte jedoch beobachtet werden, dass bei einer Reduktion der $\mathrm{Ca}^{2+}$-Beladung der Speicher auf ca. 40-50\% der Normalkapazität die Frequenz der Sparks in der Diastole deutlich reduziert ist. Außerdem konnte gezeigt werden, dass in diesem Fall auch ein ansonsten ausreichender $\mathrm{Ca}^{2+}$-Einstrom über die DHPRs keine adäquate Antwort der RyRs nach sich zieht. Dies lässt die Schlussfolgerung zu, dass die Kalziumkonzentration im Lumen des sarkoplasmatischen Retikulums die $\mathrm{Ca}^{2+}$-Freisetzung über die RyRs sowohl in der Diastole als auch im Zuge der kalziuminduzierten Kalziumfreisetzung entscheidend mit reguliert (Bassani et al. 1995; Shannon et al. 2000; Bers 2001; Trafford et al. 2001).

Jedoch findet auch eine direkte Regulierung des RyR statt. Der RyR ist ein Teil eines Multiproteinkomplexes. In diesem Komplex finden sich das FK506-Bindungsprotein 12.6 (FKBP12.6), Calmodulin (CaM), die Proteinkinase A (PKA), die $\mathrm{Ca}^{2+} / \mathrm{CaM}$ abhängige Proteinkinase II (CaMKII), die Proteinphosphatasen PP1 und PPA2, ein Ankerprotein für die PKA (mAKAP) und andere Proteine wie Spinophilin, Calsequestrin und Sorcin (Bers 2004).

Für die Entfernung des intrazellulären $\mathrm{Ca}^{2+}$ in der Diastole sind im Wesentlichen vier Mechanismen verantwortlich:

- Die sarkolemmale $\mathrm{Ca}^{2+}$-Pumpe $\left(\mathrm{Ca}^{2+}\right.$-ATPase), welche unter Energieverbrauch (ATP) das $\mathrm{Ca}^{2+}$ nach extrazellulär transportiert.

- Der mitochondriale $\mathrm{Ca}^{2+}$-Uniporter, der $\mathrm{Ca}^{2+}$ in die Mitochondrien gelangen lässt.

- Der sarkolemmale $\mathrm{Na}^{+} / \mathrm{Ca}^{2+}$-Austauscher (NCX), welcher $\mathrm{Na}^{+}$in die Zelle und im Austausch dafür $\mathrm{Ca}^{2+}$ aus der Zelle transportiert.

- Die sarkoplasmatische/endoplasmatische Retikulum $\mathrm{Ca}^{2+}$-ATPase (SERCA), welche unter Energieverbrauch $\mathrm{Ca}^{2+}$ in das sarkoplasmatische Retikulum transportiert.

Bassani et al. (1994) konnten in Kaninchenmyozten (die menschlichen Kardiomyozyten in dieser Hinsicht ähneln) zeigen, dass über die SERCA ca. 70\%, über den NCX ca. $28 \%$ und über die restlichen Mechanismen ca. $2 \%$ des $\mathrm{Ca}^{2+}$ in der Diastole abtransportiert werden. Somit wird ein Großteil des $\mathrm{Ca}^{2+}$ während der Diastole wieder in die intrazellulären Speicher transportiert. 


\section{4 $\mathrm{Ca}^{2+}$ und seine Regulation im Zellkern}

$\mathrm{Ca}^{2+}$ übernimmt in der Zelle als Second Messenger eine Vielzahl an Funktionen. So ist es an elektrischer Erregung, Kontraktion, Apoptose, Sekretion und Gentranskription beteiligt (Bers 2008). Hierbei werden durch das $\mathrm{Ca}^{2+}$ meist spezifische $\mathrm{Ca}^{2+}$-Bindungsproteine aktiviert, wie z.B. CaM oder Troponin C. Dabei werden diese Bindungsproteine häufig durch lokale $\mathrm{Ca}^{2+}-$ Erhöhungen aktiviert und nicht durch eine globale $\mathrm{Ca}^{2+}$-Erhöhung. Das bedeutet, dass es viele verschiedene, unabhängig voneinander ablaufende $\mathrm{Ca}^{2+}$-abhängige Prozesse gibt, die einzig durch lokale $\mathrm{Ca}^{2+}$-Erhöhungen ablaufen (Bers 2008). In den Mitochondrien z.B. hat $\mathrm{Ca}^{2+}$ über eine Aktivierung verschiedener Stoffwechselprozesse eine zentrale Vermittlerrolle im Gleichgewicht zwischen Energiebedarf und Energiebereitstellung (Denton und McCormack 1990; Territo et al. 2000; Bers 2008).

In den Mitochondrien z. B. hat $\mathrm{Ca}^{2+}$ über eine Aktivierung verschiedener Stoffwechselprozesse eine zentrale Vermittlerrolle im Gleichgewicht zwischen Energiebedarf und Energiebereitstellung (Denton und McCormack 1990; Territo et al. 2000; Bers 2008).

Diese Arbeit hat es sich zum Ziel gesetzt, vor allem den Zellkern und seine $\mathrm{Ca}^{2+}$-Regulierung zu untersuchen. $\mathrm{Ca}^{2+}$ hat hier eine Vielzahl von Funktionen. So hat es z.B. einen wesentlichen Einfluss auf die Apoptose und den Zellzyklus (Clapham 1995; Bers 2008). Weiterhin kann es über die Aktivierung von CaM eine Hypertrophie der Zelle bedingen (Gruver et al. 1993). Abhängig von zytosolischem und nukleärem $\mathrm{Ca}^{2+}$ ist die Aktivierung des im Zellkern gelegenen Cyclic-AMP-Response-Element-Binding-Proteins (CREB) (Dolmetsch et al. 2001). Auch der im Zellkern gelegene Transkriptionsfaktor Downstream Regulatory Element Antagonist Modulator (DREAM) wird durch nukleäres $\mathrm{Ca}^{2+}$ beeinflusst (Cheng HY et al. 2002). Über eine experimentelle, selektive Pufferung des nukleären $\mathrm{Ca}^{2+}$ mit Hilfe des $\mathrm{Ca}^{2+}$ Bindungsproteins Parvalbumin, das im Zellkern überexprimiert wurde, konnte eine Reduktion der Zellproliferation und Änderung des Zellzyklus beobachtet werden, wohingegen die Überexpression des Parvalbumins im Zytoplasma keinen der oben genannten Effekte zeigte (Rodrigues et al. 2007).

Wie oben erwähnt, ist $\mathrm{CaM}$ ein wichtiger Bestandteil des $\mathrm{Ca}^{2+}$-Signalweges der Regulation von Transkriptionsfaktoren und der damit verbundenen Hypertrophie des Herzens. CaMÜberexpression führt zur Hypertrophie (Gruver et al. 1993), im Gegensatz dazu verhindert eine verminderte CaM-Expression die Hypertrophie der Herzmuskelzellen (McDonough und Glembotski 1992). In vielen Studien konnte bei Erhöhungen des zytoplasmatischen $\mathrm{Ca}^{2+}$ eine Translokation von CaM aus dem Zytosol in den Zellkern beobachtet werden (Mermelstein et 
al. 2001; Thorogate und Torok 2004; Wu und Bers 2007). Wie das CaM in den Zellkern gelangt, ist bisher noch unklar. Es wird vermutet, dass es im Cotransport mit anderen Proteinen den Zellkern betritt (Thorogate und Torok 2007).

Bisher sind zwei Wege der CaM-induzierten Hypertrophie des Herzens bekannt. Ein wichtiger $\mathrm{Ca}^{2+}$-gesteuerter Signalweg läuft über $\mathrm{Ca}^{2+}$-Calmodulin-abhängige Proteinkinasen (CaMK). Die CaMK reguliert die Aktivität der Transkriptionsfaktoren activation protein-1 (AP-1), activating transcription factor-1 (ATF-1), serum response factor (SRF), CREB und des myocyte enhancer factor 2 (MEF2) (Linseman et al. 2003). Hierbei scheint vor allem die CaM-abhängige Aktivierung von MEF2 einen starken Einfluss auf die Hypertrophie zu haben (Passier et al. 2000). Dabei scheint die Phosphorylierung von MEF2 weniger eine Rolle zu spielen, als die Bindung an Histondeacetylasen (HDAC). HDAC sind für die Transkription wesentliche Proteine. Durch die Deacetylierung des Lysins des N-Terminus der Histone mittels HDAC bekommt das Lysin wieder eine positive Ladung, wodurch sich die Affinität des Histons für das negativ geladene Phosphat-Gerüst der DNA erhöht. Die Transkription der DNA wird durch diese Blockierung herunterreguliert (Brehm et al. 1998).

Die HDAC werden in vier Klassen unterteilt, wovon in den Kardiomyozyten überwiegend die Klasse-II-HDAC (HDAC4, HDAC5, HDAC7 und HDAC9) gebildet werden, welche eine MEF2-Bindungsstelle am N-Terminus haben, die in keiner anderen HDAC zu finden ist (Backs und Olson 2006). Die Klasse II HDAC haben an ihrem N-Terminus zwei Serine, die, wenn sie phosphoryliert werden, an das Chaperon 14-3-3 binden. Dies hat zur Folge, dass der Komplex in seiner Gesamtheit durch das chromosomal region maintenance protein 1 (CRM1) aus dem Zellkern exportiert wird. Auch wenn die CaMK die MEF2 phosphorylieren kann, so scheint die Phosphorylierung der HDAC ebenfalls durch die CaMK der entscheidende Schritt in diesem Mechanismus zu sein (Linseman et al. 2003; Backs und Olson 2006; Bers 2008). Aus diesem Mechanismus geht die essentielle Bedeutung des $\mathrm{Ca}^{2+}$ für die HDAC-MEF2abhängige Regulation der Transkription hervor.

Ein weiterer Weg zur CaM-induzierten Hypertrophie des Herzens funktioniert über die $\mathrm{Ca}^{2+}$ CaM-Calcineurin-NFAT (nuclear factor of activated T-cells)-Kaskade. Calcineurin ist eine Phosphatase, welche zwei Untereinheiten $(\mathrm{CnA}$ und $\mathrm{CnB})$ hat. $\mathrm{CnA}$ enthält die CaMBindungs- und Phosphorylierungsstelle, benötigt jedoch CnB, um dann aktiv zu werden (Bers 2008). Calcineurin dephosphoryliert NFAT, wodurch dieses in den Zellkern transportiert wird. Dort kann es zusammen mit dem Zink-Finger-Transkriptionsfaktor GATA4 zur Transkription hypertrophiefördernder Gene führen (Molketin 2004). Eine vermehrte Expression von NFAT und/oder Calcineurin führt $\mathrm{zu}$ massiver Hypertrophie und 
Herzinsuffizienz (Bers 2008). Calcineurin besitzt eine um ein Vielfaches höhere Affinität zu $\mathrm{Ca}^{2+}-\mathrm{CaM}$ als die CaMKII. Dies lässt vermuten, dass die Aktivierung der CaMKII eher durch hohe $\mathrm{Ca}^{2+}$-Transienten in der Systole eingeleitet wird, während die Aktivierung von Calcineurin auch bei kleineren $\mathrm{Ca}^{2+}$-Spiegeln in der Diastole abläuft (Dolmetsch et al. 1997). In Kardiomyozyten ist die subzelluläre Regulation dieser Signalwege noch unvollständig verstanden, jedoch steht die wesentliche Rolle des $\mathrm{Ca}^{2+}$ in Bezug auf die Regulation der Transkription und den daraus entstehenden Folgen außer Frage.

Morphologisch ist der Zellkern eine Struktur innerhalb der Zelle. Umgeben wird er von einer Kernhülle, welche von den Ausläufern des sarkoplasmatischen Retikulums gebildet wird und welche von Kanälen durchzogen ist (Fricker et al. 1997). Die Kernhülle besteht aus einer äußeren und einer inneren Schicht mit einem dazwischen liegenden Lumen, welches mit dem sarkoplasmatischen Retikulum verbunden ist (Wu und Bers 2006). Innerhalb des Lumens kann $\mathrm{Ca}^{2+}$ frei diffundieren. Somit bildet auch die Kernhülle einen $\mathrm{Ca}^{2+}$-Speicher, der strukturell und funktionell mit dem sarkoplasmatischen Retikulum verbunden ist (Wu und Bers 2006). In das Innere des Zellkerns ragen Ausläufer der Kernmembran, die das sog. nukleoplasmatische Retikulum bilden und ebenfalls mit den o.g. Rezeptoren ausgestattet sind (Guatimosim et al. 2008).

Wurde in früheren Zeiten noch angenommen, dass das $\mathrm{Ca}^{2+}$ nur passiv durch Diffusion durch die Kernporen während der Systole in den Zellkern gelangt (Genka et al. 1999), so konnte schon vorher gezeigt werden, dass die Membran der Kernhülle mit der Phosphatidylinositolphosphatkinase (Cocco et al. 1987; Divecha et al. 1991), der Phospholipase C (PLC) (Martelli et al. 2000; Berridge et al. 2003) und dem Inositoltrisphosphatrezeptor $\left(\mathrm{IP}_{3} \mathrm{R}\right)$ (Koppler et al. 1993; Mak und Foskett 1994; Malviya 1994; Stehno-Bittel et al. 1995) wichtige Komponenten für eine aktive $\mathrm{Ca}^{2+}$-Freisetzung sowohl auf der Außen- wie auch der Innenseite besitzt (Stehno-Bittel et al. 1995). Durch die Bindung spezifischer Liganden an G-Protein-gekoppelte Rezeptoren, kommt es zu einer Aktivierung der PLC. Diese hydrolysiert Phosphatidylinositol-4,5-bisphosphat $\left(\mathrm{PIP}_{2}\right) \mathrm{zu}$ Inositoltrisphosphat $\left(\mathrm{IP}_{3}\right)$ und Diacylglycerol (DAG). DAG wirkt als second messenger und trägt zur Aktivierung der Proteinkinase $\mathrm{C}$ bei. Die Proteinkinase $\mathrm{C}$ ihrerseits kann durch Enzymphosphorylierung die Genexpression beeinflussen. $\mathrm{IP}_{3}$ bindet an den $\mathrm{IP}_{3} \mathrm{R}$, welcher ein unspezifischer Kationenkanal des sarkoplasmatischen Retikulums ist, bei dessen Aktivierung $\mathrm{Ca}^{2+}$ freigesetzt wird (Krauss 2001).

Von der PLC sind bisher 13 Isoenzyme bekannt, die in 6 Subgruppen unterteilt werden: $\beta, \gamma$, $\delta, \varepsilon, \eta$ und $\zeta$ (Cockcroft 2006), von denen die PLC- $\beta_{1}$ als die im Zellkern dominante Form 
betrachtet wird (Faenza et al. 2008; Ye und Ahn 2008). Jedoch scheinen auch die anderen Isoformen nach neueren Studien eine wichtige Rolle zu spielen. So kann z. B. die im Zytoplasma lokalisierte PLC- $\delta_{1}$, nachdem sie $\mathrm{Ca}^{2+}$-abhängig aktiviert wurde, durch die

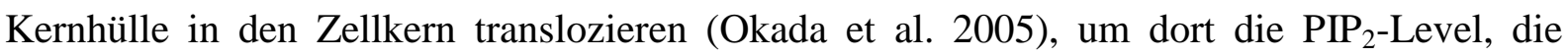
DNA-Synthese und die Zellproliferation zu regulieren (Stallings et al. 2008).

Untersuchungen haben gezeigt, dass auf der dem Nukleoplasma zugewandten Seite der Kernhülle viele G-Protein-gekoppelte Rezeptoren, wie z.B. für Angiotensin II, Endothelin-1 und Prostaglandine (Coffey et al. 1997; Bkaily et al. 2006), vorhanden sind. Unklar ist bisher, wie und ob diese aktiviert werden. Einige Studien lassen vermuten, dass in Neuronen anhand spezifischer Transporter Neurotransmitter (wie z.B. Glutamat) in den Zellkern gelangen und die dort vorhandenen Rezeptoren aktivieren (Jong et al. 2005).

Weitere Untersuchungen haben gezeigt, dass besonders in der Umgebung des Zellkerns die Dichte der $\mathrm{IP}_{3} \mathrm{R}$ am höchsten ist (Shirakawa und Miyazaki 1996; Thomas et al. 2000; Bootman et al. 2001; Vermassen et al. 2003; Higazi et al. 2009). Lange Zeit war klar, dass $\mathrm{Ca}^{2+}$-Freisetzung in der Nähe des Zellkernes Effekte innerhalb desselben zeigte, wie z.B. eine Änderung der Transkription verschiedener Gene (Dolmetsch et al. 1998). Neuere Untersuchungen zeigten, dass durch eine IP3-gesteuerte $\mathrm{Ca}^{2+}$-Freisetzung aus den perinuklären Speichern eine Aktivierung von Calcineurin stattfindet, welches seinerseits NFTA dephosphoryliert und den oben beschriebenen Signalweg einleitet (Higazi et al. 2009), und dass die IP3-gesteuerte nukleäre $\mathrm{Ca}^{2+}$-Freisetzung eine Phosphorylierung von HDAC5 via CaMKII bewirkt (Wu et al. 2006).

In der Membran des Zellkerns wurden weiterhin mit PIP $_{2}$ und der PLC wichtige Komponenten des oben genannten Signalweges gefunden (Downes et al. 2005). Vermehrt wurden diese in kleinen Regionen des Zellkernes beobachtet, die man nuclear speckles (zu Deutsch etwa „Kernflecken“) nennt und von denen man annimmt, dass sie Lagerstätten für prä-mRNA-Splicing-Faktoren sind. Bisher ist noch unklar, welchen Zweck die nuclear speckles erfüllen, jedoch weiß man, dass sie an der Produktion von Diacylglycerin und Inositoltrisphosphat zur Kontrolle der RNA-Produktion beteiligt sind (Alcazar-Roman und Wente 2008).

Kockskämper et al. (2008) konnten durch Zufuhr einer niedrigen Endothelin-1-Konzentration eine selektive Erhöhung des nukleären $\mathrm{Ca}^{2+}$-Spiegels in adulten Kardiomyozyten erreichen und somit zum ersten Mal demonstrieren, dass eine nukleäre Regulation des $\mathrm{Ca}^{2+}$ unabhängig von der zytoplasmatischen erfolgen kann. 


\subsection{Zielsetzung der Arbeit}

Nach wie vor ist die $\mathrm{Ca}^{2+}$-Regulation im und um den Zellkern nicht hinreichend verstanden. Hat man bisher angenommen, dass das intranukleäre $\mathrm{Ca}^{2+}$ alleine passiv durch Diffusion durch die Kernporen reguliert wird, so verdichten sich die Hinweise, dass es auch eine autonome $\mathrm{Ca}^{2+}$-Regulation des Zellkernes geben könnte. Dies könnte in Kardiomyozyten wesentliche Bedeutung für die Regulation der Transkription und die Entstehung von Hypertrophie haben.

Ziel dieser Arbeit war die Charakterisierung des nukleären $\mathrm{Ca}^{2+}$-Transienten in elektrisch stimulierten Kardiomyozyten unter verschiedenen physiologischen Bedingungen.

Es sollten folgende Fragen beantwortet werden:

- Kommt es zu einer frequenzabhängigen Änderung des nukleären $\mathrm{Ca}^{2+}$-Transienten?

- Kommt es zu einer pausenabhängigen Änderung des nukleären $\mathrm{Ca}^{2+}$-Transienten?

- Kommt es zu einer cAMP-abhängigen Änderung des nukleären $\mathrm{Ca}^{2+}$-Transienten?

- Zeigt sich eine unterschiedliche Regulation von zytoplasmatischem und nukleärem $\mathrm{Ca}^{2+}$-Transienten unter diesen Bedingungen?

Die Erhöhung der intrazellulären cAMP-Konzentration erfolgte mittels Forskolin, welches direkt die Adenylatzyklase aktiviert. Die dadurch verursachte cAMP-Erhöhung führt ihrerseits zur Stimulierung der Proteinkinase A. 


\section{Material und Methoden}

\subsection{Isolation der Kaninchenmyozyten}

\subsubsection{Lösungen und Substanzen}

\subsubsection{Pufferlösung}

Als Pufferlösung wurde eine modifizierte Tyrode-Lösung verwendet. Gelöst wurden hier alle Substanzen in Aqua bidest. Die Konzentrationen betrugen $137 \mathrm{mM}$ Natriumchlorid ( $\mathrm{NaCl})$, 5,4 mM Kaliumchlorid (KCl), 1,2 mM Magnesiumsulfat $\left(\mathrm{MgSO}_{4}\right), 20 \mathrm{mM}$ 2-(4-(2Hydroxyethyl)-1-piperazin)-Ethansulfonsäure (HEPES), 1,2 $\mathrm{mM}$ Dinatriumhydrogenphosphat $\left(\mathrm{Na}_{2} \mathrm{HPO}_{4}\right)$ und $18 \mathrm{mM}$ D-Glukose. Da diese Pufferlösung in der Regel einen saueren $\mathrm{pH}$ besaß, wurde durch Titration von $1 \mathrm{M}$ Natriumhydroxid $(\mathrm{NaOH}) \operatorname{der} \mathrm{pH}$ auf 7,35 angehoben. Es handelte sich hierbei um eine nominell kalziumfreie Tyrodelösung. Nach der Isolation und dem Kalziumaufbau der Zellen wurde eine Tyrodelösung mit $2 \mathrm{mM}$ Kalziumchlorid $\left(\mathrm{CaCl}_{2}\right)$ für den weiteren Versuchsablauf verwendet.

\subsubsection{Kollagenaselösung}

Die Enzymlösung sorgte dafür, die extrazellulären Kollagene aufzulösen, um die Myozyten aus dem Zellverband zu lösen. Als Medium dienten hier $80 \mathrm{ml}$ der kalziumfreien Tyrodelösung. Die Konzentrationen der einzelnen Substanzen betrugen $60 \mathrm{mM}$ Taurin (Sigma T9931) (7,5 mg/ml), 7 mM D,L-Glutaminsäure (Sigma G1126) (1,175 mg/ml), 2 mM DL-Carnitin (Sigma C9500) (0,39 mg/ml), $80 \mathrm{mg}$ Kollagenase Typ 2 (Worthington, LS004177) (1 mg/ml), 11 Einheiten Protease XIV (Sigma P5147) (0,03 mg/ml) und 0,025 $\mathrm{mM} \mathrm{CaCl}{ }_{2}$. 


\subsubsection{Stopp-Lösung}

Auch hierfür diente die kalziumfreie Tyrodelösung als Grundlage. Die Stopp-Lösung enthielt zusätzlich 0,05 mM CaCl $2,2 \%$ Albumin Fraktion V (Sigma A7517) und $20 \mathrm{mM} \mathrm{2,3-}$ Butandion monoxim (BDM, Sigma B0753).

\subsubsection{Albuminlösung}

Für den letzten Waschgang der Isolation wurde diese Lösung verwendet. Sie bestand aus 500 ml M199-Medium (Sigma M7528), 5 mM Taurin (Sigma T9931) (0,635 mg/ml), 5 mM D, LCarnitin (Sigma C9500) (1 mg/ml), 5 mM D,L-Kreatin (Sigma 291196) (0,655 mg/ml), $5 \mathrm{ml}$ 100x Penicillin/Streptomyocin (Sigma P4333), $5 \mathrm{ml} 2 \mathrm{mM}$ L-Glutamin (PAA M11-004) und 6\% Albumin Fraktion V (Sigma A7517) (375 mg/ml).

\subsubsection{Myozytenisolation}

Nach der Sedierung mit 2,5 ml Trapanal wurde der Brustkorb des Tieres eröffnet und das Herz entnommen.

Nun wurde die Spitze einer Kanüle in das Lumen der Aorta vorgeschoben und die Aorta an der Kanüle festgenäht, um alle Lösungen direkt über das koronare Gefäßsystem in das Herz leiten zu können. Anschließend wurde die Kanüle an der Langendorff-Anlage befestigt.

An dieser Anlage wurden sämtliche Lösungen, welche in das Herz geleitet wurden, vorher auf $37^{\circ} \mathrm{C}$ erwärmt, mit Sauerstoff begast und dann über die Kanüle retrograd in die Aorta geleitet, um von dort aus in das Koronarsystem zu gelangen.

Zunächst wurde das Herz mit 150-200 ml kalziumhaltiger Tyrodelösung (1 $\mathrm{mM} \mathrm{CaCl}$ ) perfundiert. Es erfolgte nach ca. 5 Minuten ein Wechsel auf $400 \mathrm{ml}$ kalziumfreie Tyrodelösung, welche für ca. 10 Minuten perfundiert wurde. Anschließend wurde das Herz mit der Kollagenaselösung perfundiert, was ca. 12-13 Minuten dauerte. Schließlich erfolgte der Wechsel auf die Stopp-Lösung, von der $70 \mathrm{ml}$ durch das Herz geleitet wurden.

Das Herz wurde dann von der Kanüle entfernt und unterhalb der Vorhöfe durchgeschnitten, wodurch Ventrikel und Vorhof getrennt wurden. Um eine Kalziumüberladung zu verhindern, erfolgte ein schrittweiser Kalziumaufbau mit Lösungen aufsteigender Kalziumkonzentration, bis die Kalziumkonzentration der Tyrodelösung $1 \mathrm{mM}$ betrug. 


\subsection{Isolation der Mäusemyozyten}

\subsubsection{Lösungen und Substanzen}

\subsubsection{Pufferlösung}

Hier wurde die oben genannte Tyrodelösung verwendet, mit dem Unterschied, dass die Konzentration der D-Glukose $10 \mathrm{mM}$ betrug. Auch die Kalziumkonzentration der kalziumhaltigen Tyrodelösung wurde hier reduziert und betrug nun $0,5 \mathrm{mM} \mathrm{CaCl}$.

\subsubsection{Kollagenaselösung}

Als Grundlage dienten hier $50 \mathrm{ml}$ Tyrodelösung, die $0,025 \mathrm{mM} \mathrm{CaCl} 2$ enthielt. Hinzu wurden 40 mg Kollagenase Typ 2 (Worthington, LS004177) gegeben $(0,8$ mg/ml).

\subsubsection{Myozytenisolation}

In einen Behälter wurden $400 \mathrm{ml}$ Isofluran gegeben, um die Maus darin zu sedieren. Sobald die Maus sediert war, wurde diese mit 250 Einheiten Heparin intraperitoneal antikoaguliert. Anschließend erfolgte nach zervikaler Dislokation die Entnahme des Herzens. Unter dem Mikroskop erfolgte dann die Kanülierung der Aorta. Danach wurde das Herz an die Langendorff-Anlage angeschlossen. Zunächst wurde das Herz für 2 Minuten mit kalziumfreier Tyrodelösung und anschließend für 5 Minuten mit der Kollagenaselösung perfundiert.

Danach wurde das Herz von der Anlage genommen und es begannen die Zellisolierung und der Kalziumaufbau, der mit 0,5 $\mathrm{mM} \mathrm{CaCl}_{2}$-haltiger Tyrodelösung beendet wurde.

\subsection{Vorbereitung zur Messung}

\subsubsection{Lösungen und Substanzen}

\subsubsection{Fluo-4/AM}


Es handelte sich bei Fluo-4 um einen Fluoreszenzfarbstoff, mit dessen Hilfe es möglich war, Kalziumkonzentrationen im nano- und mikromolaren Bereich $\mathrm{zu}$ messen. Da $\mathrm{Ca}^{2+}$ sehr schnell von diesem Farbstoff dissoziiert, war es möglich, Messungen mit hoher zeitlicher Auflösung zu machen. Fluo-4 ist negativ geladen und kann nicht frei durch die Membran der Zelle diffundieren. $\mathrm{Zu}$ diesem Zweck erfolgte eine Veresterung des Farbstoffs, was zur Verwendung von nicht-Ca ${ }^{2+}$-sensitivem Fluo-4/Azetoxymethylester (AM) führte. Fluo-4/AM kann frei durch die Zellmembran diffundieren und wird intrazellulär von unspezifischen Esterasen gespalten, so dass der Farbstoff wieder eine Ladung besitzt und die Zelle nicht mehr verlassen kann. In dieser Form kann Fluo-4 $\mathrm{Ca}^{2+}$ binden und fluoreszieren. Verwendet wurde hier 6,25 ml kalziumhaltige Tyrode-Lösung, in welche $50 \mu \mathrm{g}$ Fluo-4/AM (MW 1096,95, Molecular Probes, F14201) und $20 \mu$ Pluronic (Molecular Probes, P3000MP) gelöst wurden. Dadurch entstand eine $8 \mu \mathrm{M}$ Fluo-4/AM-Konzentration. Die Lagerung erfolgte bei $20^{\circ} \mathrm{C}$.

\subsubsection{Laminin}

Laminin ist ein Protein der Basalmembran, welches die Eigenschaft, besitzt Kollagene, Integrine und Proteoglykane (wie z. B. das Dystroglykan) zu binden (Timpl et al. 1984). Für den Versuch wurden $20 \mu \mathrm{l}$ aus der mit $\mathrm{NaCl}$ versetzten Suspensionslösung des Laminin (Sigma L2020) (1 mg/ml) in $1 \mathrm{ml}$ kalziumfreier Tyrodelösung verdünnt. Im Anschluss wurden Kulturschälchen mit einer geringen Menge dieser Lösung benetzt. Nach ca. 1 Stunde wurde die Laminin-haltige Lösung entfernt und anschließend die Zellsuspension aufgetragen. Dadurch konnten die Zellen am Boden des Kulturschälchens anhaften. Dies hatte den Sinn den Zellverlust durch wiederholte Waschvorgänge vor der Messung zu verringern. Die Lagerung erfolgte bei $-65^{\circ} \mathrm{C}$.

\subsubsection{Forskolin}

Forskolin ist ein aus dem Harfenstrauch Coleus forskolii gewonnenes Diterpen. Bis auf das Isoenzym IX werden alle Adenylatzyklasen vom Forskolin aktiviert, was zu einer Bildung von zyklischem Adenosinmonophosphat (cAMP) aus Adenosintriphosphat (ATP) führt. Hierdurch erfolgt eine Stimulierung der Proteinkinase A. Das für den Versuch verwendete Forskolin (MW 410,5, Sigma, F6886, 044K7042) wurde bei $-20^{\circ} \mathrm{C}$ gelagert. Es wurden 2,1 $\mathrm{mg}$ in $510 \mu \mathrm{l}$ Dimethylsulfoxid (DMSO) gelöst, dies entsprach einer 10-mM-Konzentration. 
Am jeweiligen Versuchstag wurden dann $50 \mu \mathrm{l}$ dieser Lösung mit $50 \mathrm{ml}$ kalziumhaltiger Tyrodelösung zu einer $10 \mu \mathrm{M}$ Lösung verdünnt, welche während der Messung eingesetzt wurde.

\subsubsection{Ausplattieren der Zellen und Beladung mit Fluo-4/AM}

Nach dem Laminieren der Kulturschälchen wurde die Zellsuspension aufgetragen. Es wurde 60 Minuten gewartet, damit eine möglichst hohe Zahl von Zellen am Boden des Schälchens anhafteten. Da es sich bei Fluo-4/AM um einen fluoreszierenden Farbstoff handelte, wurden alle weiteren Schritte im abgedunkelten Raum durchgeführt. Ein Tropfen der Farbstoffhaltigen Tyrodelösung wurde in Abhängigkeit vom jeweiligen Versuch für 20 Minuten (Messung der $\left[\mathrm{Ca}^{2+}\right]$-Transienten) oder 40 Minuten (Fotos Färbung der intrazellulären $\mathrm{Ca}^{2+}$ Speicher) im Schälchen belassen. Nach Ablauf dieser Zeit wurde mittels einer Pipette die Flüssigkeitssuspension, welche sich im Schälchen befand, entfernt und mit kalziumhaltiger Tyrode-Lösung aufgefüllt. Ein einmaliger Waschvorgang mit kalziumhaltiger Tyrodelösung folgte, um eventuell verbliebene Farbstoffreste aus dem Schälchen zu entfernen. Durchgeführt wurden diese Vorgänge, ebenso wie die folgenden Messungen, bei Raumtemperatur (22$\left.25^{\circ} \mathrm{C}\right)$.

\subsection{Messapparatur}

Für die Messungen wurde ein Konfokalmikroskop der Firma VisiTech International (Sunderland, U.K.) verwendet.

Das verwendete Umkehrmikroskop stammte von der Firma Nikon (Eclipse TE 2000-U). Bei dem Objektiv handelte es sich um ein 40x-Ölimmersions-Objektiv (SFluor 40X/1.30 Oil, Nikon). Da es eine hohe numerische Apertur besaß (N.A. =1.30), eignete es sich besonders gut für Fluoreszenzmessungen. Die numerische Apertur beschreibt das Vermögen des Objektivs, Licht zu sammeln. Sie bestimmt außerdem das Auflösungsvermögen. Links an das Mikroskop angeschlossen befand sich die konfokale Einheit, an welche ein Argonionen-Laser als Lichtquelle und eine hochempfindliche ICCD (intensified charge-coupled device)-Kamera (XR-Mega 10, Stanford Photonics, Palo Alto, U.S.A.) angeschlossen waren. Die Kamera ihrerseits war mit dem Messrechner verbunden, an welchen sie die Bilder übertrug. In der konfokalen Einheit befand sich die sog. Nipkowscheibe. Diese bestand aus zwei Scheiben, welche über eine Achse miteinander verbunden waren. Zwischen den Scheiben befand sich 
ein dichroischer Spiegel, welcher Licht in Abhängigkeit von seiner Wellenlänge reflektierte oder passieren ließ. Die dem Laser zugewandte Scheibe beinhaltete zahlreiche Mikrolinsen, die andere Scheibe besaß dazu korrespondierende Lochblenden. Über eine Stimulationseinheit (Scientific Instruments, Heidelberg) erfolgte die Erregung der Zellen. Zwei Kabel gingen von dieser Einheit aus und mündeten in Platindrähte, welche im Kulturschälchen platziert wurden. Hierüber erfolgte die elektrische Stimulierung. Für die Versuche mit Forskolin wurden zusätzlich eine Pumpe (MC-360, Schütt Labortechnik, Göttingen) und eine Superfusionsapparatur benötigt. Über die Superfusionsapparatur wurden die Versuchslösungen in das Schälchen geleitet, über die Pumpe erfolgte eine kontinuierliche Absaugung der Lösung in der Kulturschale, um ein Überlaufen zu verhindern.

\subsection{Durchführung einer Messung}

Zunächst wurde das Kulturschälchen auf dem Mikroskoptisch fixiert. Es erfolgte dann das Platzieren der Platindrähte der Stimulationseinheit innerhalb des Schälchens. Bei eingeschalteter Stimulation wurde eine Zelle ausgewählt, die sich entsprechend der Stimulation rhythmisch kontrahierte und fest am Boden haftete. Über den Laser wurde Licht der Wellenlänge $488 \mathrm{~nm}$ in die konfokale Einheit geleitet. Die Mikrolinsen fokussierten das Licht durch die Lochblenden, wodurch eine optimale Lichtausbeute erzielt wurde. Über ein System aus Spiegeln gelangte das Licht zum Kulturschälchen, wo es auf die Zellen traf und den Farbstoff erregte. Das vom fluoreszierenden Farbstoff ausgehende Licht gelangte auf demselben Weg durch die Lochblenden zurück, konnte jedoch, im Gegensatz zu dem Licht des Lasers, auf Grund seiner höheren Wellenlänge den dichroischen Spiegel nicht durchdringen und wurde so in Richtung Kamera reflektiert, welche ihre Daten auf den Messrechner übertrug. Es entstanden hierdurch mit $120 \mathrm{~Hz}$ zeitlicher Auflösung aufgenommene 2D-Videos, welche zur Auswertung verwendet wurden.

\subsection{Auswertung}

\subsubsection{Analyse der elektrisch stimulierten $\left[\mathrm{Ca}^{2+}\right]$-Transienten}

Anhand der Bilder (siehe Abbildung 2.1) erfolgte nun die Auswertung. Zu sehen sind eine Zelle und in der Mitte der Zelle der deutlich hervorstechende Zellkern. Um den Zellkern und um die Zelle wurden nun Markierungen gezogen, über welche mittels der zugehörigen 
Analysesoftware (Camera Standalone, VisiTech International, Sunderland, U.K.) die Fluoreszenz gemessen wurde. Hierbei wurden Zellkern und Zelle getrennt voneinander beurteilt. Es wurde ebenfalls ein Teil des Hintergrunds markiert und die dort gemessene Hintergrund-Fluoreszenz ermittelt. Dieser Wert wurde von den Zell- und Zellkerndaten subtrahiert, um so die Fluoreszenz zu erhalten, die von der Zelle stammte. Inklusive dieses Schrittes erfolgten alle nun folgenden Auswertungen mit dem Programm Igor Pro (Wavemetrics, Oregon, U.S.A.).

Nachdem die Hintergrundfluoreszenz subtrahiert wurde, wurde die Fluoreszenz der Zelle ohne Stimulation gemessen, d. h. unter Ruhebedingungen $\left(F_{\text {Ruhe }}\right.$ oder $\left.F_{0}\right)$. Sämtliche Fluoreszenz-Werte der folgenden Messung wurden durch diesen Wert dividiert, wodurch die gemessene normierte Fluoreszenz zu Beginn jeder Messung 1 betrug $\left(\mathrm{F} / \mathrm{F}_{0}\right)$. Somit konnte die relative Fluoreszenzänderung während der Messung in einer Zelle und im Vergleich zu anderen Zellen beurteilt werden.

Gemessen wurde die diastolische Fluoreszenz (Wert unmittelbar vor dem Beginn der Systole), der systolische Spitzenwert der Fluoreszenz, die Zeit, welche vom gemessenen diastolischen Wert bis zum systolischen Wert benötigt wurde, die Zeit zum Maximum oder Time to peak (TTP). Außerdem wurde der Abfall der Fluoreszenz mit einer monoexponentiellen Funktion gefittet. Die dabei erhaltene Geschwindigkeitskonstante $\mathrm{k}_{2}$ wurde in die Zeitkonstante Tau $(\tau)$ umgerechnet $\left(\tau=1 / \mathrm{k}_{2}\right)$. Sämtliche Werte wurden getrennt für Zelle (= Zytoplasma) und Zellkern (= Nukleoplasma) ermittelt.

\subsubsection{Kalibrierung der $\left[\mathrm{Ca}^{2+}\right]$-Konzentration aus den Fluoreszenzänderungen}

Auf der Grundlage der von Grynkiewicz et al. (1985) formulierten Methode zur Kalibrierung von fluoreszierenden $\mathrm{Ca}^{2+}$-Farbstoffen konnte eine Formel für die Kalibrierung von $\left[\mathrm{Ca}^{2+}\right]$ aus der Fluoreszenz von Fluo-4 erstellt werden (Ljubojevic et al. 2011): 
1

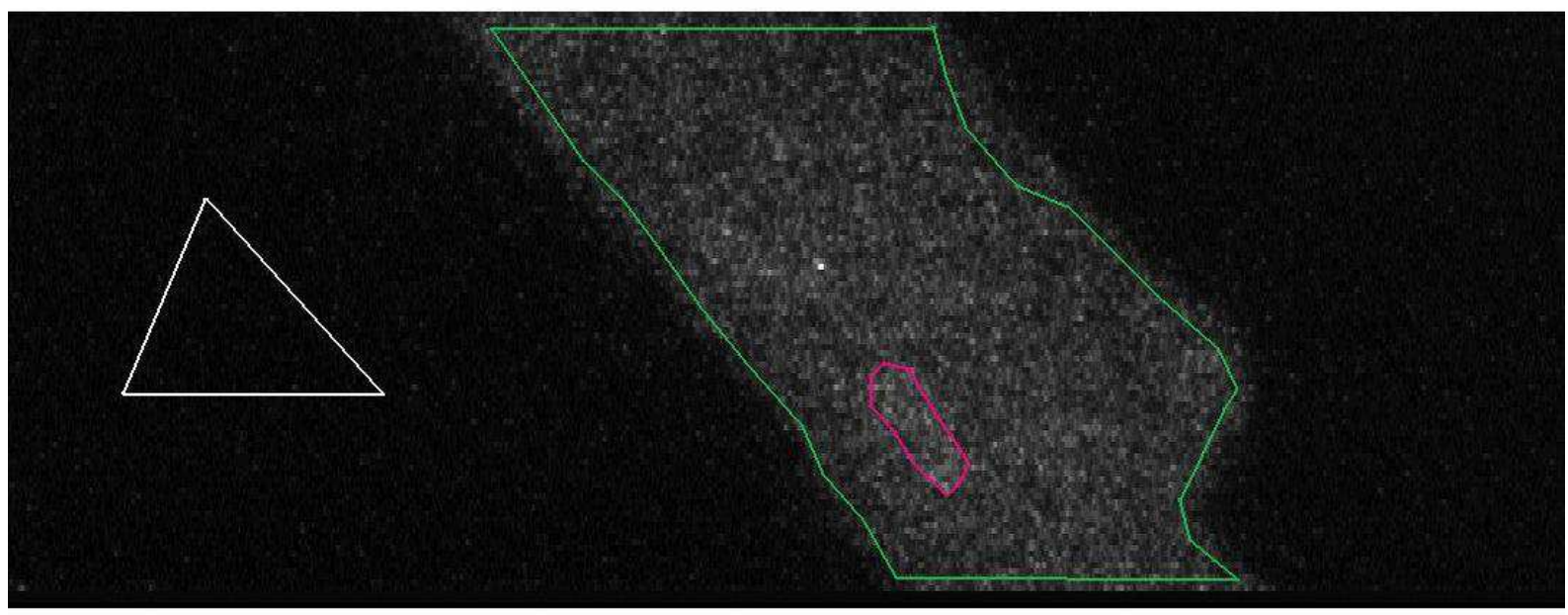

2

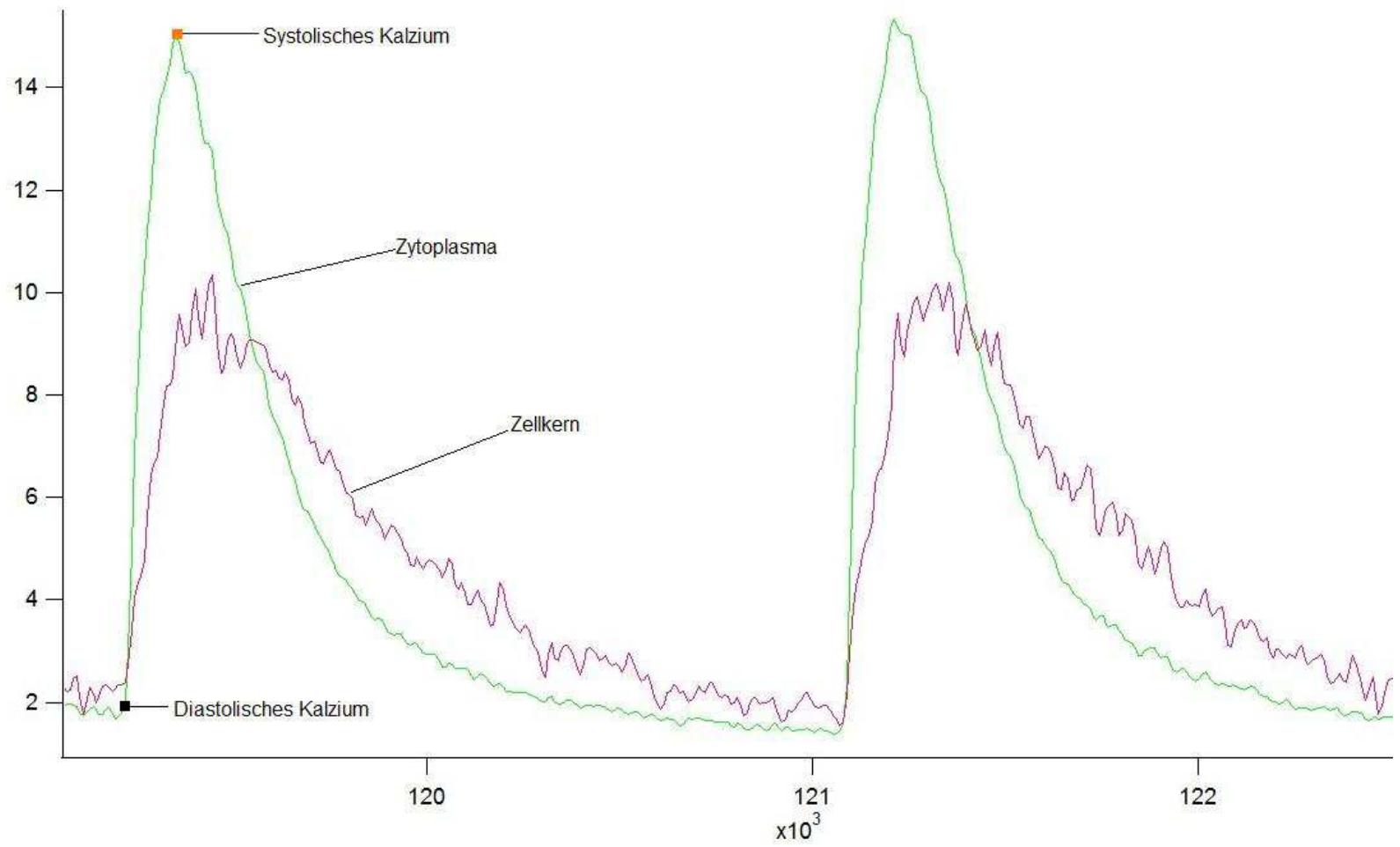

Abbildung 2.1 - Auswertung: In 1 ist eine Zelle mit Zellkern in Ruhe gezeigt. Die Markierungen, welche die Zelle (Grün), den Zellkern (Lila) und den Hintergrund (Weiß) umschließen, sind die Messareale, aus welchen das Analyseprogramm die Fluoreszenz ermittelt. In 2 ist eine Auswertung dieser Messdaten zu sehen. Angezeigt wird hier die Fluoreszenzänderung (y-Achse) in Abhängigkeit von der Zeit (x-Achse, in Millisekunden) bei elektrischer Stimulation. Die grüne Spur steht hierbei für die Fluoreszenzänderung der Zelle, die lila Spur für die Fluoreszenzänderung des Zellkerns. Markiert sind die in die Auswertung eingehenden Daten: Der diastolische Kalziumwert und der systolische Spitzenwert. 
$\left[\mathrm{Ca}^{2+}\right]=\mathrm{K}_{\mathrm{d}} *\left(\mathrm{R} *\left(\mathrm{~K}_{\mathrm{d}}+\mathrm{R}_{\mathrm{f}} *\left[\mathrm{Ca}^{2+}\right]_{\mathrm{rest}}\right)-\left(\mathrm{K}_{\mathrm{d}}+\left[\mathrm{Ca}^{2+}\right]_{\mathrm{rest}}\right)\right) /\left(\mathrm{R}_{\mathrm{f}} *\left(\mathrm{~K}_{\mathrm{d}}+\left[\mathrm{Ca}^{2+}\right]_{\mathrm{rest}}\right)-\mathrm{R} *(\mathrm{Kd}+\right.$ $\left.\left.\mathrm{Rf} *\left[\mathrm{Ca}^{2+}\right]_{\text {rest }}\right)\right)$

Hierbei war $\mathrm{R}_{\mathrm{f}}$ die dynamische Breite (dynamic range) des Farbstoffs, das ist die maximale Fluoreszenz bei sättigenden $\mathrm{Ca}^{2+}$-Konzentrationen dividiert durch die minimale Fluoreszenz in Abwesenheit von $\mathrm{Ca}^{2+}$.

$\mathrm{K}_{\mathrm{d}}$ ist die Dissoziationskonstante der $\mathrm{Ca}^{2+}$-Bindung an den Farbstoff. R entspricht der relativen Fluoreszenzänderung $\left(\mathrm{F} / \mathrm{F}_{\text {Ruhe }}\right)$. $\left[\mathrm{Ca}^{2+}\right]_{\text {Rest }}$ (Zellkern: $91 \mathrm{nM}$; Zytoplasma: $\left.74 \mathrm{nM}\right), \mathrm{K}_{\mathrm{d}}$ (Zellkern: 1212 nM; Zytoplasma: $1099 \mathrm{nM}$ ) und $\mathrm{R}_{\mathrm{f}}$ (Zellkern: 71; Zytoplasma: 47) konnten experimentell für die Myozyten der Maus bestimmt werden, wodurch nun in MausVentrikelmyozyten eine Kalibrierung des $\left[\mathrm{Ca}^{2+}\right]$ aus der relativen Fluoreszenzänderung (R) möglich war (Ljubojevic et al. 2011).

\subsubsection{Statistik}

Aus den Ergebnissen der Messungen wurden die Mittelwerte für die gemessenen Parameter errechnet. Um die Variabilität der Daten zu bestimmen, wurde der mittlere Fehler des Mittelwertes (standard error of the mean, SEM) errechnet. In dieser Arbeit wurden die Ergebnisse als Mittelwert \pm SEM angegeben. Der Vergleich von Stichproben wurde mittels des Student-t-Tests für zwei verbundene oder für zwei unverbundene Stichproben durchgeführt.

Um zwischen verschiedenen Gruppen Unterschiede statistisch $\mathrm{zu}$ belegen, wurde die Varianzanalyse (analysis of variance, ANOVA) durchgeführt, gefolgt von einem Dunnettoder Bonferroni-Test. Als statistisch signifikant wurden Unterschiede mit einer Irrtumswahrscheinlichkeit $<0,05(\mathrm{P}<0,05)$ bezeichnet. 


\section{Ergebnisse}

\subsection{Frequenzabhängige $\mathrm{Ca}^{2+}$-Änderungen in Kaninchenventrikelmyozyten}

Abbildung 3.1 zeigt die gesammelten Ergebnisse der frequenzabhängigen $\mathrm{Ca}^{2+}$ - $̈$ nderungen in den Ventrikelmyozyten des Kaninchens.

In Abbildung 3.1A ist anhand einer Beispielmessung der Verlauf des $\mathrm{Ca}^{2+}$-Transienten bei verschiedenen Frequenzen verdeutlicht. Gezeigt werden der Transient des zytoplasmatischen $\mathrm{Ca}^{2+}$ und des $\mathrm{Ca}^{2+}$ des Zellkerns. Für jede Frequenz wurde ein Transient aus der gleichen Messung ausgewählt und aufgetragen, die jeweilige Frequenz ist über den Spuren zu sehen.

Deutlich wird hier, dass der Transient des $\mathrm{Ca}^{2+}$ im Zellkern, unabhängig von der Frequenz, später den Höhepunkt erreichte, langsamer abfiel und höhere Werte erreichte, als der Transient des zytoplasmatischen $\mathrm{Ca}^{2+}$. Bei steigender Frequenz stiegen sowohl der diastolische als auch der maximale systolische $\mathrm{Ca}^{2+}$-Wert in beiden Zellkompartimenten.

\subsubsection{Frequenzabhängige Änderungen des diastolischen $\mathrm{Ca}^{2+}$}

In der Abbildung 3.1B ist die Änderung der diastolischen $\mathrm{Ca}^{2+}$-Werte in Abhängigkeit von der Frequenz aufgetragen. Gemessen wurde die relative Änderung der Fluoreszenz gegenüber der Ruhefluoreszenz ohne elektrische Stimulation ( $\left.\mathrm{F} / \mathrm{F}_{\mathrm{Ruhe}}\right)$. Die Messungen begannen bei 0,3 $\mathrm{Hz}$ und die Stimulationsfrequenz wurde in Schritten von $0,2 \mathrm{~Hz}$ bis auf $1.3 \mathrm{~Hz}$ gesteigert. Aufgetragen sind die Mittelwerte der relativen $\mathrm{Ca}^{2+}$ - $̈$ nderungen des Zytoplasmas (schwarz) und des Zellkerns (rot). Zu sehen ist, dass sowohl das diastolische $\mathrm{Ca}^{2+}$ im Zellkern als auch im Zytoplasma bei steigender Frequenz ebenfalls anstiegen. Im Zytoplasma wurde ein Anstieg von $1,49 \pm 0,06$ bei $0,3 \mathrm{~Hz}$ auf $3,51 \pm 0,54$ bei $1,3 \mathrm{~Hz}(\mathrm{P}<0,05)$ beobachtet. Das entspricht etwas mehr als einer Verdoppelung (236\%) des Ausgangswertes. Im Zellkern ging

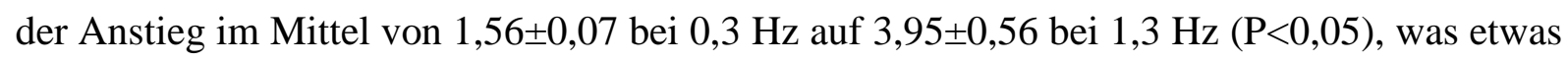
mehr als einer Verdoppelung (253\%) entspricht. 


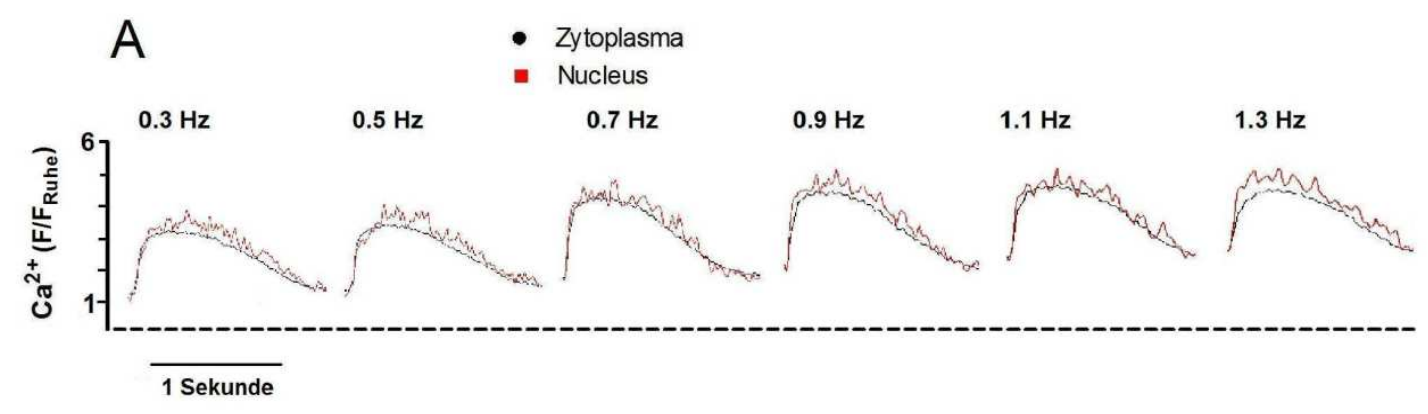

B

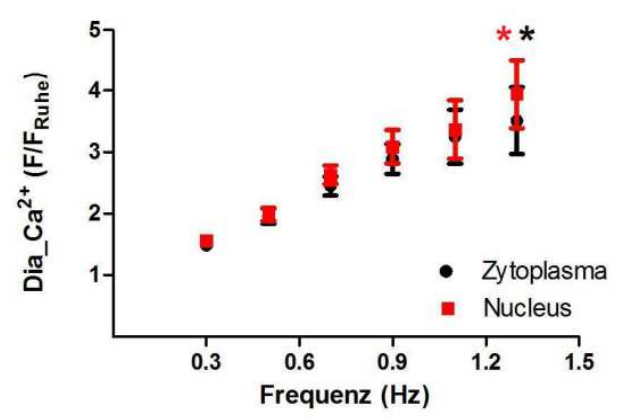

D

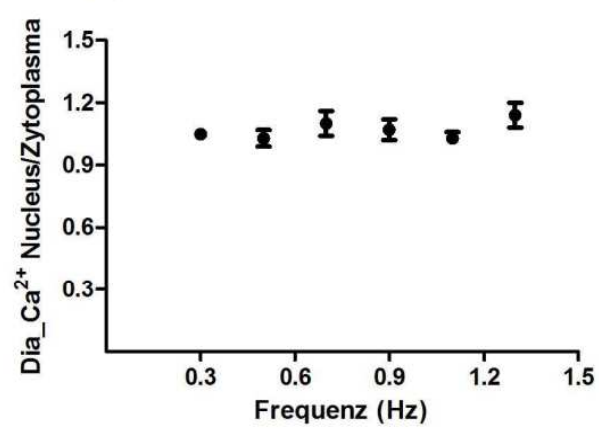

$\mathrm{F}$

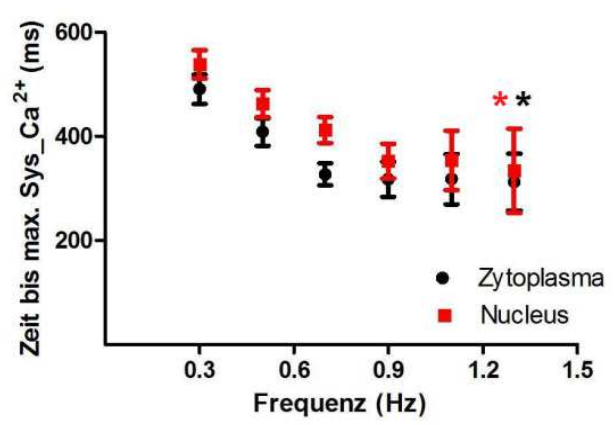

C

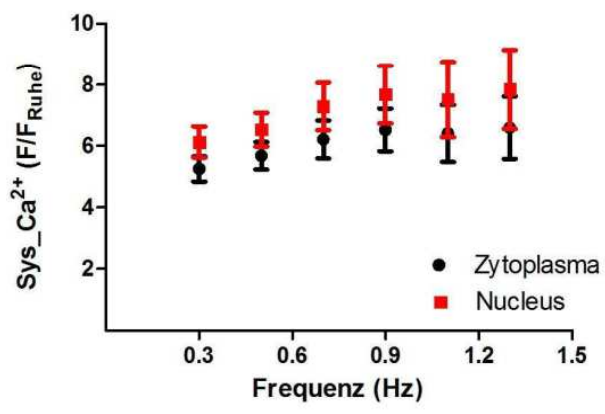

$\mathrm{E}$

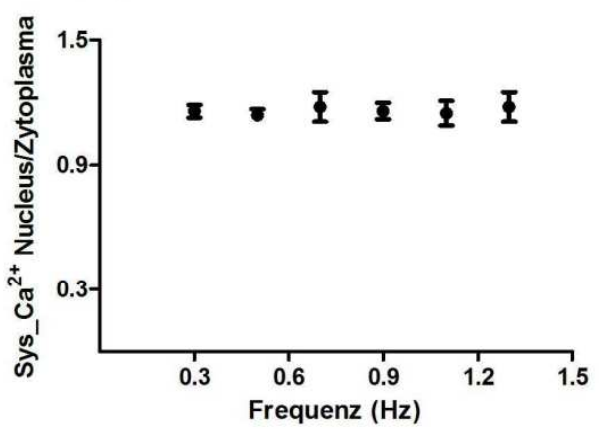

G

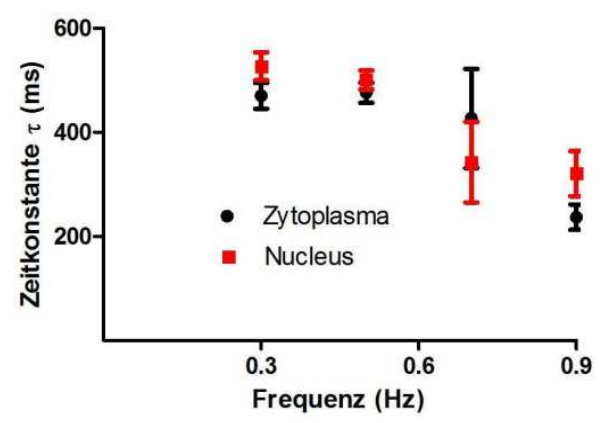

Abbildung 3.1 - Frequenzabhängige Änderungen des $\mathbf{C a}^{2+}$ in Ventrikelmyozyten des

Kaninchens: In A ist anhand einer Beispielmessung der Transientenverlauf bei 
verschiedenen Frequenzen gezeigt. Auf der Ordinate ist in A bis $C$ die relative $\mathrm{Ca}^{2+}$ Konzentrationsänderung aufgetragen. Angegeben ist diese in Fluoreszenz (F) über Ruhefluoreszenz ( $\left.F_{\text {Ruhe }}\right)$. Der zytoplasmatische $\mathrm{Ca}^{2+}$-Transient ist in Schwarz, der des Zellkerns in Rot aufgetragen. $B$ und $C$ befassen sich mit dem diastolischen und systolischen $\mathrm{Ca}^{2+}$. In D und E ist das Verhältnis von zytoplasmatischem und nukleoplasmatischem $\mathrm{Ca}^{2+}$ gezeigt. Die Zeit bis zum maximalen systolischen $\mathrm{Ca}^{2+}$-Wert (TTP=Time to peak) wurde in F und die Zeitkonstante $\tau$, welche den Abfall des systolischen Maximums auf den diastolischen Wert beschreibt, wurde in $G$ dargestellt. Die gezeigten Werte entsprechen den Mittelwerten aller Messungen $(n=6-24) . *=P<0,05$ versus $0,3 \mathrm{~Hz}$.

Bei $0,3 \mathrm{~Hz}$ zeigten beide Kompartimente, Zytoplasma und Zellkern, ähnliche diastolische $\mathrm{Ca}^{2+}$-Konzentrationen, wobei ein stärkerer frequenzabhängiger Anstieg des $\mathrm{Ca}^{2+}$ im Zellkern als im Zytoplasma zu vermuten war.

Um dies genauer $\mathrm{zu}$ prüfen, wurde das Verhältnis der relativen Fluoreszenz $\left(\mathrm{F} / \mathrm{F}_{\text {Ruhe }}\right)$ zwischen Zellkern und Zytoplasma berechnet (Abbildung 3.1D). Es war nur eine geringe Schwankung dieses Verhältnisses zu beobachten. Bei einem Verhältnis von 1,05 $\pm 0,02$ (Zellkern/Zytoplasma) bei $0,3 \mathrm{~Hz}$ im Vergleich zu einem Verhältnis von 1,14 $\pm 0,06(\mathrm{P}>0,05)$ bei $1,3 \mathrm{~Hz}$ wurden keine statistisch signifikanten Unterschiede beobachtet. Somit konnte ein stärkerer Anstieg des diastolischen $\mathrm{Ca}^{2+}$ in einem der beiden Kompartimente gegenüber dem anderen nicht nachgewiesen werden.

\subsubsection{Frequenzabhängige Änderungen des systolischen $\mathrm{Ca}^{2+}$}

Abbildung 3.1C gibt die relative Änderung des systolischen $\mathrm{Ca}^{2+}$ wieder. $\mathrm{Zu}$ beobachten ist auch hier, dass sowohl das $\mathrm{Ca}^{2+}$ des Zytoplasmas als auch des Zellkerns bei steigender Frequenz anstiegen.

Betrachtet man die Ergebnisse genauer, so ist eine Änderung des systolischen $\mathrm{Ca}^{2+}$ im Zytoplasma von $5,25 \pm 0,41$ bei $0,3 \mathrm{~Hz}$ auf $6,60 \pm 1,02$ bei $1,3 \mathrm{~Hz}(\mathrm{P}>0,05)$ zu beobachten. Im Zellkern stieg $F / F_{\text {Ruhe }}$ von $6,13 \pm 0,50$ bei $0,3 \mathrm{~Hz}$ auf $7,85 \pm 1,30$ bei $1,3 \mathrm{~Hz}(\mathrm{P}>0,05)$ an. In beiden Kompartimenten war dieser Anstieg statistisch nicht signifikant.

Betrachtet man das Verhältnis des $\mathrm{Ca}^{2+}$ in beiden Kompartimenten (Abbildung 3.1E), so zeigten sich keine signifikanten Unterschiede bezüglich der Änderungen des systolischen $\mathrm{Ca}^{2+}$ bei steigender Frequenz.

Bei 0,3 Hz betrug das Verhältnis 1,16 $\pm 0,03$, bei 1,3 Hz 1,18 $\pm 0,07(\mathrm{P}>0,05)$. 


\subsubsection{Zeit bis zum Erreichen des systolischen maximalen $\mathrm{Ca}^{2+}$}

Gemessen wurde für jede Frequenz die Zeit, welche der Transient brauchte, um ausgehend vom diastolischen $\mathrm{Ca}^{2+}$ zu Beginn der Systole sein Maximum zu erreichen (TTP = Time to peak). Abbildung 3.1F zeigt die Mittelwerte der TTP in Abhängigkeit von der Frequenz. Auffällig ist, dass das systolische Maximum bei steigender Frequenz sowohl im Zellkern als auch im Zytoplasma schneller erreicht wurde. So war für das Zytoplasma eine Verringerung der TTP von $491 \pm 28 \mathrm{~ms}$ bei $0,3 \mathrm{~Hz}$ auf $312,17 \pm 55$ bei $1,3 \mathrm{~Hz}(\mathrm{P}<0,05)$ und für den Zellkern von $539 \pm 27 \mathrm{~ms}$ bei $0,3 \mathrm{~Hz}$ auf $334 \pm 81 \mathrm{~ms}$ bei $1,3 \mathrm{~Hz}(\mathrm{P}<0,05)$ zu beobachten. Diese Zunahme der Anstiegsgeschwindigkeit des $\mathrm{Ca}^{2+}$-Transienten war statistisch signifikant. Deshalb kann gefolgert werden, dass bei steigender Frequenz die TTP sowohl im Zellkern als auch im Zytoplasma fällt.

Berechnet man das Verhältnis der TTP beider Kompartimente (Zellkern/Zytoplasma), so betrug dies bei einer Frequenz von 0,3 Hz 1,12 $\pm 0,04$ und bei 1,3 Hz 1,03 $\pm 0,07$ (P>0,05). Das bedeutet, dass keine Unterschiede zwischen den Änderungen der TTP bei steigender Frequenz zwischen beiden Kompartimenten bestanden.

\subsubsection{Zeitkonstante des Abfalls des $\mathrm{Ca}^{2+}$-Transienten}

Errechnet wurde die Zeitkonstante des Abfalls des $\mathrm{Ca}^{2+}$-Transienten. In Abbildung 3.1G ist zu sehen, dass diese Werte nur bis zu einer Frequenz von $0,9 \mathrm{~Hz}$ ermittelt wurden, da bei höheren Frequenzen diese nicht mehr fehlerfrei zu ermitteln waren.

Der Zellkern brauchte immer länger als das Zytoplasma, bis das $\mathrm{Ca}^{2+}$ auf sein diastolisches Niveau gefallen war. Bei steigender Frequenz konnte in beiden Zellkompartimenten eine kleiner werdende Zeitkonstante ermittelt werden. Im Zytoplasma sank die Zeitkonstante von $470 \pm 25 \mathrm{~ms}$ bei $0,3 \mathrm{~Hz}$ auf $237 \pm 24 \mathrm{~ms}$ bei $0,9 \mathrm{~Hz}(\mathrm{P}<0,05)$. Für den Zellkern kam es zu einer Änderung von $527 \pm 27 \mathrm{~ms}$ bei $0,3 \mathrm{~Hz}$ auf $321 \pm 43 \mathrm{~ms}$ bei $0,9 \mathrm{~Hz}(\mathrm{P}<0,05)$.

Errechnete man das Verhältnis der Zeitkonstanten von Zellkern und Zytoplasma, so betrug dies $1,14 \pm 0,05$ bei $0,3 \mathrm{~Hz}$ und $1,31 \pm 0,03$ bei $0,9 \mathrm{~Hz}(\mathrm{P}>0,05)$.

\subsection{Frequenzabhängige $\mathrm{Ca}^{2+}$-Änderungen in Kaninchenvorhofmyozyten}

In Abbildung 3.2 finden sich die Ergebnisse der frequenzabhängigen $\mathrm{Ca}^{2+}$-Änderungen für den Zellkern und das Zytoplasma in Vorhofmyozyten des Kaninchens. 
Abbildung 3.2A zeigt eine Beispielmessung. $\mathrm{Zu}$ sehen sind hier die $\mathrm{Ca}^{2+}-$ Transienten des Zellkerns und des Zytoplasmas bei steigenden Frequenzen. Auffällig ist hier, anders als bei den Ventrikelmyozyten, ein besonders starker Anstieg des systolischen Maximums bei einem Frequenzanstieg von $0,3 \mathrm{~Hz}$ auf $0,7 \mathrm{~Hz}$.

\subsubsection{Frequenzanhängige Änderungen des diastolischen $\mathrm{Ca}^{2+}$}

In den hier durchgeführten Messungen zeigte sich sowohl im Zytoplasma als auch im Zellkern, analog zu den Ventrikelmyozyten, ein Anstieg des diastolischen $\mathrm{Ca}^{2+}$ bei steigender Frequenz (Abbildung 3.2B). Das diastolische $\mathrm{Ca}^{2+}$ im Zytoplasma stieg von 1,40 $\pm 0,08$ bei 0,3 $\mathrm{Hz}$ auf $3,85 \pm 0,15$ bei $1,5 \mathrm{~Hz}$ an $(\mathrm{P}<0,05)$. Im Zellkern stieg das diastolische $\mathrm{Ca}^{2+}$ von $1,41 \pm 0,08$ bei $0,3 \mathrm{~Hz}$ auf $5,07 \pm 0,66$ bei $1,5 \mathrm{~Hz}$ an $(\mathrm{P}<0,05)$.

Der Quotient von Zellkern und Zytoplasma änderte sich nicht (Abbildung 3.2D). Er betrug $1,03 \pm 0,04$ bei $0,3 \mathrm{~Hz}$ und $1,31 \pm 0,15$ bei $1,5 \mathrm{~Hz}(\mathrm{P}>0,05)$.

\subsubsection{Frequenzabhängige Änderungen des systolischen $\mathrm{Ca}^{2+}$}

Ein frequenzabhängiger Anstieg ließ sich auch hier beobachten (Abbildung 3.2C), jedoch war dieser nicht so ausgeprägt wie beim diastolischen $\mathrm{Ca}^{2+}$. Im Zytoplasma kam es zu einem Anstieg von $13,98 \pm 1,74$ bei $0,3 \mathrm{~Hz}$ auf $19,26 \pm 1,79$ bei $1,5 \mathrm{~Hz}(\mathrm{P}>0,05)$, im Zellkern von $13,03 \pm 1,89$ bei $0,3 \mathrm{~Hz}$ auf $18,29 \pm 2,3$ bei $1,5 \mathrm{~Hz}(\mathrm{P}>0,05)$.

Eine statistische Signifikanz konnte hier in Bezug auf die frequenzabhängige Steigerung des systolischen $\mathrm{Ca}^{2+}$ weder im Zytoplasma noch im Zellkern nachgewiesen werden.

Nach Berechnung des Verhältnisses des systolischen $\mathrm{Ca}^{2+}$ im Zellkern im Vergleich zum Zytoplasma (Abbildung 3.2E) konnte ebenfalls keine Frequenzabhängigkeit nachgewiesen werden $(\mathrm{P}>0,05)$. 


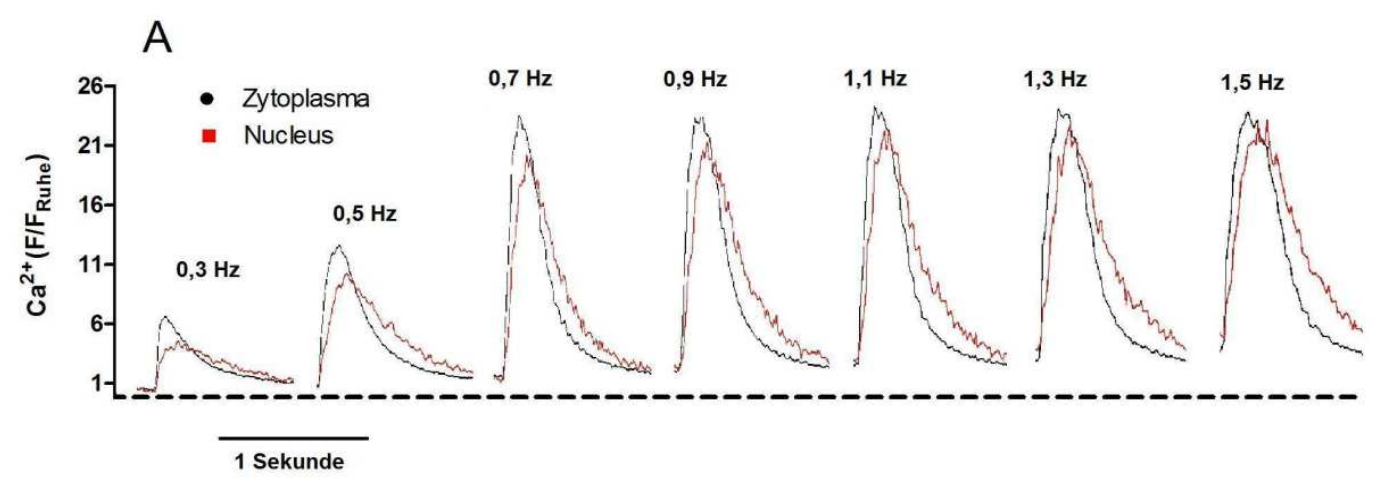

B

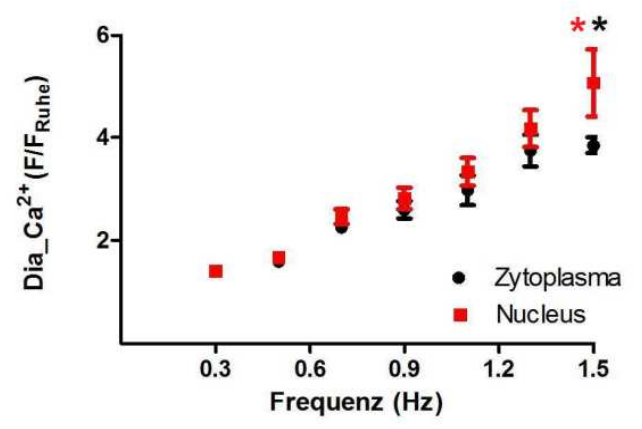

D

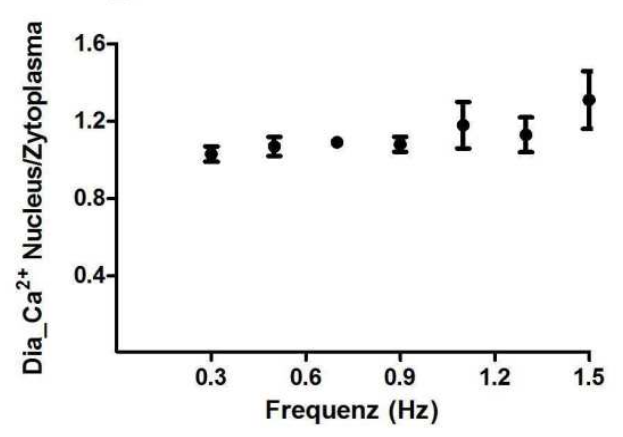

$\mathrm{F}$

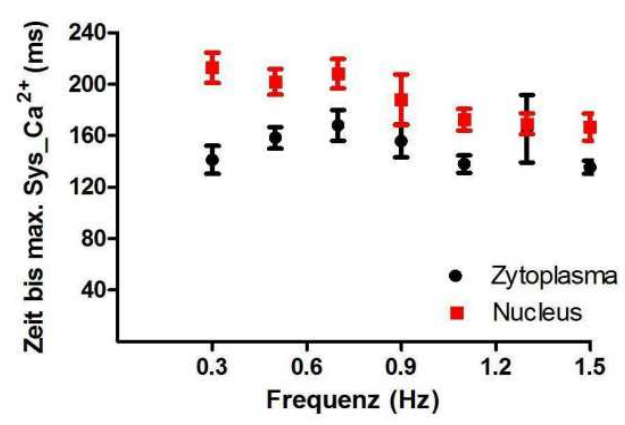

C

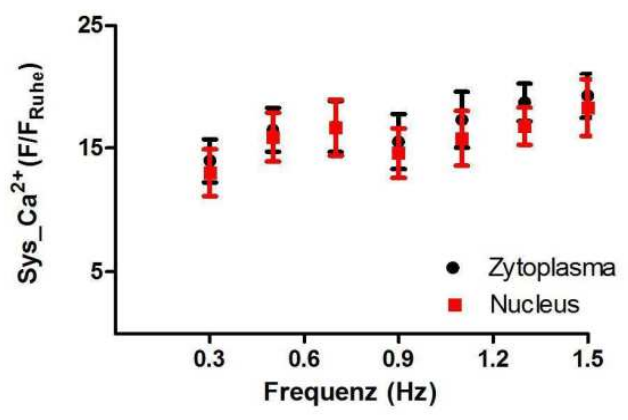

$\mathrm{E}$

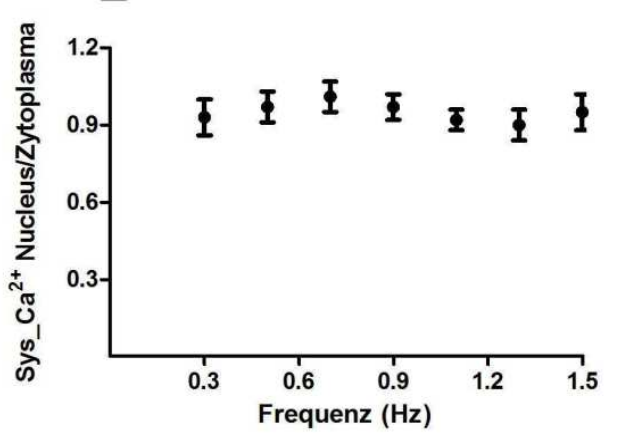

G

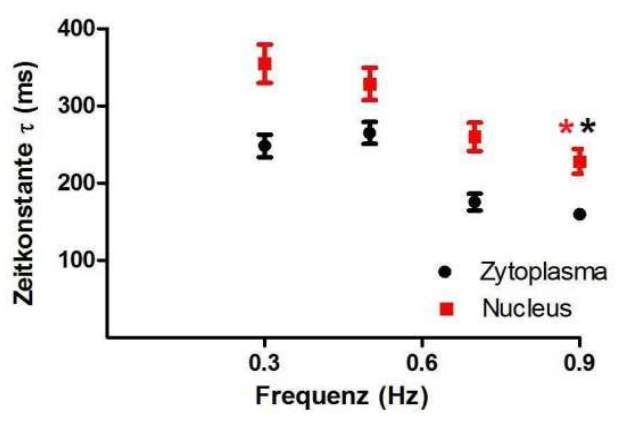

Abbildung 3.2 - Ergebnisse der frequenzabhängigen Änderungen des $\mathrm{Ca}^{2+}$ in Vorhofmyozyten des Kaninchens: A zeigt eine Beispielmessung. In B bis E werden die 
Mittelwerte aller erhobenen Daten $(n=4-21)$ in Abhängigkeit von der Frequenz aufgetragen. $B$ und $C$ beschäftigen sich mit dem diastolischen und systolischen $\mathrm{Ca}^{2+}$. In $D$ und $E$ wird das Verhältnis des diastolischen, bzw. systolischen $\mathrm{Ca}^{2+}$ des Zellkerns und Zytoplasmas in Abhängigkeit von der Frequenz dargestellt. F gibt die TTP in Abhängigkeit von der Frequenz wieder. Die Zeitkonstante $\tau$ wird in Abhängigkeit von der Frequenz in $G$ dargestellt. * = $P<0,05$ versus $0,3 \mathrm{~Hz}$.

\subsubsection{Zeit bis zum Erreichen des systolischen maximalen $\mathrm{Ca}^{2+}$}

Die Zeit bis zum Erreichen des systolischen $\mathrm{Ca}^{2+}$ (TTP) war im Zellkern nicht abhängig von der Frequenz (Abbildung 3.2F). Sie betrug $213 \pm 12 \mathrm{~ms}$ bei $0,3 \mathrm{~Hz}$ und $167 \pm 10 \mathrm{~ms}$ bei $1,5 \mathrm{~Hz}$ $(\mathrm{P}>0,05)$.

Ähnlich verhielt es sich im Zytoplasma. TTP betrug hier $141 \pm 11 \mathrm{~ms}$ bei $0,3 \mathrm{~Hz}, 168 \pm 12 \mathrm{~ms}$ bei $0,7 \mathrm{~Hz}$ und $135 \pm 5 \mathrm{~ms}$ bei $1,5 \mathrm{~Hz}(\mathrm{P}>0,05)$.

\subsubsection{Zeitkonstante des Abfalls des $\mathrm{Ca}^{2+}$-Transienten}

Ähnlich wie bei den Ventrikelmyozyten konnten nur bis $0,9 \mathrm{~Hz}$ die Werte für die Zeitkonstante $\tau$ fehlerfrei ermittelt werden. Sowohl im Zellkern wie auch im Zytoplasma kam es $\mathrm{zu}$ einer frequenzabhängigen Verringerung der Zeitkonstante des Abfalls des $\mathrm{Ca}^{2+}$ Transienten (Abbildung 3.2G).

So kam es bei einem Frequenzanstieg von $0,3 \mathrm{~Hz}$ auf $0,9 \mathrm{~Hz}$ zu einer Reduktion der Zeitkonstanten von $248 \pm 14 \mathrm{~ms}$ auf $160 \pm 6 \mathrm{~ms}$ für das Zytoplasma $(\mathrm{P}<0,05)$ und von $355 \pm 25$ ms auf 228 \pm 16 ms für den Zellkern $(\mathrm{P}<0,05)$.

Die Berechnung des Verhältnisses (Zellkern/Zytoplasma) ergab ähnliche Werte von $1,45 \pm 0,07$ bei $0,3 \mathrm{~Hz}$ und von $1,42 \pm 0,06$ bei $0,9 \mathrm{~Hz}(\mathrm{P}>0,05)$.

Abbildung 3.2G zeigt außerdem, dass die Zeitkonstante des Abfalls des $\mathrm{Ca}^{2+}$-Transienten im Zellkern deutlich größer war als im Zytoplasma.

\subsection{Frequenzabhängige $\mathrm{Ca}^{2+}$-Änderungen in Mausventrikelmyozyten}

Abbildung 3.3A zeigt eine Beispielmessung von $\mathrm{Ca}^{2+}$-Transienten eines Mausventrikelmyozyten. Die Stimulation wurde beginnend bei $0,5 \mathrm{~Hz}$ in $0,5 \mathrm{~Hz}-\mathrm{Schritten}$ bis $4 \mathrm{~Hz}$ erhöht. Wie bei den Kaninchenventrikelmyozyten stiegen in diesem Beispiel das 
systolische und diastolische $\mathrm{Ca}^{2+}$ bei steigender Frequenz sowohl im Zytoplasma als auch im Zellkern an. Auch schien sich die Kinetik der $\mathrm{Ca}^{2+}$-Transienten frequenzabhängig zu ändern. Im gezeigten Beispiel erreichte das systolische $\mathrm{Ca}^{2+}$ im Zytoplasma höhere Werte als im Zellkern, was sich auch bei steigender Frequenz nicht änderte. Dies galt für alle Messungen an Mausventrikelmyozyten.

\subsubsection{Frequenzabhängige Änderungen des diastolischen $\mathrm{Ca}^{2+}$}

Bei steigender Frequenz kam es zu einem Anstieg der diastolischen $\mathrm{Ca}^{2+}$-Spiegel (Abbildung 3.3B). Im Zytoplasma betrug der diastolische $\mathrm{Ca}^{2+}$-Spiegel $1,21 \pm 0,03$ bei $0,5 \mathrm{~Hz}$. Es kam zu

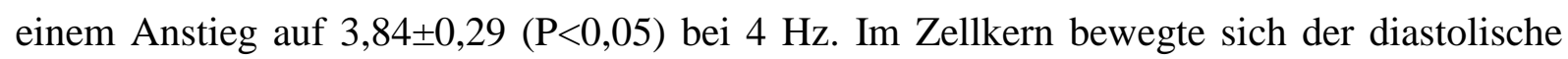
$\mathrm{Ca}^{2+}$-Spiegel ausgehend von $1,30 \pm 0,05$ bei $0,5 \mathrm{~Hz}$ auf $4,06 \pm 0,41(\mathrm{P}<0,05)$ bei $4 \mathrm{~Hz}$.

Bei den Mausventrikelmyoyzten konnte eine Umrechnung der Fluoreszenzänderungen in $\mathrm{Ca}^{2+}$-Konzentrationen (in $\mathrm{nM}$ ) erfolgen, da entsprechende Werte aus in-situ-Kalibrierungen vorlagen (Ljubojevic et al. 2011; siehe Seite 26-28). Abbildung 3.3D zeigt, dass es zu einem statistisch signifikanten frequenzabhängigen Anstieg der diastolischen $\mathrm{Ca}^{2+}$-Konzentration kam. Im Zytoplasma stieg die diastolische $\mathrm{Ca}^{2+}$-Konzentration von $92 \pm 6 \mathrm{nM}$ bei $0,5 \mathrm{~Hz}$ auf $453 \pm 69 \mathrm{nM}(\mathrm{P}<0,05)$ bei $4 \mathrm{~Hz}$. Im Zellkern erhöhte sich die diastolische $\mathrm{Ca}^{2+}$-Konzentration von $127 \pm 7 \mathrm{nM}$ bei $0,5 \mathrm{~Hz}$ auf $920 \pm 146 \mathrm{nM}(\mathrm{P}<0,05)$ bei $4 \mathrm{~Hz}$.

Betrachtet man den Anstieg in beiden Kompartimenten und errechnet das Verhältnis (Nukleus /Zytoplasma), so betrug dies $1,40 \pm 0,04$ bei $0,5 \mathrm{~Hz}$ und $1,64 \pm 0,21 \quad(\mathrm{P}<0,05)$ bei $4 \mathrm{~Hz}$ (Abbildung 3.4A). Dies bedeutet, dass die diastolische $\mathrm{Ca}^{2+}$-Konzentration im Zellkern frequenzabhängig stärker anstieg als im Zytoplasma.

\subsubsection{Frequenzabhängige Änderungen der systolischen Kalziumspiegel}

Auch für das systolische $\mathrm{Ca}^{2+}$ ließ sich ein frequenzabhängiger Anstieg beobachten (Abbildung 3.3C). Im Zytoplasma kam es dabei von 4,68 $\pm 0,26$ bei 0,5 Hz zu einem Anstieg auf 7,83 $\pm 0,70(\mathrm{P}<0,05)$ bei $4 \mathrm{~Hz}$, im Zellkern ging dieser von $3,85 \pm 0,19$ bei $0,5 \mathrm{~Hz}(\mathrm{P}<0,05)$ auf 7,23 $\pm 0,61$ bei $4 \mathrm{~Hz}$ (Abbildung 3.3C). 


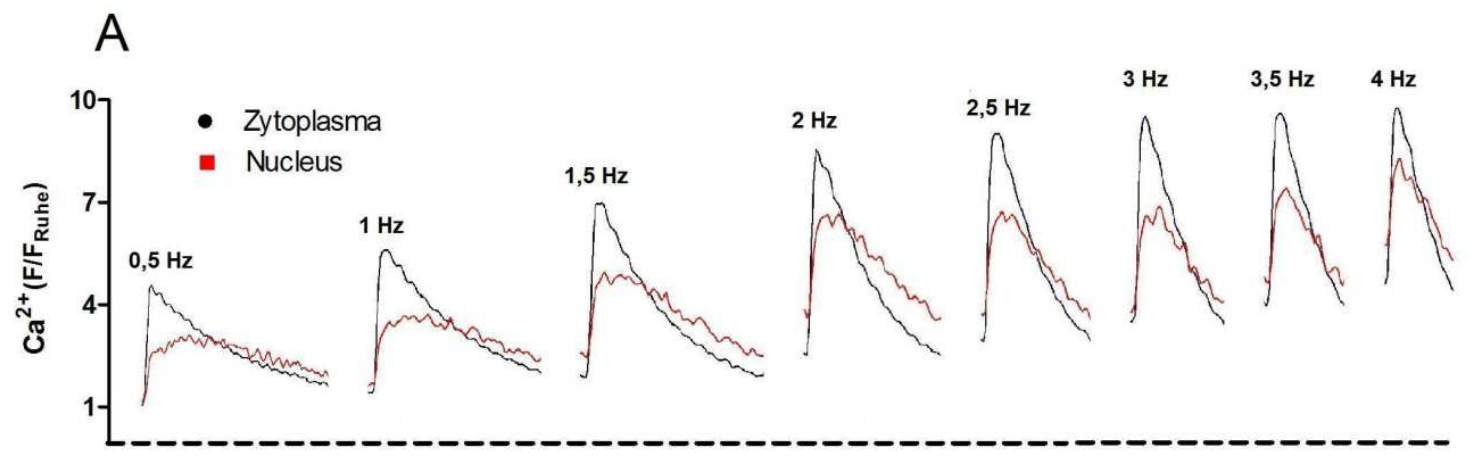

1 Sekunde

B

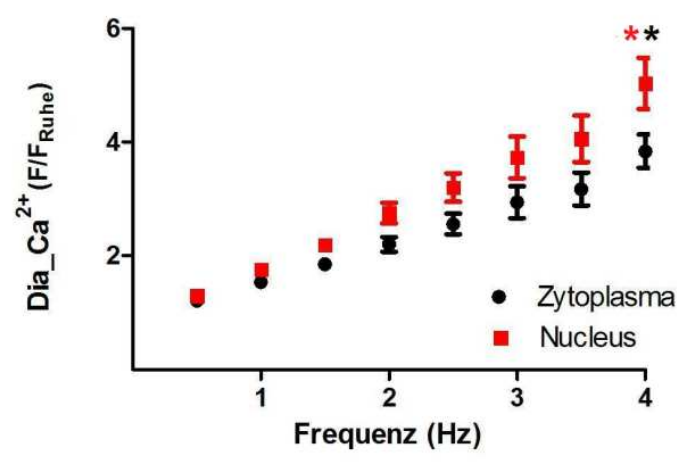

D

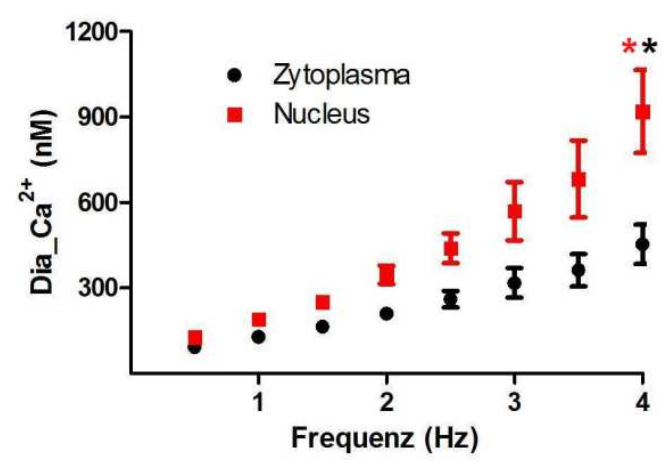

C

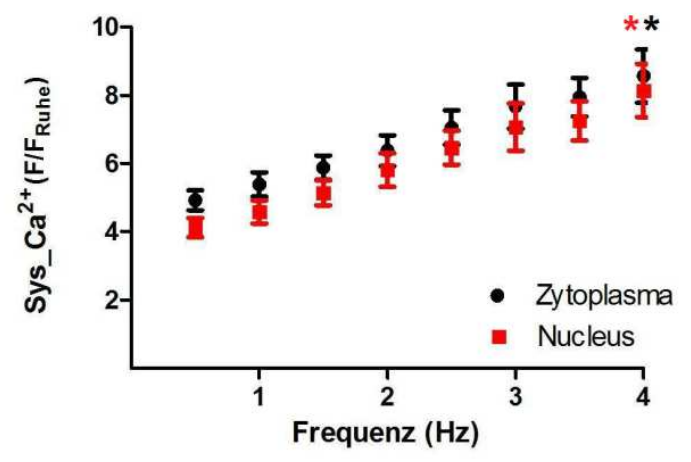

E

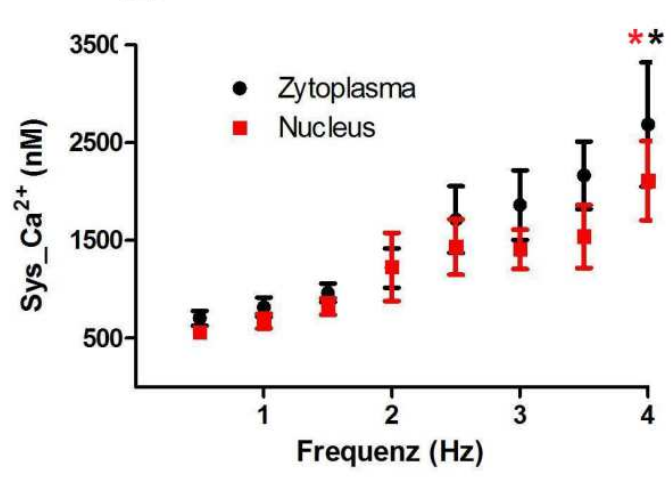

Abbildung 3.3 - Diastolische und systolische frequenzabhängige $\mathbf{C a}^{2+}$-Änderungen in Ventrikelmyozyten der Maus Teil 1: A zeigt anhand einer Beispielmessung die $\mathrm{Ca}^{2+}$ Transienten bei verschiedenen Frequenzen. B und $C$ zeigen die relativen $\mathrm{Ca}^{2+}{ }_{-}$Änderungen 
des diastolischen und systolischen $\mathrm{Ca}^{2+}$ über dem Ruhe-Ca ${ }^{2+}\left(F / F_{R u h e}\right)$. In D und E wurden diese Werte in $\mathrm{Ca}^{2+}$-Konzentrationen umgerechnet, die Einheit hier beträgt nanomolar (nM). Gezeigt sind die Mittelwerte der Messungen $(n=10-20)$. $*=P<0,05$ versus $0,5 \mathrm{~Hz}$.

Betrachtet man die berechneten $\mathrm{Ca}^{2+}$-Konzentrationen (Abbildung 3.3E), so kam es im Zytoplasma zu einem Anstieg von $703 \pm 74 \mathrm{nM}$ bei $0,5 \mathrm{~Hz}$ auf $2685 \pm 634 \mathrm{nM}(\mathrm{P}<0,05)$ bei 4 Hz. Im Zellkern stieg die systolische $\mathrm{Ca}^{2+}$-Konzentration von $560 \pm 45 \mathrm{nM}$ bei $0,5 \mathrm{~Hz}$ auf $2111 \pm 403 \mathrm{nM}(\mathrm{P}<0,05)$ bei $4 \mathrm{~Hz}$.

Berechnet man auch hier das Verhältnis Nukleus/Zytoplasma (Abbildung 3.4B), so konnte eine Änderung von $0,84 \pm 0,04$ bei $0,5 \mathrm{~Hz}$ auf $0,91 \pm 0,11(\mathrm{P}>0,05)$ bei $4 \mathrm{~Hz}$ beobachtet werden. Somit konnte, anders als beim diastolischen $\mathrm{Ca}^{2+}$, kein statistisch signifikanter Unterschied im frequenzabhängigen Anstieg des systolischen $\mathrm{Ca}^{2+}$ zwischen den beiden Kompartimenten nachgewiesen werden.

\subsubsection{Zeit bis zum Erreichen des systolischen $\mathrm{Ca}^{2+}$}

Im Zytoplasma war die Zeit bis zum Erreichen des systolischen $\mathrm{Ca}^{2+}$ (TTP) bei allen gemessenen Frequenzen nahezu konstant (Abbildung 3.4C). Die geringen Unterschiede waren statistisch nicht signifikant ( $\mathrm{P}>0,05)$. Während die TTP bei $0,5 \mathrm{~Hz}$ bei $53 \pm 3 \mathrm{~ms}$ lag, betrug sie bei $2 \mathrm{~Hz} 44 \pm 3 \mathrm{~ms}$ und bei $4 \mathrm{~Hz} 49 \pm 3 \mathrm{~ms}$.

Anders verhielt es sich im Zellkern. Hier fiel die TTP von $108 \pm 11 \mathrm{~ms}$ bei $0,5 \mathrm{~Hz}$ auf $67 \pm 5 \mathrm{~ms}$ bei $2 \mathrm{~Hz}$ ab $(\mathrm{P}<0,05)$ und weiter auf $57 \pm 8 \mathrm{~ms}$ bei $4 \mathrm{~Hz}$ ab $(\mathrm{P}>0,05)$ (Abbildung 3.4C).

Eine Berechnung des Verhältnisses zwischen Zellkern und Zytoplasma zeigte eine signifikante Änderung von $2,14 \pm 0,26$ bei $0,5 \mathrm{~Hz}$ auf $1,39 \pm 0,09$ bei $2,5 \mathrm{~Hz}(\mathrm{P}<0,05)$. Es zeigte sich also, dass die Zeit bis zum Erreichen des systolischen $\mathrm{Ca}^{2+}$ im Zellkern zunächst abfiel, jedoch bei höheren Frequenzen annähernd konstant blieb.

\subsubsection{Abfall des $\mathrm{Ca}^{2+}$-Transienten}

Die Zeitkonstante $\tau$ des Abfalls des $\mathrm{Ca}^{2+}$-Transienten konnte bei der Maus auf Grund der sehr schnellen Kinetik nicht zuverlässig errechnet werden, weshalb hier die Zeit ermittelt wurde, die das systolische $\mathrm{Ca}^{2+}$ braucht, um auf 50\% seines Ausgangswertes abzufallen (RT50) (Abbildung 3.4D). 
A

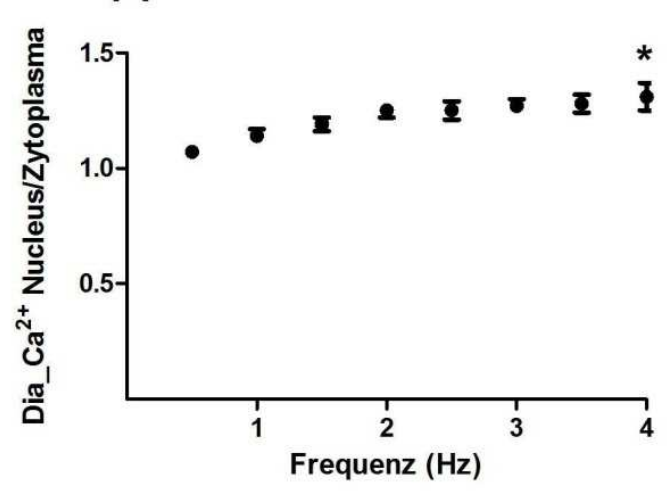

C

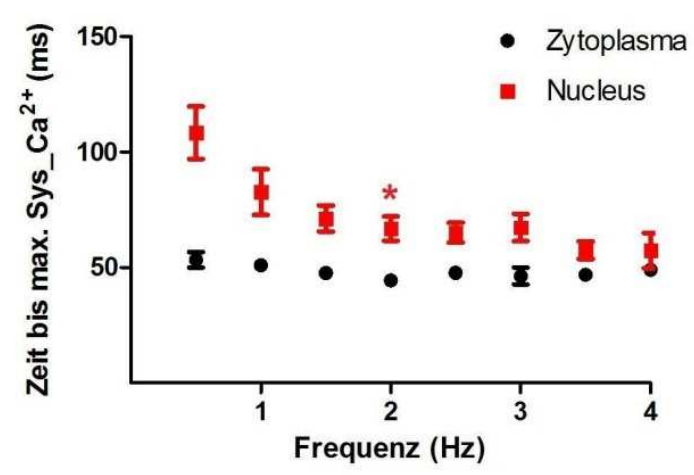

B
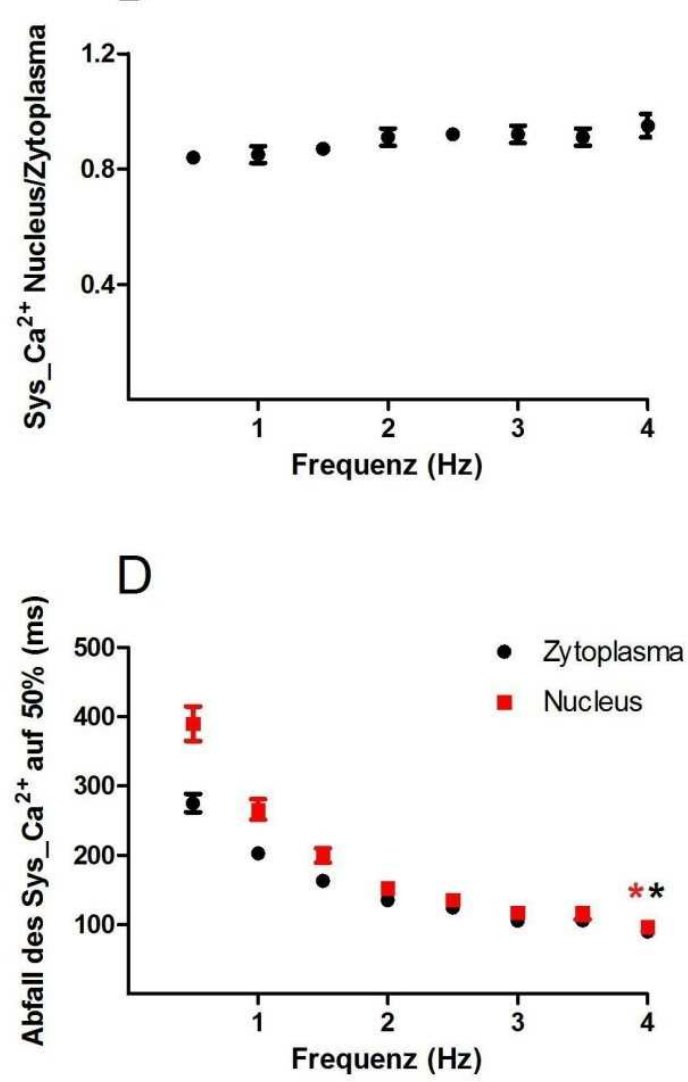

Abbildung 3.4 - Diastolische und systolische frequenzabhängige $\mathrm{Ca}^{2+}$ - Änderungen in Ventrikelmyozyten der Maus Teil 2: In A und B wird das Verhältnis der relativen $\mathrm{Ca}^{2+}$ Änderungen zwischen Zellkern und Zytoplasma aufgetragen. C befasst sich mit der TTP, während D den Abfall des $\mathrm{Ca}^{2+}$-Transienten zeigt (Relaxion time 50\% = RT 50). $*=P<0,05$ versus $0,5 \mathrm{~Hz}$.

Sowohl im Zytoplasma als auch im Zellkern nahm die RT50 zu Beginn stark ab, um sich dann bei höheren Frequenzen auf einem konstanten Niveau zu stabilisieren. So konnte im Zytoplasma ein Abfall der RT50 von $275 \pm 13 \mathrm{~ms}$ bei $0,5 \mathrm{~Hz}$ auf $90 \pm 5 \mathrm{~ms}(\mathrm{P}<0,05)$ bei $4 \mathrm{~Hz}$ beobachtet werden. Im Zellkern fiel die RT50 von $390 \pm 25 \mathrm{~ms}$ bei $0,5 \mathrm{~Hz}$ auf $97 \pm 6 \mathrm{~ms}$ $(\mathrm{P}<0,05)$ bei $4 \mathrm{~Hz}$. 


\section{4 $\mathrm{Ca}^{2+}$-Änderungen in Vorhofmyozyten des Kaninchens nach definierter Pause der} Stimulation

Für das Pausenprotokoll wurden der letzte elektrisch stimulierte $\mathrm{Ca}^{2+}$-Transient vor der Pause und die fünfzehn $\mathrm{Ca}^{2+}$-Transienten nach der Stimulationspause ausgewertet, die Stimulationsfrequenz betrug 0,5 Hz. Die Pause selber betrug eine Minute. In Abbildung 3.5A ist dies anhand einer Beispielmessung gezeigt. Der erste $\mathrm{Ca}^{2+}$-Transient in dieser Messung ist der letzte vor der Pause gemessene $\mathrm{Ca}^{2+}$-Transient.

Betrachtet man den ersten $\mathrm{Ca}^{2+}$-Transienten nach der Pause, so fällt auf, dass das systolische $\mathrm{Ca}^{2+}$ des Zellkerns und des Zytoplasmas deutlich höher waren als vor der Pause. Im direkt darauf folgenden Transienten fiel das systolische $\mathrm{Ca}^{2+}$ in bei beiden Kompartimenten unter das vor der Pause. Dieser Trend setzte sich 7 Transienten lang fort, bevor das systolische $\mathrm{Ca}^{2+}$ langsam, dafür aber kontinuierlich, wieder anstieg.

Bei Betrachtung des diastolischen $\mathrm{Ca}^{2+}$ fällt auf, dass es direkt nach der Pause, vor dem ersten Transienten, den Ruhewert in beiden Kompartimenten erreicht hatte. Dann stieg es initial an und blieb anschließend nahezu konstant.

\subsection{1 Änderung des diastolischen $\mathrm{Ca}^{2+}$ nach der Stimulationspause}

Am ausgeprägtesten war die Änderung des diastolischen $\mathrm{Ca}^{2+}$ beim ersten Transienten nach

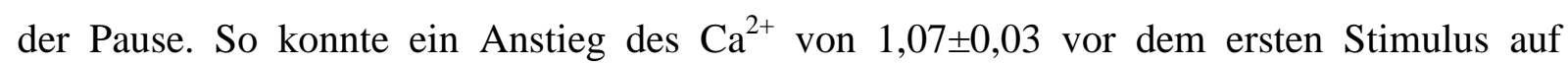

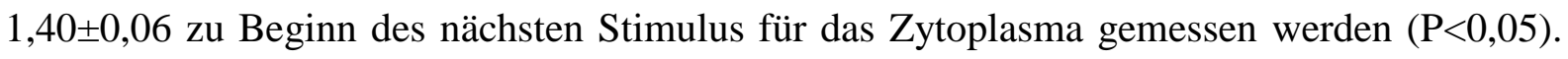
Im Zellkern stieg das diastolische $\mathrm{Ca}^{2+}$ von 1,08 $\pm 0,02$ auf $1,68 \pm 0,14(\mathrm{P}<0,05)$.

Das im weiteren Verlauf gemessene diastolische $\mathrm{Ca}^{2+}$ schwankte zwar noch geringfügig, jedoch waren diese Schwankungen im Zytoplasma und im Zellkern nicht statistisch signifikant. Daher kann gefolgert werden, dass das diastolische $\mathrm{Ca}^{2+}$ bereits nach zwei Transienten nach der Pause wieder sein normales Niveau erreicht hatte.

Vergleicht man nun noch das Verhalten der beiden Kompartimente, in dem man deren Verhältnis errechnet (Zellkern/Zytoplasma), so konnte kein statistisch signifikanter Unterschied beobachtet werden. 


\subsection{2 Änderung des systolischen $\mathrm{Ca}^{2+}$ nach der Stimulationspause}

Anders als für das diastolische $\mathrm{Ca}^{2+}$, konnte die größte Änderung des systolischen $\mathrm{Ca}^{2+}$ nicht direkt im ersten Stimulus nach der Pause beobachtet werden. Der größte Unterschied lag zwischen dem ersten Stimulus nach der Pause und dem darauf folgenden. Im Zytoplasma

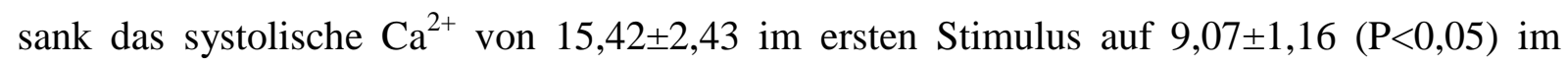
zweiten Stimulus nach der Pause und entsprechend im Zellkern von 15,39 $\pm 1,99$ auf 7,61 $\pm 0,79$ $(\mathrm{P}<0,05)$.

Dies bedeutet einen signifikanten Anstieg des $\mathrm{Ca}^{2+}$ sowohl im Zellkern, als auch im Zytoplasma nach der Pause. Anhand dieser Daten ließ sich zunächst ein unterschiedlich starker Anstieg des $\mathrm{Ca}^{2+}$ im Zellkern gegenüber dem Zytoplasma vermuten, jedoch konnte dies anhand der Berechnung des Verhältnisses zwischen diesen beiden Kompartimenten nicht nachgewiesen werden.

\section{5 $\mathrm{Ca}^{2+}$-Änderungen in Ventrikelmyozyten der Maus nach definierter Pause der Stimulation}

In Mausventrikelmyozyten wurden ebenfalls Messungen des $\mathrm{Ca}^{2+}$-Transienten bei stabiler Frequenz und nach definierter Pause vorgenommen. Die Stimulationsfrequenz betrug $1 \mathrm{~Hz}$. Im gezeigten Beispiel in der Abbildung 3.6A sieht man, dass hier das systolische $\mathrm{Ca}^{2+}$ des Zytoplasmas höhere Werte erreichte als das des Zellkerns.

Nach der Pause zeigte sich ein Anstieg von diastolischem und systolischem $\mathrm{Ca}^{2+}$ beim ersten stimulierten $\mathrm{Ca}^{2+}$-Transienten. Bereits beim zweiten Transienten fielen diese Werte auf ein Niveau ab, welches unterhalb desjenigen vor der Pause lag. Dieser Abfall dauerte nur 3 Schläge an, es kam dann wieder zu einem kontinuierlichen Anstieg, bis das $\mathrm{Ca}^{2+}$ sich in beiden Kompartimenten fast dem Ausgangswert vor der Pause näherte.

\subsection{1 Änderung des diastolischen $\mathrm{Ca}^{2+}$ nach der Stimulationspause}

Abbildung 3.6B zeigt, wie bei dem Kaninchen, unmittelbar vor dem ersten Transienten nach

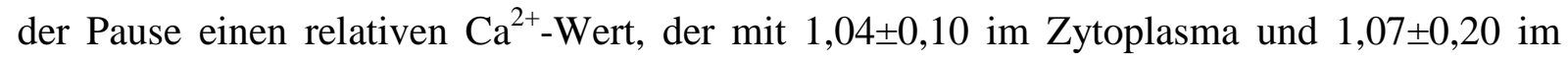
Zellkern fast dem Ruhewert ohne Stimulation entsprach. Mit Beginn der Stimulation stieg der diastolische Wert initial auf $1,48 \pm 0,07$ im Zytoplasma $(\mathrm{P}<0,05)$ und auf $1,96 \pm 0,10$ im Zellkern $(\mathrm{P}<0,05)$ an. 


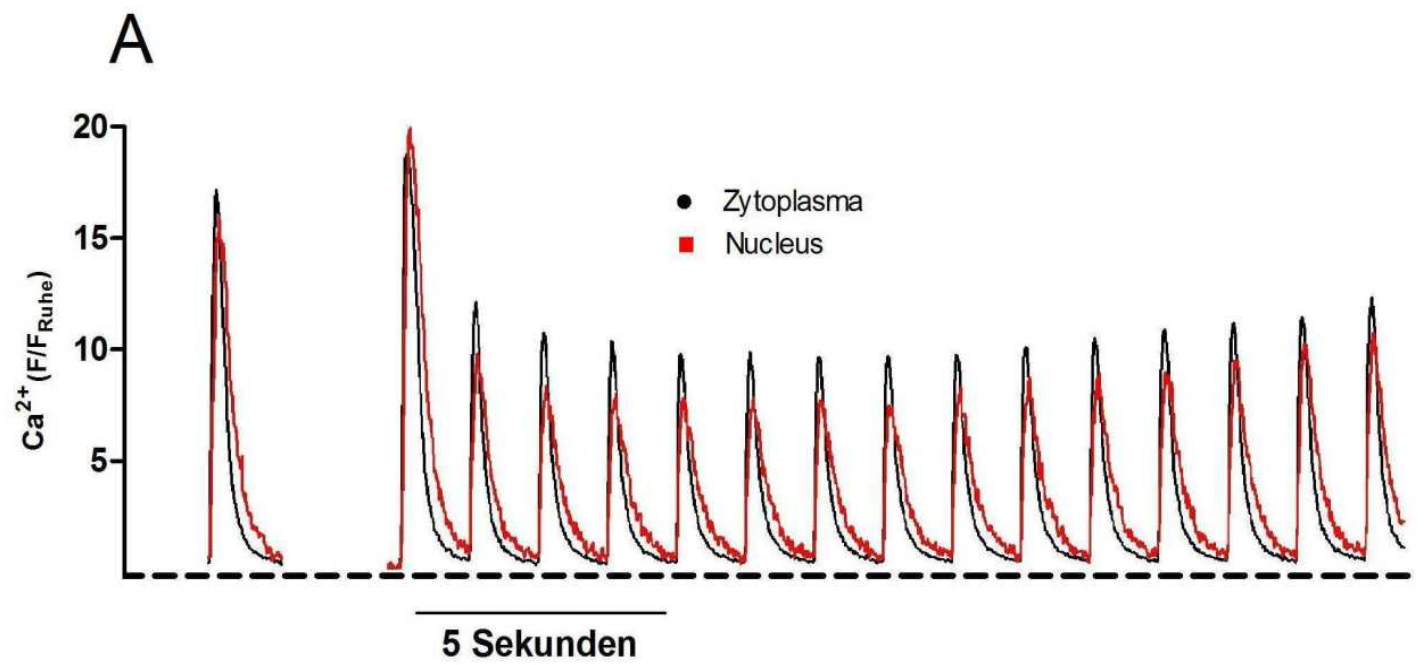

B
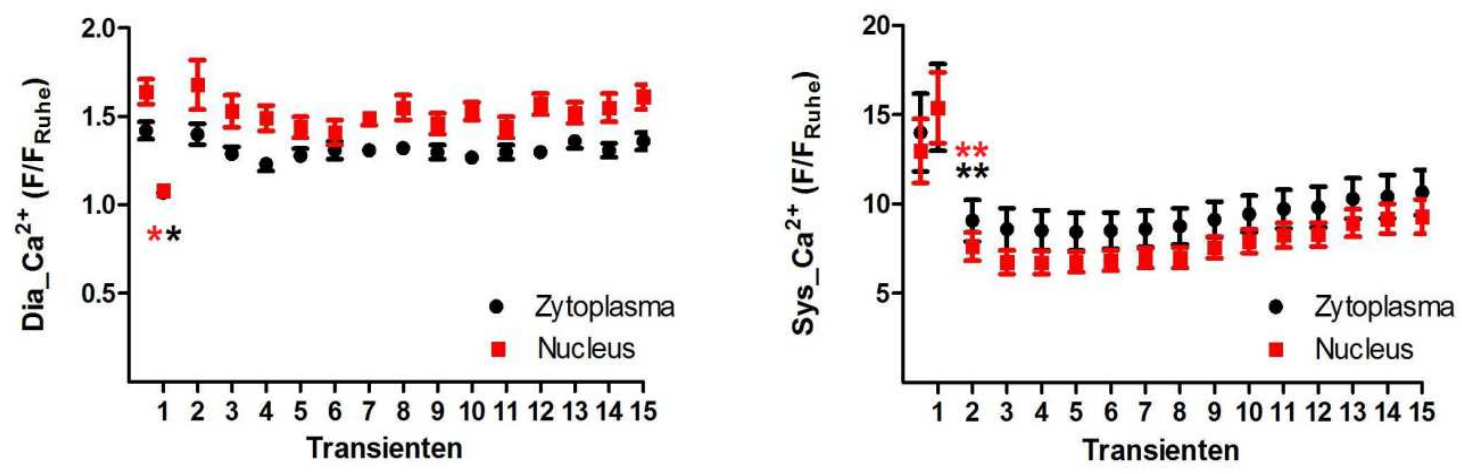

D
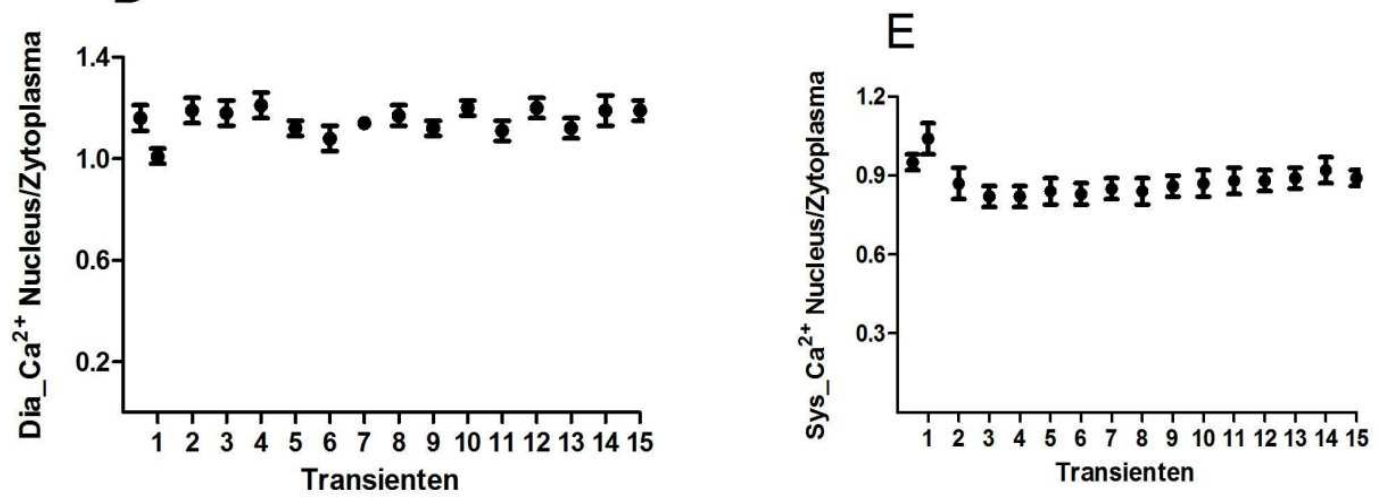

Abbildung 3.5 $-\mathrm{Ca}^{2+}$ in Vorhofmyozyten des Kaninchens nach einer Stimulationspause: In A ist eine Beispielmessung zu sehen. Der erste Transient in der Beispielmessung, sowie der 
erste Punkt in den folgenden Grafiken, wurde vor der Pause gemessen. Alle folgenden Transienten sind direkt nach der Pause gemessen. B zeigt die diastolischen $\mathrm{Ca}^{2+}$-Änderungen, $C$ die systolischen $\mathrm{Ca}^{2+}{ }_{-}$Änderungen. In $\mathrm{D}$ und $\mathrm{E}$ wird das Verhältnis der relativen $\mathrm{Ca}^{2+}{ }_{-}$ Änderungen der Diastole (D) und Systole (E) gezeigt. Aufgetragen sind die Mittelwerte aller Messungen $(n=9) . *=P<0,05$ Kontrolle versus erster Postpause-Transient; $* *=P<0,05$ erster Postpause-Transient versus zweiter Postpause-Transient.

Berechnet man die $\mathrm{Ca}^{2+}$-Konzentration (Abbildung 3.6D), so betrug diese unmittelbar vor der Pause $78 \pm 1 \mathrm{nM}$ im Zytosol und 99 $\pm 2 \mathrm{nM}$ im Zellkern. Zu Beginn der Stimulation stieg sie auf $128 \pm 8$ nM im Zytosol $(\mathrm{P}<0,05)$ und auf 218 \pm 14 nM im Zellkern $(\mathrm{P}<0,05)$.

Somit war sowohl für die relative Fluoreszenzänderung als auch für die $\mathrm{Ca}^{2+}$-Konzentration in der Diastole ein signifikanter Anstieg im Zytoplasma und im Zellkern nach der Pause zu verzeichnen.

Anschließend fiel die relative Fluoreszenzänderung im Zytoplasma direkt nach dem ersten

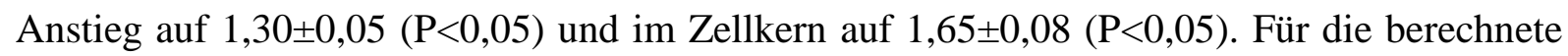
diastolische $\mathrm{Ca}^{2+}$-Konzentration betrug der entsprechende Wert im Zytoplasma 107 $\pm 6 \mathrm{nM}$ $(\mathrm{P}<0,05)$ und im Zellkern 174 $\pm 11 \mathrm{nM}(\mathrm{P}<0,05)$.

Anschließend näherte sich das diastolische $\mathrm{Ca}^{2+}$ wieder dem Wert vor der Pause an. Dies galt für Zellkern und Zytoplasma.

Das Verhältnis des diastolischen $\mathrm{Ca}^{2+}$ zwischen Zellkern und Zytoplasma ist in Abbildung 3.6F dargestellt. Hier ergaben sich statistisch signifikanten Änderungen nach der Stimulationspause. Somit konnte eine unterschiedliche Konzentrationsänderung des diastolischen $\mathrm{Ca}^{2+}$ zwischen Zellkern und Zytoplasma nachgewiesen werden.

\subsection{2 Änderung des systolischen $\mathrm{Ca}^{2+}$ nach der Stimulationspause}

Im Zytoplasma war ein Anstieg des systolischen $\mathrm{Ca}^{2+}$ von 4,64 $\pm 0,27$ vor der Pause auf $7,53 \pm 0,32$ nach der Pause $(\mathrm{P}<0,05)$ und im Zellkern von 3,74 $\pm 0,22$ vor der Pause auf 6,51 $\pm 0,32$ nach der Pause $(\mathrm{P}<0,05)$ (Abbildung 3.6C) zu verzeichnen. Für die systolische $\mathrm{Ca}^{2+}$-Konzentration ging der Anstieg im Zytoplasma von $699 \pm 83 \mathrm{nM}$ vor der Pause auf $2021 \pm 241 \mathrm{nM}(\mathrm{P}<0,05)$. Im Zellkern kam es zu einem Anstieg von 546 $\pm 62 \mathrm{nM}$ vor der Pause auf $1533 \pm 178 \mathrm{nM}$ nach der Pause $(\mathrm{P}<0,05)$ (Abbildung 3.6E).

Dies bedeutete einen statistisch signifikanten Anstieg des systolischen $\mathrm{Ca}^{2+}$ für den ersten $\mathrm{Ca}^{2+}-$ Transienten nach der Pause in beiden Kompartimenten. 

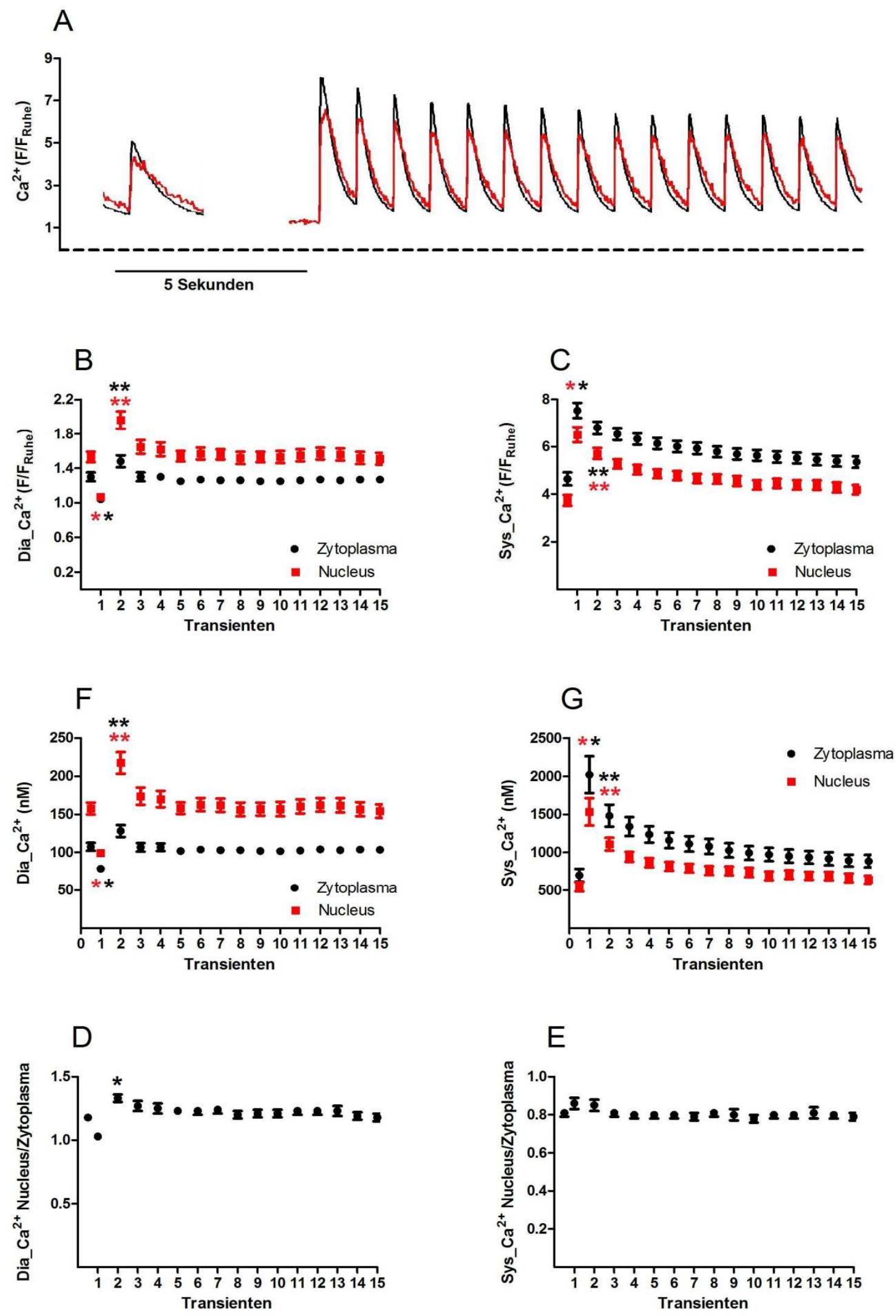

Abbildung 3.6 - $\mathrm{Ca}^{2+}$ in Ventrikelmyozyten der Maus nach einer Stimulationspause: $A$ zeigt eine Beispielmessung. $B$ und $C$ beschreiben die Änderungen des $\mathrm{Ca}^{2+}$, wobei hier die 
relative Änderung $F / F_{\text {Ruhe }}$ gemessen wurde $(n=17)$. In $D$ und $E$ wurde dies mit den errechneten Konzentrationen aufgetragen, $F$ und $G$ zeigen das Verhältnis zwischen Zellkern und Zytoplasma. $*=P<0,05$ Kontrolle versus erster Postpause-Transient; $* *=P<0,05$ erster Postpause-Transient versus zweiter Postpause-Transient.

Im zweiten Transienten nach der Pause zeigte sich, analog zum diastolischen $\mathrm{Ca}^{2+}$, ein Abfall

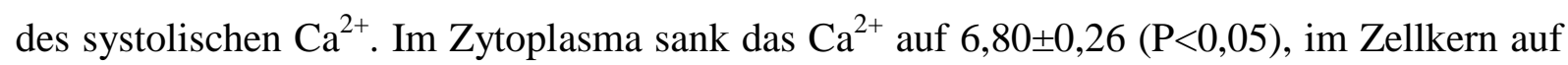
5,72 $\pm 0,23(\mathrm{P}<0,05)$. Die $\mathrm{Ca}^{2+}$-Konzentration (Abbildung 3.6E) sank im Zytoplasma auf $1480 \pm 145 \mathrm{nM}(\mathrm{P}<0,05)$ und im Zellkern auf $1108 \pm 83 \mathrm{nM}(\mathrm{P}<0,05)$.

Dieser Abfall des systolischen $\mathrm{Ca}^{2+}$ setzte sich über mehrere Transienten fort, bis gegen Ende der Messung wieder Werte erreicht wurden wie vor der Pause.

Das Verhältnis des systolischen $\mathrm{Ca}^{2+}$ für Zellkern und Zytoplasma war annähernd konstant (Abbildung 3.6G).

\section{6 Änderung des systolischen und diastolischen $\mathrm{Ca}^{2+}$ in Mäusekardiomyozyten unter pharmakologischer Beeinflussung durch Forskolin}

Zur Beantwortung der Frage nach einer pharmakologischen Beeinflussung der $\mathrm{Ca}^{2+}$ Homöostase im Zytoplasma und im Zellkern erfolgten Messungen mit Forskolin. Dieses aktiviert die Adenylatcyclase direkt, welche die Umwandlung von ATP in cAMP katalysiert. In Abbildung 3.7A ist eine Originalmessung gezeigt. Unter kontinuierlicher elektrischer Stimulation erfolgte die Messung der $\mathrm{Ca}^{2+}$-Transienten im Minutentakt über fünf Minuten. Dem voran ging eine Kontrollmessung ohne Forskolin.

Im gezeigten Beispiel ist zu sehen, dass es in der ersten Messung, eine Minute nach Beginn der kontinuierlichen Applikation von Forskolin, zu einem Anstieg des systolischen $\mathrm{Ca}^{2+}$ im Zellkern und im Zytoplasma kam. Dieser Anstieg war in der ersten Messung am ausgeprägtesten. In den folgenden Messungen stieg das systolische $\mathrm{Ca}^{2+}$ kaum noch, und es blieb auf einem konstanten Niveau.

Das diastolische $\mathrm{Ca}^{2+}$ schien in dieser Messung keine Veränderungen unter der Gabe von Forskolin zu erfahren, dies galt für Zellkern und Zytoplasma. 


\subsubsection{Veränderungen des diastolischen $\mathrm{Ca}^{2+}$ unter Forskolin}

Anhand von Abbildung 3.7B scheint es, als ob es eine Minute nach der Applikation von Forskolin zu einem Abfall des diastolischen $\mathrm{Ca}^{2+}$ in beiden Kompartimenten kam. Dieser bewegte sich für das Zytoplasma von 1,21 $\pm 0,05$ ausgehend vor der Forskolinapplikation auf 1,13 $\pm 0,05$ eine Minute nach der Applikation von Forskolin $(\mathrm{P}>0,05)$. Für den Zellkern änderte sich das diastolische $\mathrm{Ca}^{2+}$ von 1,34 $\pm 0,06$ auf 1,18 $\pm 0,04(\mathrm{P}>0,05)$. Beide Änderungen waren jedoch statistisch nicht signifikant.

Berechnet man die Konzentration des diastolischen $\mathrm{Ca}^{2+}$, so bewegte sich die Änderung im

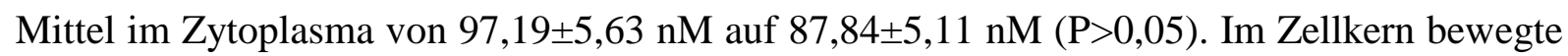
sich diese Änderung des diastolischen $\mathrm{Ca}^{2+}$ von $132,90 \pm 8,19 \mathrm{nM}$ auf $113,05 \pm 4,29 \mathrm{nM}$ $(\mathrm{P}<0,05)$ (Abbildung 3.7D). In den folgenden Messungen schien es weder im Zellkern noch im Zytoplasma eine große Variation des diastolischen $\mathrm{Ca}^{2+} \mathrm{zu}$ geben.

Auch wenn man eine Änderung des diastolischen $\mathrm{Ca}^{2+}$ nach der Applikation von Forskolin vermutete, so war eine statistische Signifikanz der relativen und kalibrierten $\mathrm{Ca}^{2+}$ - $̈$ nderungen hier weder für den Zellkern noch für das Zytoplasma gegeben.

\subsubsection{Veränderungen des systolischen $\mathrm{Ca}^{2+}$ unter Forskolin}

Ein ausgeprägter Anstieg des systolischen $\mathrm{Ca}^{2+}$ ließ sich in der ersten Messung nach Applikation von Forskolin im Zellkern und im Zytoplasma nachweisen. So fand im Zytoplasma ein Anstieg von 4,92 $\pm 0,39$ vor der Applikation von Forskolin auf 7,13 $\pm 0,47$ nach der Applikation statt $(\mathrm{P}<0,05)$ (Abbildung 3.7C). Im Zellkern bewegte sich die Änderung von 4,27 $\pm 0,32$ vor auf $6,17 \pm 0,38$ eine Minute nach Applikation von Forskolin $(\mathrm{P}<0,05)$. Berechnet man die Konzentration des systolischen $\mathrm{Ca}^{2+}$ (Abbildung 3.7E), so kam es zu

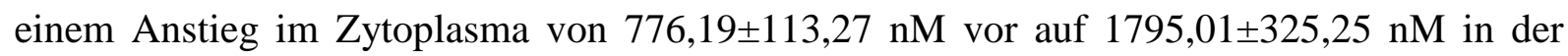
ersten Messung nach der Applikation von Forskolin $(\mathrm{P}<0,05)$. Im Zellkern war eine Änderung von $667,21 \pm 81,77 \mathrm{nM}$ vor auf $1324,21 \pm 158,39 \mathrm{nM}$ nach Applikation von Forskolin zu verzeichnen $(\mathrm{P}<0,05)$. Somit konnte sowohl für die relative $\mathrm{Ca}^{2+}$ - Änderung $(\mathrm{F} / \mathrm{FRuhe})$ als auch für die errechnete $\mathrm{Ca}^{2+}$-Konzentration eine statistisch signifikante Änderung nach Forskolinapplikation nachgewiesen werden.

In den folgenden Minuten war kein signifikanter Unterschied des systolischen $\mathrm{Ca}^{2+}$ im Zellkern und im Zytoplasma zu verzeichnen. 


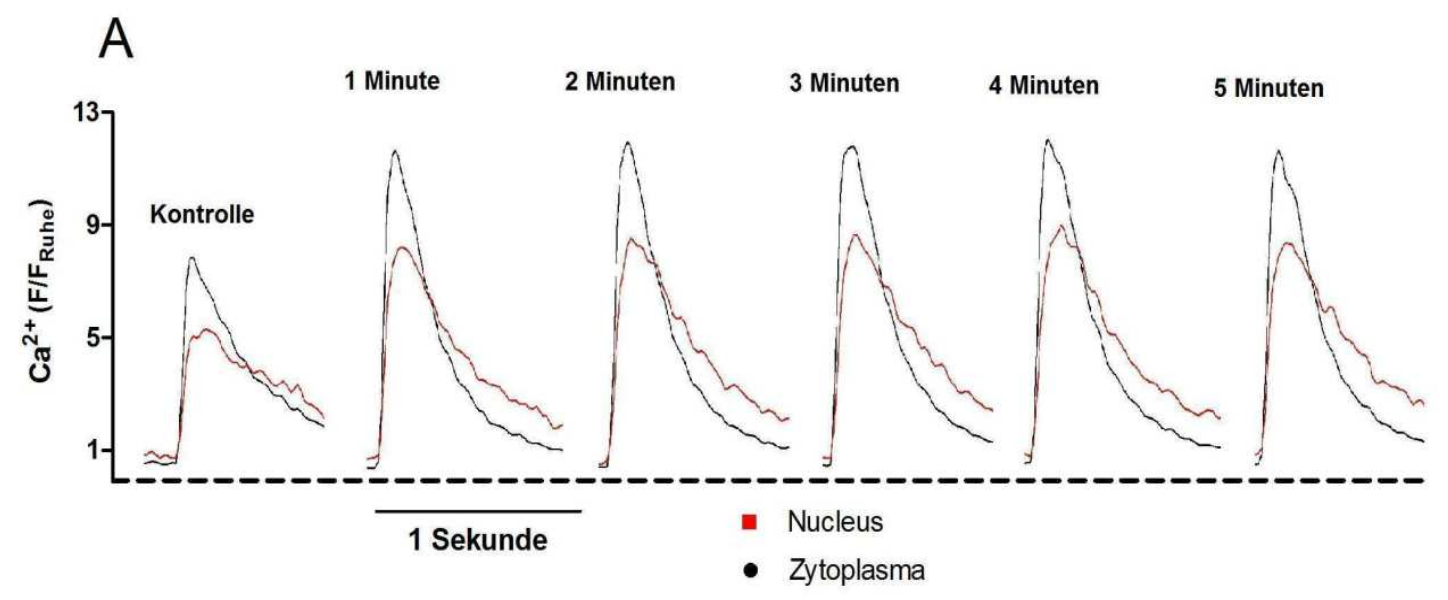

B

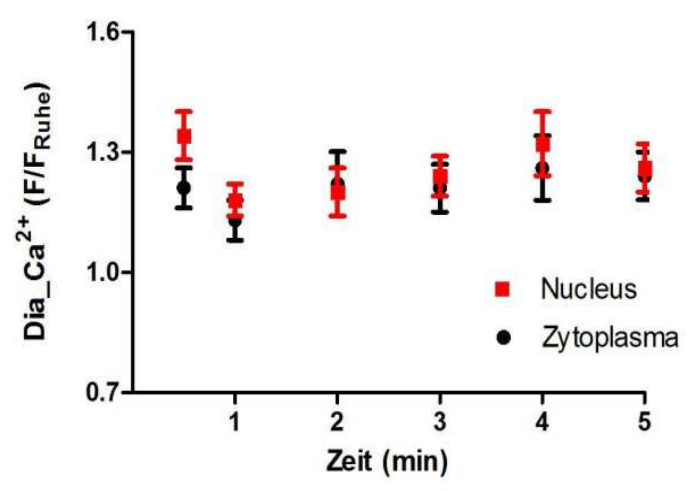

D

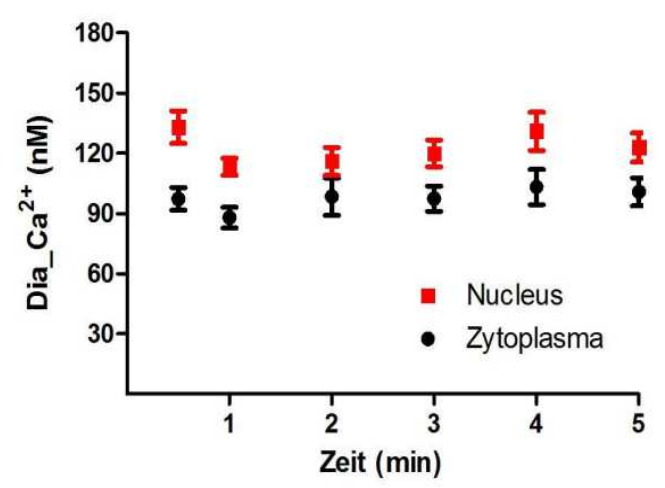

C

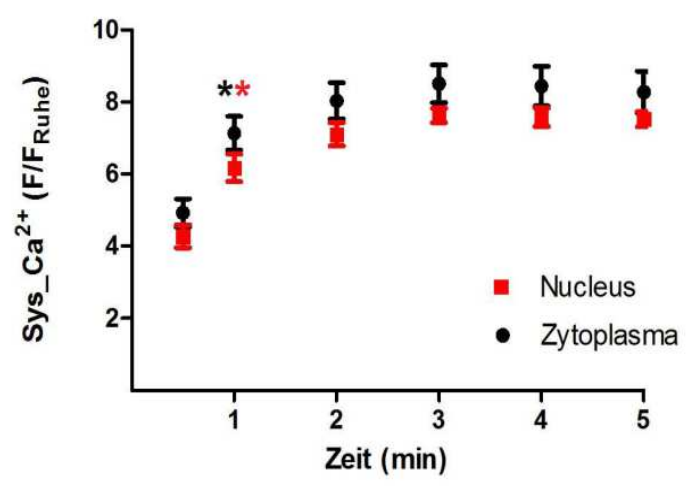

E

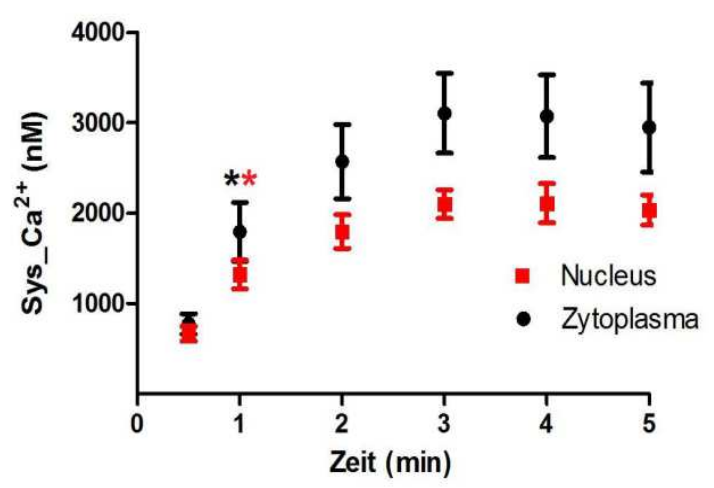

Abbildung 3.7 - $\mathrm{Ca}^{2+}$-Änderungen nach Applikation von Forskolin Teil 1: A zeigt eine Beispielmessung. Der erste Transient steht für die Kontrollmessung vor Forskolinapplikation. 
$B$ zeigt das gemessene diastolische $\mathrm{Ca}^{2+}$, während $\mathrm{C}$ das systolische $\mathrm{Ca}^{2+}$ zeigt. In $\mathrm{D}$ ist das kalibrierte diastolische $\mathrm{Ca}^{2+}$ und in $\mathrm{E}$ das systolische $\mathrm{Ca}^{2+}$ aufgetragen $(n=10) . *=P<0,05$ Kontrolle versus 1-5 Minuten nach Forskolinapplikation.

A

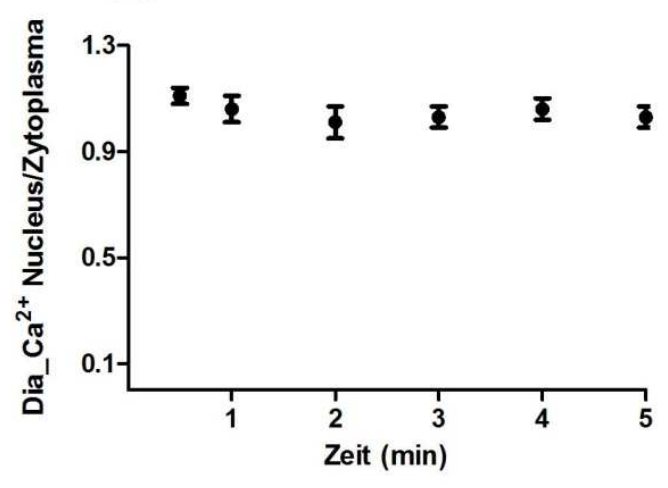

C

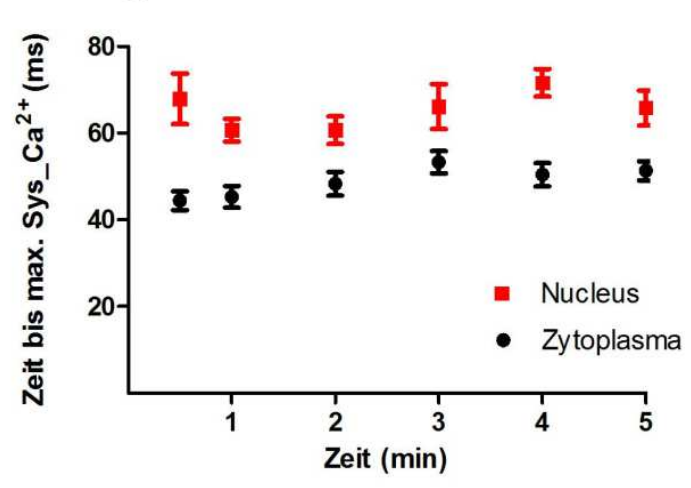

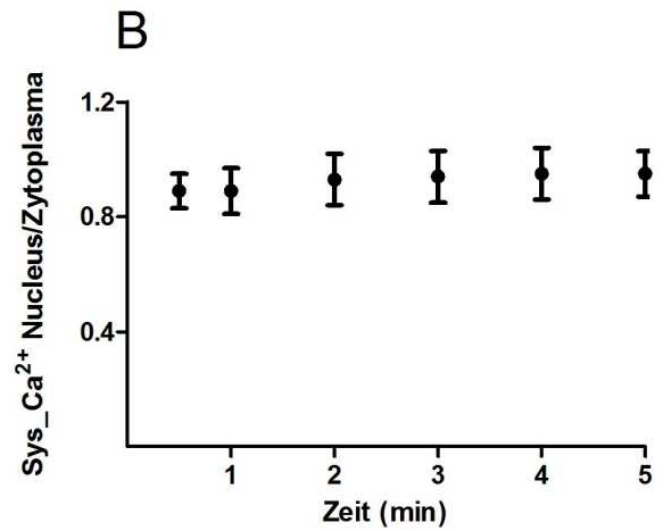

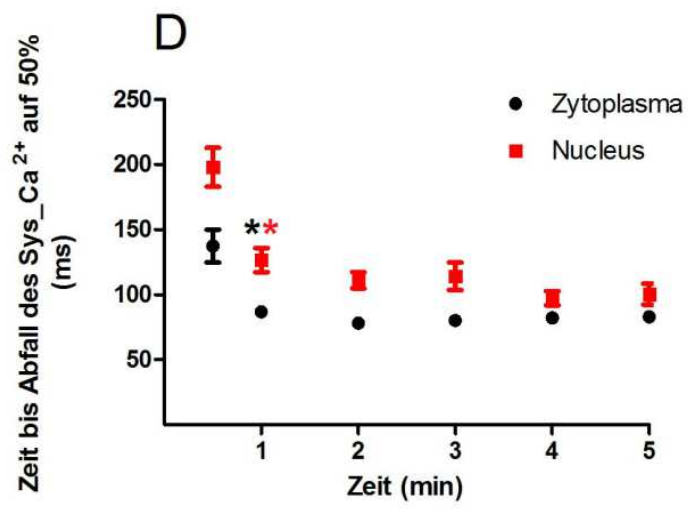

Abbildung 3.8 - $\mathrm{Ca}^{2+}$-Änderungen nach Applikation von Forskolin Teil 2: A zeigt das Verhältnis der relativen diastolischen $\mathrm{Ca}^{2+}$-Werte $\left(F / F_{\text {Ruhe }}\right)$ zwischen Zellkern und Zytoplasma, B das Verhältnis des systolischen $\mathrm{Ca}^{2+}$ zwischen Zellkern und Zytoplasma. C 
(TTP) und D (RT50) befassen sich mit der Kinetik der $\mathrm{Ca}^{2+}$-Transienten. $*=P<0,05$ Kontrolle versus 1-5 Minuten nach Forskolinapplikation.

Um zu analysieren, ob die Änderungen des systolischen $\mathrm{Ca}^{2+}$ zwischen Zellkern und Zytoplasma variieren, wurde auch hier das entsprechende Verhältnis errechnet (Abbildung 3.8B). Es zeigten sich nur geringe, statistisch nicht signifikante Änderungen. Somit konnte kein durch Forskolin verursachter Unterschied zwischen Zellkern und Zytoplasma bezüglich des Verhaltens der Änderungen des systolischen $\mathrm{Ca}^{2+}$ beobachtet werden.

\subsubsection{Zeit bis zum Erreichen des systolischen $\mathrm{Ca}^{2+}$}

Die Zeit bis zum Erreichen des systolischen maximalen $\mathrm{Ca}^{2+}$ (TTP) schien nach Applikation von Forskolin nur gering zu variieren. Die größte zu verzeichnende Änderung gab es im Zellkern zwischen der Kontrolle und der ersten Messung nach Forskolin-Applikation. So fiel die TTP von $68 \pm 6 \mathrm{~ms}$ auf $61 \pm 3 \mathrm{~ms}(\mathrm{P}>0,05)$. Dieser Unterschied war jedoch statistisch nicht signifkant, was auch für alle anderen Änderungen der TTP in Zellkern und Zytoplasma gilt. Somit konnte keine durch Forskolin bedingte Änderung der TTP beobachtet werden (Abbildung 3.8C).

\subsubsection{Abfall des $\mathrm{Ca}^{2+}$-Transienten}

Die RT50 schien durch Forskolin eine Beeinflussung erfahren zu haben (Abbildung 3.8D). So fiel sie im Zytoplasma von $137 \pm 13 \mathrm{~ms}$ vor auf $87 \pm 4 \mathrm{~ms}$ in der ersten Messung nach Forskolingabe $(\mathrm{P}<0,05)$. Im Zellkern fiel sie von $198 \pm 15 \mathrm{~ms}$ vor auf $127 \pm 9 \mathrm{~ms}$ nach der ersten Minute nach Forskolingabe $(\mathrm{P}<0,05)$. In den folgenden Minuten kam es zu keiner weiteren statistisch signifikanten Änderung der RT50 im Zellkern oder Zytoplasma. Die RT50 wurde somit unter Forskolin sowohl im Zytoplasma als auch im Zellkern reduziert. Ein Unterschied dieses Effekts zwischen Zellkern und Zytoplasma konnte nicht nachgewiesen werden.

\subsection{Zellkerne und perinukleäre $\mathrm{Ca}^{2+}$-Speicher in Kardiomyozyten des Kaninchens}

Ein weiterer Aspekt dieser Arbeit waren Aufnahmen von Zellkernen in Ventrikelmyozyten und Vorhofmyozyten des Kaninchens zur Charakterisierung der perinukleären $\mathrm{Ca}^{2+}$-Speicher. 
A
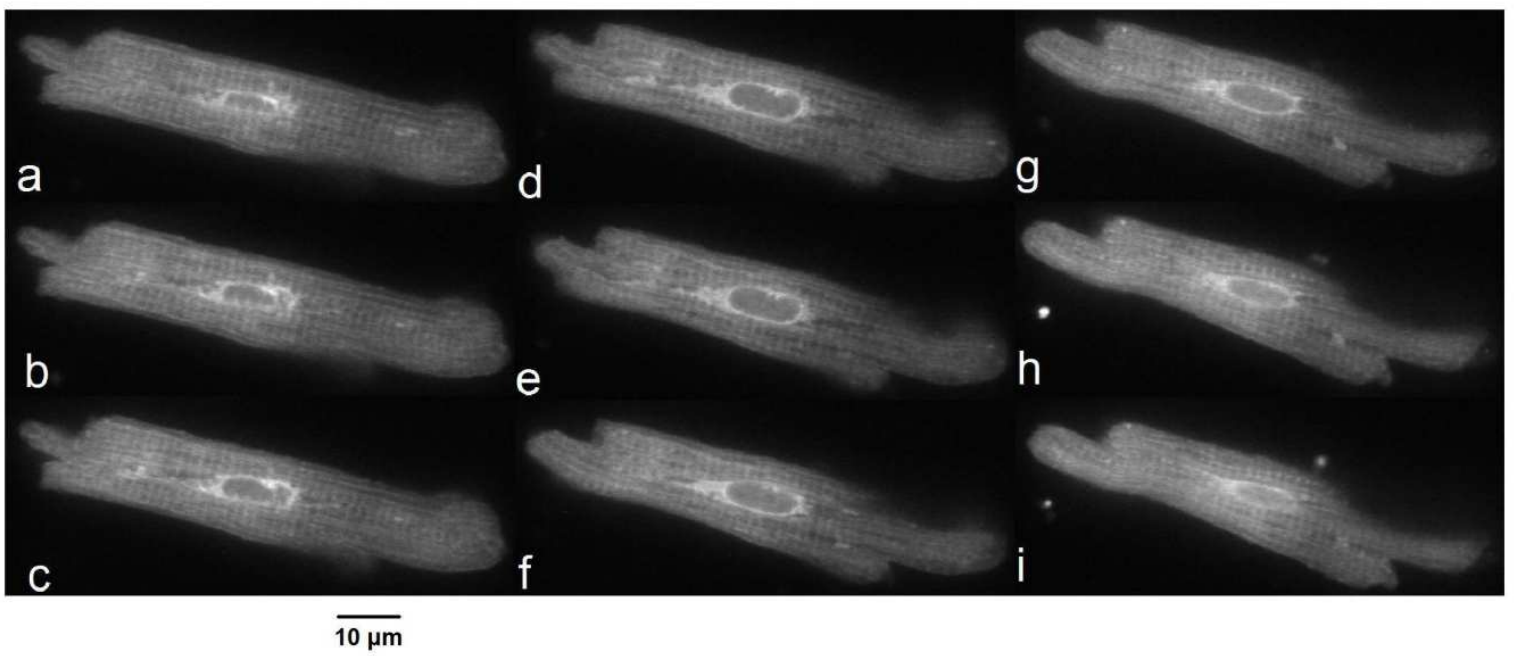

B

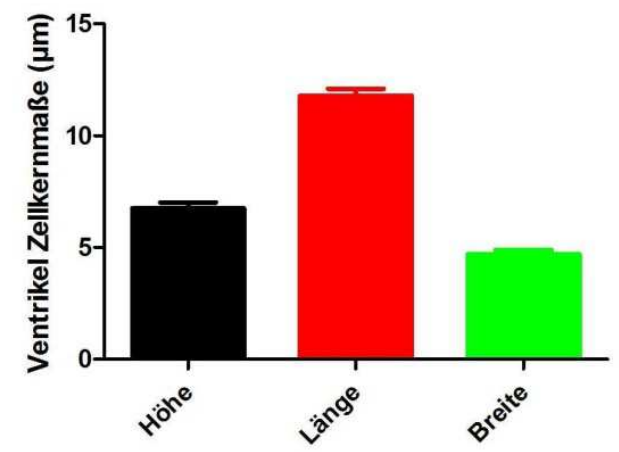

C

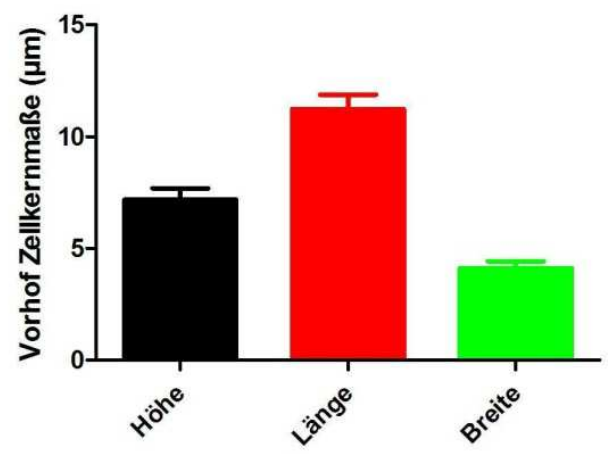

D

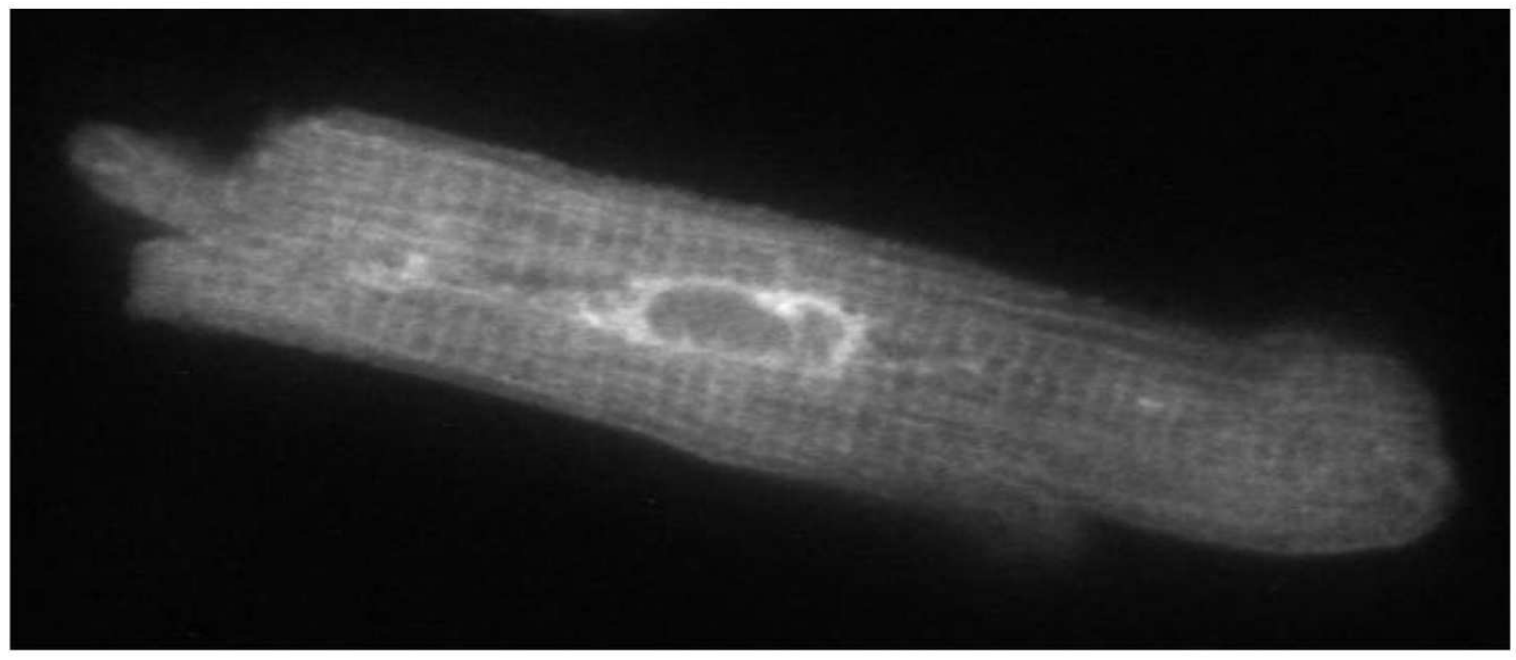

Abbildung 3.9 - Färbung der intrazellulären $\mathrm{Ca}^{2+}{ }_{-}$Speicher der Ventrikel- und Vorhofmyozyten des Kaninchens: In A ist eine Beispielmessung gezeigt. Dabei sind die 
Bilder fortlaufend nach dem Alphabet gekennzeichnet. B und C zeigen die Maße der Zellkerne der Ventrikel- $(n=35)$ und Vorhofmyozyten $(n=11)$. In D ist ein einzelnes Bild aus A vergrößert dargestellt.

In Abbildung 3.9A ist eine Beispielmessung eines Vorhofmyozyten des Kaninchens gezeigt. Die Zelle wurde nach Beladung (40 min) mit dem Farbstoff Fluo-4 in regelmäßigen Abständen photographiert. Der Abstand zwischen zwei Bildern betrug $1 \mu \mathrm{m}$.

In Abbildung 3.9D ist ein vergrößertes Bild der Zelle aus Abbildung 3.9A gezeigt. Es handelt sich dabei um eine konfokale Aufnahme der Zelle, in welcher sich im Zentrum eine ovale Struktur, der Zellkern, befindet. In der Zelle ist ein gitterförmiges Netz erkennbar. Hierbei handelt es sich um das sarkoplasmatische Retikulum. Dieses reicht von der Zellmembran bis zur Kernhülle. Von der Kernhülle ausgehend ragen einige Einstülpungen in den Zellkern. Diese nukleären Tubuli scheinen den Zellkern nicht oder nur selten komplett zu durchziehen.

\subsubsection{Ausmaße des Zellkerns in Ventrikel- und Vorhofmyozyten des Kaninchens}

In Abbildung 3.9B sind die Mittelwerte der Kernmaße der Ventrikelmyozyten dargestellt. Hierbei wurden Länge, Höhe und Breite des Zellkerns ausgemessen. Die Kerne waren

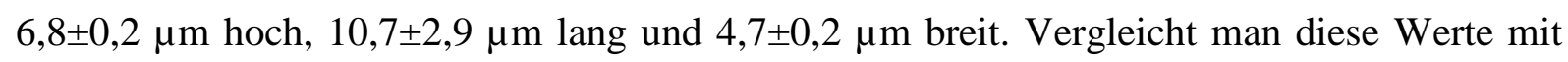
den Kernmaßen der Vorhofmyozyten $(7,2 \pm 0,5 \mu \mathrm{m}$ hoch, 11,2 $\pm 0,6 \mu \mathrm{m}$ lang und 4,1 $\pm 0,3 \mu \mathrm{m}$ breit), so gibt es keine signifikanten Unterschiede. Der einzige Unterschied zwischen Ventrikel- und Vorhofmyozyten bestand darin, dass Ventrikelmyozyten zwei, Vorhofmyozyten jedoch nur einen Kern besaßen.

\subsubsection{Kerntubuli}

Anhand der Aufnahmen des Zellkernes konnten die Einstülpungen der Kernhülle in den Zellkern ausgezählt werden. Die Anzahl dieser Tubuli in Ventrikelmyozyten und Vorhofmyozyten schien sich voneinander zu unterscheiden. So betrug die Anzahl der Tubuli in Vorhofmyozyten 3,9 $\pm 0,4$ und in Ventrikelmyozyten 7,1 $\pm 0,4(\mathrm{P}<0,05)$ (Abbildung 3.10). 


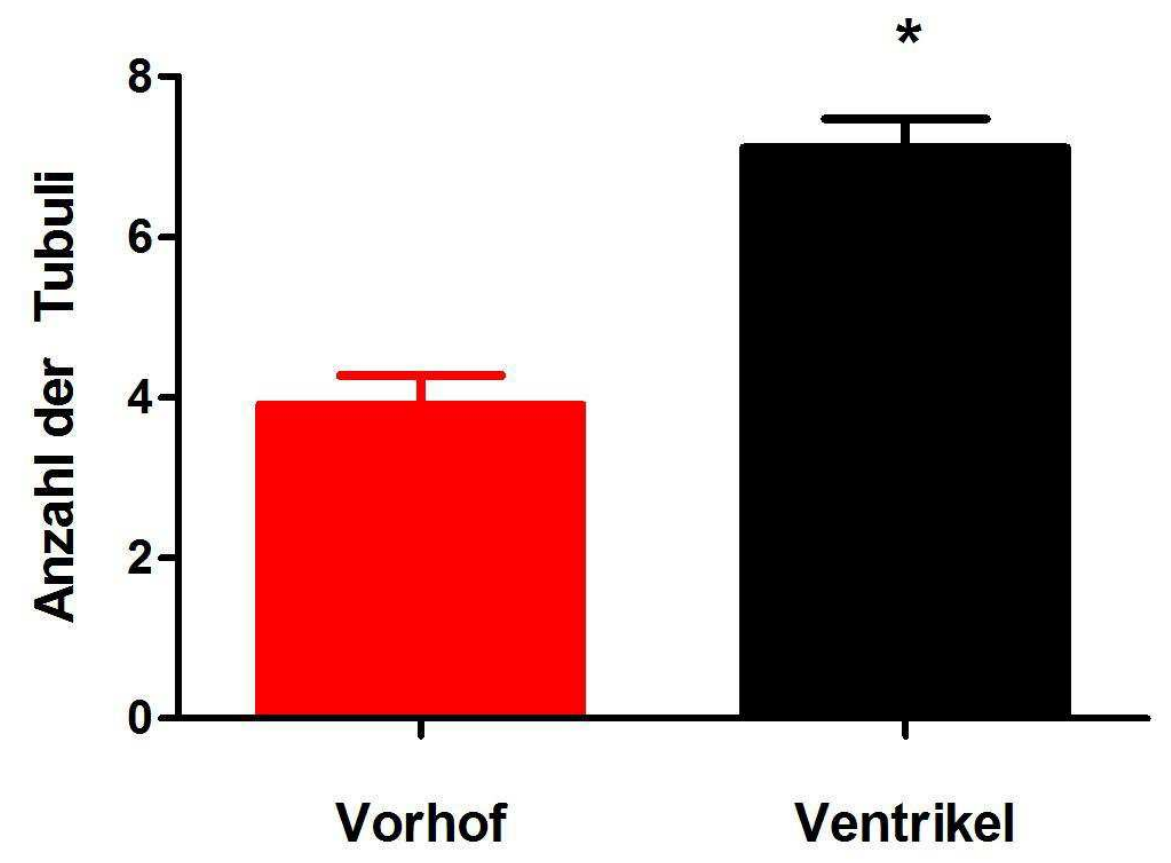

Abbildung 3.10 - Anzahl der Kerntubuli: Die Anzahl der Kerntubuli war in Ventrikelmyozyten größer als in Vorhofmyozyten. * $P<0,05$ versus Vorhof. 


\section{Diskussion}

In dieser Arbeit wurden mittels 2D-Konfokalmikroskopie und dem $\mathrm{Ca}^{2+}$-sensitiven Farbstoff Fluo-4 elektrisch stimulierte $\mathrm{Ca}^{2+}$-Transienten in Kardiomyozyten untersucht. Frequenzabhängige Änderungen sowie Änderungen nach Applikation des direkten Adenylatzyklase-Aktivators Forskolin wurden charakterisiert. Im Mittelpunkt dieser Arbeit standen vor allem der Zellkern und seine $\mathrm{Ca}^{2+}$-Regulation. Im Zellkern können durch $\mathrm{Ca}^{2+}$ wichtige Prozesse wie Apoptose, Zellzyklus und Gentranskription beeinflusst werden (Clapham 1995; Wu et al. 2006; Bers 2008). Bisher wurde angenommen, dass der $\mathrm{Ca}^{2+}-$ Einstrom in den Zellkern passiv durch die Kernporen erfolgt (Genka et al. 1999). In den letzten Jahren fanden sich jedoch zunehmend Hinweise für eine eigene, aktive Regulation des nukleären $\mathrm{Ca}^{2+}$. So konnten im Kern $\mathrm{Ca}^{2+}$-Bindungsproteine (z.B. CaM), $\mathrm{Ca}^{2+}$-abhängige Enzyme (z.B. CaMKII) und in der Kernmembran $\mathrm{Ca}^{2+}{ }_{-}$Kanäle (z.B. IP $\left.{ }_{3} \mathrm{R}\right)$ und die SERCA nachgewiesen werden (Badminton et al. 1996; Bootman et al. 2000; Echevarria et al. 2003; Gerasimenko O. und Gerasimenko J. 2004).

Die wichtigsten Ergebnisse dieser Arbeit sind zusammengefasst:

- $\quad$ Eine Steigerung der Stimulationsfrequenz führte in Kardiomyozyten der Maus und des Kaninchens zu einer Steigerung des diastolischen $\mathrm{Ca}^{2+}$, in den Mausmyozyten auch zur Steigerung des systolischen $\mathrm{Ca}^{2+}$. Dies galt für Zytoplasma und Zellkern.

- Bei steigender Frequenz veränderte sich auch die Kinetik der $\mathrm{Ca}^{2+}$-Transienten. In Vorhof- und Ventrikelmyozyten kam es zu einem schnelleren Abfall des $\mathrm{Ca}^{2+}$ Transienten, in den Ventrikelmyozyten sank zudem die TTP. Dies galt ebenfalls für Zytoplasma und Zellkern.

- Unter Forskolin kam es zu einem Anstieg des systolischen $\mathrm{Ca}^{2+}$, das diastolische $\mathrm{Ca}^{2+}$ erfuhr im Zytoplasma keine Veränderungen, im Zellkern zeigte sich ein Abfall des diastolischen $\mathrm{Ca}^{2+}$.

- Die TTP war unter Forskolin unverändert, die RT50 nahm unter Forskolin ab.

- Frequenzabhängig kam es in den Ventrikelmyozyten der Maus im Zellkern zu einem stärkeren Anstieg des diastolischen $\mathrm{Ca}^{2+}$ als im Zytoplasma, ebenso nahm die RT50 im Zellkern bis zu einer Frequenz von $2 \mathrm{~Hz}$ schneller ab, als im Zytoplasma. 


\subsection{Frequenzabhängige Änderungen des $\mathrm{Ca}^{2+}$-Spiegels}

Mit Hilfe der 2D-Konfokalmikroskopie und dem $\mathrm{Ca}^{2+}$-sensitiven Fluoreszenzfarbstoff Fluo-4 wurden zytoplasmatische und nukleäre $\mathrm{Ca}^{2+}$-Transienten in elektrisch stimulierten Myozyten gemessen. Unter Stimulation zeigte sich in den Messungen, dass es bei steigender Frequenz zu einem Anstieg des diastolischen $\mathrm{Ca}^{2+} \mathrm{kam}$. Dies traf für die Ventrikelmyozyten der Maus und des Kaninchens sowie für die Vorhofmyozyten des Kaninchens zu. So kam es in den Myozyten des Kaninchens bei einer Steigerung der Stimulationsfrequenz von 0,3 Hz auf 1,3 $\mathrm{Hz}$ ungefähr zu einer Verdoppelung des diastolischen $\mathrm{Ca}^{2+}$ in Zytoplasma und Zellkern. In den Myozyten der Maus kam es bei einer Steigerung der Stimulationsfrequenz von 0,5 Hz auf $4 \mathrm{~Hz}$ zu einer Vervierfachung der diastolischen $\mathrm{Ca}^{2+}$-Konzentration im Zytoplasma und zu einer Verachtfachung im Zellkern. Unterschiede wurden auch bezüglich des systolischen $\mathrm{Ca}^{2+}$ beobachtet. So kam es in den Zellen des Kaninchens zu keinem signifikanten, frequenzabhängigen Anstieg des systolischen $\mathrm{Ca}^{2+}$. In den Zellen der Maus konnte jedoch eine starke Steigerung des systolischen $\mathrm{Ca}^{2+}$ beobachtet werden, die im Zytoplasma und Zellkern etwa gleich groß war.

Der unterschiedlich starke Anstieg der diastolischen $\mathrm{Ca}^{2+}$-Konzentration zwischen Zellkern und Zytoplasma in den Maus-Ventrikelmyozyten lässt sich am ehesten mit der unterschiedlichen Kinetik der $\mathrm{Ca}^{2+}$-Transienten dieser beiden Kompartimente erklären. Da der Abfall des $\mathrm{Ca}^{2+}$ im Zellkern im Wesentlichen durch die passive Diffusion durch die Kernporen erfolgt, sinkt das systolische $\mathrm{Ca}^{2+}$ hier langsamer ab. In der Folge kommt es bei steigenden Frequenzen durch diese verlangsamte Kinetik zu einem stärkeren Anstieg des diastolischen $\mathrm{Ca}^{2+}$ im Zellkern als im Zytoplasma.

Die frequenzabhängige Erhöhung des systolischen $\mathrm{Ca}^{2+}$ in Maus-Ventrikelmyozyten war im Zellkern und Zytoplasma etwa gleich groß. Dies deutet darauf hin, dass das systolische $\mathrm{Ca}^{2+}$ im Kern dem systolischen $\mathrm{Ca}^{2+}$ im Zytoplasma folgt bzw. von diesem bestimmt wird. Die systolische Erhöhung im Zytoplasma führt durch Diffusion des $\mathrm{Ca}^{2+}$ durch die Kernporen zu einer nachfolgenden Erhöhung im Kern. In Kaninchen-Myozyten wurde keine frequenzabhängige Erhöhung des systolischen $\mathrm{Ca}^{2+}$ beobachtet. Dass dies hier nicht beobachtet wurde, kann unter anderem daran liegen, dass die Stimulationsfrequenz während der Messungen deutlich unterhalb der physiologischen Herzfrequenz des Kaninchens lag und systolische $\mathrm{Ca}^{2+}$ - ̈̈nderungen erst bei höheren Frequenzen zu erwarten sind. Da die Zellen in 
vitro unter Stimulation mit höheren Frequenzen zu Arrhythmien neigten, konnte dies hier nicht weiter untersucht werden.

Ein andauernder Anstieg des diastolischen $\mathrm{Ca}^{2+}$, wie hier beobachtet, ist entscheidend für die Genese der Herzinsuffizienz. So tragen erhöhte diastolische $\mathrm{Ca}^{2+}$-Spiegel zur Entwicklung der Hypertrophie des Herzens und damit zum Fortschreiten der Herzinsuffizienz bei (Zhang und Brown 2004; Backs und Olson 2006; Little et al. 2009). Unter Berücksichtigung der Ergebnisse dieser Arbeit ist besonders die Tachykardie-induzierte Kardiomoypathie, kurz Tachykardiomyopathie, von Interesse. So kommt es durch tachykarde Herzrhythmusstörungen (z.B. Vorhofflimmern) zu einer ventrikulären Dysfunktion, welche bei Normalisierung der Herzfrequenz reversibel ist (Ramesh Iyer 2008). Kommt es über längere Zeit hinweg $\mathrm{zu}$ dauerhaften oder langen Intervallen von tachykarden Herzrhythmusstörungen, so kann sich eine Tachykardiomyopathie ausbilden. Wichtig ist, dass die Entwicklung einer Tachykardiomyopathie vom Intervall und von der Dauer der tachykarden Phasen abhängt, sprich: Menschen mit anhaltender tachykarder Herzrhythmusstörung entwickeln schneller eine Tachykardiomyopathie als jene, die diese Rhythmusstörungen nur intermittierend ausbilden (Quiniou et al. 2000; Shinbane et al. 1997). Hierbei scheint eine Herzfrequenz von über 100/min die Voraussetzung zu sein (Umana et al. 2003). Dabei sind die Pathomechanismen auf zellulärer Ebene noch unvollständig verstanden. Eine Möglichkeit, den Pathomechanismus zu erklären, wäre die in dieser Arbeit beobachtete frequenzabhängige Steigerung des diastolischen $\mathrm{Ca}^{2+}$. Wie bereits erwähnt, kommt es $\mathrm{Ca}^{2+}$ abhängig zu einer Aktivierung von Signalkaskaden, die zur vermehrten Expression von Herzinsuffizienz fördernden Proteinen führen. Deshalb kann eine langanhaltende Frequenzsteigerung zu erhöhten $\mathrm{Ca}^{2+}$-Spiegeln, besonders auch im Zellkern, führen, was die Ausbildung einer Tachykardiomyopathie bedingen kann.

Eine frequenzabhängige Erhöhung der $\mathrm{Ca}^{2+}$-Spiegel führt zu einer verstärkten Aktivierung der $\mathrm{Ca}^{2+}$-Bindungsproteine. Eine wichtige Rolle scheinen die bereits beschriebenen Signalkaskaden über CaM-CaMKII-HDAC und CaM-Calcineurin-NFAT zu spielen. So zeigten Bossuyt et al. (2008), dass eine verstärkte Aktivierung der CaMKII und der Proteinkinase D (PKD) ursächlich oder verstärkend auf die Ausbildung einer Herzinsuffizienz wirken kann, eine Blockierung dieser Enzyme verhindert die Ausbildung.

Bezüglich der Regulierung des NFAT scheint es Unterschiede zwischen Ventrikel- und Vorhofymyozyten zu geben. NFAT wird in vier Isoenzyme unterteilt, welche im Herzen gebildet werden (Rinne et al. 2010). Diese Isoenzyme befinden sich in unterschiedlichen Kompartimenten der Zelle und scheinen unterschiedlich reguliert zu werden. So befindet sich 
NFATc1 überwiegend im Zellkern, bei Hemmung von Calcineurin und Senkung der $\mathrm{Ca}^{2+}$ Spiegel kommt es zu einem verstärkten Export aus dem Zellkern (Rinne et al. 2010), was ebenfalls eine Abhängigkeit von frequenzbedingten $\mathrm{Ca}^{2+}$ - $̈$ nderungen bedeutet. Im Gegensatz dazu befindet sich NFATc3 überwiegend im Zytoplasma, kann jedoch durch eine Angiotensin II- und Endothelin-1-Stimulierung in den Zellkern überführt werden, wobei dies nur in Vorhofmyzoyten zu beobachten war, nicht jedoch in Ventrikelmyozyten (Rinne et al. 2010).

Dies lässt vermuten, dass die Regulation der NFAT-Isoformen sich zwischen Ventrikel- und Vorhofmyozyten unterscheidet, wobei die wichtigsten regulierenden Mechanismen das intrazelluläre Calcineurin-aktivierende $\mathrm{Ca}^{2+}$, aber auch die im Zellkern lokalisierten Kinasen und der Kernexport sind.

Hieraus wird klar, dass die beobachtete frequenzabhängige Erhöhung des diastolischen $\mathrm{Ca}^{2+}$ essentiell in die Transkription und die Funktion der Zelle eingreifen und somit pathophysiologische Mechanismen triggern kann.

\subsection{Frequenzabhängige Änderung der Kinetik des $\mathrm{Ca}^{2+}$-Transienten}

Bei steigender Frequenz kam es zu einer Änderung der Kinetik des $\mathrm{Ca}^{2+}$-Transienten. In den Ventrikelmyozyten des Kaninchens kam es sowohl im Zellkern wie auch im Zytoplasma zu einer Reduktion der TTP um ca. 25\% bei einem Anstieg der Frequenz von 0,3 Hz auf 1,3 Hz. In der Maus waren es bei einem Frequenzanstieg von 0,5 Hz auf $4 \mathrm{~Hz}$ im Zytoplasma ca. 5\%, im Zellkern jedoch fast 45\%. Hier konnte in der Maus ein signifikanter Unterschied zwischen Zellkern und Zytoplasma beobachtet werden.

Betrachtet man den Abfall des $\mathrm{Ca}^{2+}$-Transienten, so kam es zu einer Reduktion der Zeitkonstanten $\tau$ im Kaninchenventrikel von ca. 50\% im Zytoplasma und von ca. 40\% im Zellkern, im Kaninchenvorhof waren es ca. $40 \%$ im Zytoplasma und ca. 40\% im Zellkern. Für den Mausventrikel verringerte sich die RT50 im Zellkern um ca. 70\%, im Zytoplasma um 65\%. Somit kam es in allen untersuchten Zelltypen sowohl im Zellkern als auch im Zytoplasma zu einem schnelleren Abfall des $\mathrm{Ca}^{2+}$-Transienten.

Prinzipiell ist der $\mathrm{Ca}^{2+}$-Transient des Zellkerns langsamer als der des Zytoplasmas. Eine Ursache hierfür könnte in der Funktion der Kernporen liegen. Diese sind Proteinkomplexe in deren Mitte ein zylinderförmiger Kanal liegt (Stoffler et al. 2006). Dieser Kanal ist durchlässig für Moleküle von einer Größe von bis zu $9 \mathrm{~nm}$. Er erlaubt Ionen, Metaboliten, Nukleinsäuren und Proteinen den passiven Transport durch Diffusion (Lee MA et al. 1998). Proteine mit einer Größe von mehr als $\sim 50 \mathrm{kDa}$ müssen energieabhängig durch den Kanal 
hindurch transportiert werden, wie z.B. NFAT (Hallhuber et al. 2006). Der Kanal selber kann durch Bindung spezifischer Proteine an dafür vorgesehenen Bindungsstellen seine Struktur ändern und sich verschließen, wobei nachgewiesen wurde, dass trotz des Verschlusses weiterhin kleine Moleküle diffundieren können (Kramer et al. 2007). Dies deutet auf kleinere Ionenkanäle in der Peripherie des Kernporenkomplexes hin (Shahin et al. 2001). Danker et al. (2001) zeigten, dass die Kernporen unter physiologischen Bedingungen dauerhaft aktiv sind, eine Modulation durch Erhöhung von ATP oder Verminderung des zytoplasmatischen $\mathrm{Ca}^{2+}$ zeigte eine verminderte Durchlässigkeit der Kernpore (Shahin et al. 2001), jedoch gibt es auch Beobachtungen einer Beeinflussung der Kernporen durch nukleäres $\mathrm{Ca}^{2+}$. So konnten Wei et al. (2003) nachweisen, dass es nach Reduktion von nukleären $\mathrm{Ca}^{2+} \mathrm{zu}$ keiner Änderung des Diffusionsverhaltens spezifischer Proteine über die Kernporen kam. Andere Beobachtungen zeigten eine Veränderung der Permeabilität nach Änderung des zytoplasmatischen $\mathrm{Ca}^{2+}$, nicht jedoch nach Änderungen des nukleären $\mathrm{Ca}^{2+}$ (O’Brien et al. 2007). Trotz dieser unterschiedlichen Beobachtungen können die Studien einen Hinweis auf eine $\mathrm{Ca}^{2+}$-abhängige Modulation der Durchlässigkeit der Kernporen bestätigen (Bootman et al. 2009).

Als Sensor für das intranukläre $\mathrm{Ca}^{2+}$ wird das Membranprotein gp210 betrachtet, welches in das Lumen des Zellkerns ragt und dort die $\mathrm{Ca}^{2+}$-Konzentration misst. Dabei kommuniziert es mit den Kernporen (Greber et al. 1990). Derzeit ist noch ungeklärt, ob und wie $\mathrm{Ca}^{2+}$ die Kernporen beeinflusst, ob das intranukleäre oder das zytoplasmatische $\mathrm{Ca}^{2+}$ (oder beide) einen Einfluss haben. Jedoch liegt die Vermutung nahe, dass durch $\mathrm{Ca}^{2+}$ eine entscheidende Regulierung der Durchlässigkeit der Kernporen erfolgt (Bootman et al. 2009).

Da der nukleäre $\mathrm{Ca}^{2+}$-Transient durch Diffusion von $\mathrm{Ca}^{2+}$ aus dem Zytoplasma durch die Kernporen zu Stande kommt, zeigt er gegenüber dem zytoplasmatischem $\mathrm{Ca}^{2+}$-Transienten eine verzögerte Kinetik.

Eine weitere Erklärung für den verzögerten Abfall des $\mathrm{Ca}^{2+}$-Transienten liegt in einem Fehlen der $\mathrm{Ca}^{2+}$-ATPasen auf der Innenseite der Kernhülle (Humbert et al. 1996), weshalb schnelle $\mathrm{Ca}^{2+}$-Abfälle, im Gegensatz zum Zytoplasma, nur verzögert im Zellkern auftreten. Jedoch gibt es, bis auf die TTP in den Mausmyozyten, keine Unterschiede zwischen den beiden Kompartimenten in der frequenzbedingten Änderung der Kinetik der $\mathrm{Ca}^{2+}$-Transienten. Der $\mathrm{Ca}^{2+}$-Abtransport im Zytoplasma erfolgt im Wesentlichen durch die SERCA, welche das $\mathrm{Ca}^{2+}$ in die intrazellulären Speicher, das sarkoplasmatische Retikulum, transportiert. Bisher ist unklar, wie dies im Zellkern geschieht, jedoch wurde auch hier die SERCA nachgewiesen, allerdings nur auf der äußeren Kernhülle. Vermutlich muss also das $\mathrm{Ca}^{2+}$ zunächst durch die 
Kernporen aus dem Zellkern heraus diffundieren und wird erst dann von der SERCA in die Kernhülle transportiert.

\section{3 Änderungen des $\mathrm{Ca}^{2+}$-Transienten nach Forskolingabe}

Forskolin führt über die Aktivierung der Adenylatcyclase zur Bildung von cAMP, welches seinerseits die PKA aktiviert. Die PKA besteht aus zwei katalytischen Untereinheiten (CUntereinheiten) und zwei regulatorischen Untereinheiten (R-Untereinheiten). Bei Anstieg der cAMP-Konzentration bindet dieses an den R-Untereinheiten, wodurch diese abdissoziieren und die C-Untereinheiten aktiv werden (Cox und Taylor 1994). Die PKA erfüllt in der Zelle eine Vielzahl von Funktionen, unter anderem phosphoryliert sie CREB, reguliert den Fettstoffwechsel und hat Einfluss aus Zellwachstum und Zelldifferenzierung. Zwei weitere für diese Arbeit wichtige Funktionen sind:

- Die Regulation der DHPRs (Kamp und Hell 2000).

- Die Phosphorylierung von Phospholamban, was zu einer Stimulierung der SERCA führt (Masterson et al. 2011).

Hierdurch wird klar, dass die PKA in Kardiomyozyten eine wichtige Rolle in der Regulation und Funktion des $\mathrm{Ca}^{2+}$ übernimmt. Physiologisch kommt es in der Herzmuskelzelle durch $\beta$ adrenerge Stimulation zur Erhöhung der cAMP-Spiegel, wodurch Forskolin in dieser Messreihe eine $\beta$-adrenerge Stimulation unter Versuchsbedingungen simulierte.

Forskolin wurde unter andauernder elektrischer Stimulation mit einer Frequenz von $1 \mathrm{~Hz}$ kontinuierlich appliziert. Als Ergebnis zeigte sich eine Zunahme des systolischen $\mathrm{Ca}^{2+}$ bei gleichbleibendem diastolischen $\mathrm{Ca}^{2+}$.

Die Kinetik des $\mathrm{Ca}^{2+}$-Transienten erfuhr unter Forskolin ebenfalls eine Änderung. Während die TTP keine signifikanten Änderungen erfuhr, kam es unter Forskolin zu einem Abfall der RT50 sowohl im Zellkern als auch im Zytoplasma. Ein statistisch signifikanter Unterschied zwischen der RT50 des Zellkerns und des Zytoplasmas ließ sich nicht feststellen.

Unter Forskolin kam es zu einer signifikanten Erhöhung der systolischen $\mathrm{Ca}^{2+}$-Konzentration und Verringerung der RT50 sowohl im Zytoplasma als auch im Zellkern. Dieser Effekt zeigt eine $\beta$-adrenerg gesteuerte, PKA-vermittelte Regulation der $\mathrm{Ca}^{2+}$-Homöstase in den Kardiomyozyten. Im Zytoplasma kann der Anstieg des systolischen $\mathrm{Ca}^{2+}$ durch eine verstärkte Aktivierung der DHPRs und einer daraus resultierenden verstärkten $\mathrm{Ca}^{2+}$ induzierten $\mathrm{Ca}^{2+}$-Freisetzung aus dem SR erklärt werden. Der Abfall der RT50 im Zytoplasma 
lässt sich durch die verstärkte Aktivität der SERCA aufgrund der Phosphorylierung von Phospholamban erklären.

Bezüglich des Zellkerns rückt vor allem die Diskussion von zwei möglichen Mechanismen der cAMP-vermittelten Änderung des $\mathrm{Ca}^{2+}$-Transienten in den Mittelpunkt. So kann auf der einen Seite eine passive Regulation des nukleären $\mathrm{Ca}^{2+}$ durch das zytoplasmatische $\mathrm{Ca}^{2+}$ erfolgen. Durch den Anstieg des $\mathrm{Ca}^{2+}$ im Zytoplasma in der Systole kommt es zu einer passiv vom $\mathrm{Ca}^{2+}$-Konzentrationsunterschied gesteuerten Diffusion des $\mathrm{Ca}^{2+}$ in den Zellkern, was die verzögerte Erhöhung des systolischen $\mathrm{Ca}^{2+}$ im Zellkern erklärt. Umgekehrt kann dies auch den verzögerten Abfall des $\mathrm{Ca}^{2+}$-Transienten im Zellkern erklären. Unter diesen Bedingungen diffundiert $\mathrm{Ca}^{2+}$, seinem Konzentrationsgradienten folgend, aus dem Zellkern heraus. Auf der anderen Seite kann eine durch $\beta$-adrenerge Stimulation veränderte aktive $\mathrm{Ca}^{2+}$-Regulation des Zellkerns oder eine Änderung der Permeabilität der Kernporen nicht ausgeschlossen werden, auch wenn diese Arbeit keine Hinweise auf einen solchen Mechanismus geliefert hat.

\subsection{Unterschiedliche Regulation des $\mathrm{Ca}^{2+}$ im Kern und im Zytoplasma}

Bei der frequenzabhängigen Messung des $\mathrm{Ca}^{2+}$-Transienten konnten in den Myozyten des Kaninchens keine Unterschiede zwischen Zellkern und Zytoplasma gefunden werden. Anders verhielt es sich bei der Maus. Hier zeigte sich frequenzabhängig ein stärkerer Anstieg des diastolischen $\mathrm{Ca}^{2+}$ im Zellkern als im Zytoplasma, weiterhin fiel die RT50 im Zellkern bis zu einer Frequenz von $2 \mathrm{~Hz}$ statistisch signifikant stärker ab als im Zytoplasma.

Eine mögliche Ursache für diesen Unterschied können die niedrigen Frequenzen $(0,3$ bis 1,3 $\mathrm{Hz}$ ) sein, mit welchen die Myozyten des Kaninchens stimuliert wurden. Da die Myozyten des Kaninchens unter den in den Messungen gegebenen Umständen bei höheren Frequenzen schnell zu Alternans und Arrhythmien neigten, konnten aber nur relativ niedrige Frequenzen untersucht werden. Unter physiologischen Bedingungen erreicht das Kaninchen (ebenso wie die Maus) deutlich höhere Frequenzen, weshalb auch dort bei höheren Frequenzen ein statistisch signifikanter unterschiedlich starker Anstieg des diastolischen $\mathrm{Ca}^{2+}$, sowie eine veränderte Kinetik vermutet werden kann.

Unter Forskolin kam es zu keinem unterschiedlichen Verhalten der $\mathrm{Ca}^{2+}$-Änderungen im Zellkern und Zytoplasma, das systolische $\mathrm{Ca}^{2+}$ stieg im Zytoplasma und im Zellkern etwa gleich stark an. Auch in der Postpausenmessung zeigte sich kein unterschiedliches Verhalten der $\mathrm{Ca}^{2+}$-Konzentrationen des Zellkerns und des Zytoplasmas, alle $\mathrm{Ca}^{2+}$-Änderungen waren in beiden Kompartimenten stets fast gleich stark ausgeprägt. 
Eine Erklärung für die übermäßig starke Steigerung des diastolischen $\mathrm{Ca}^{2+}$ im Zellkern kann in der Kinetik des $\mathrm{Ca}^{2+}$-Transienten angenommen werden. Das $\mathrm{Kern}-\mathrm{Ca}^{2+}$ erreicht im Gegensatz zum $\mathrm{Ca}^{2+}$ des Zytoplasmas verzögert seinen systolischen Wert und es fällt auch verzögert wieder auf den diastolischen Wert ab. Dies liegt daran, dass das $\mathrm{Ca}^{2+}$ im Zytoplasma erst passiv durch die Kernporen in den Zellkern diffundieren muss, während es im Zytoplasma aus dem sarkoplasmatischen Retikulum direkt freigesetzt wird. Während ein Abtransport des $\mathrm{Ca}^{2+}$ aus Zytoplasma in der Diastole aktiv durch den NCX und die SERCA erfolgt, muss das $\mathrm{Ca}^{2+}$ des Zellkerns erst wieder durch die Kernporen aus dem Zellkern heraus diffundieren, um anschließend über die SERCA in die Kernhülle transportiert zu werden. Durch eine Abnahme der Diastolendauer bei steigender Frequenz hat die Zelle nun weniger Zeit, das $\mathrm{Ca}^{2+}$ in seine Speicher oder nach extrazellulär zu befördern, weshalb sich der diastolische $\mathrm{Ca}^{2+}$-Spiegel frequenzabhängig erhöht. Im Zellkern ist dieser Effekt ausgeprägter, da das $\mathrm{Ca}^{2+}$ zunächst noch durch die Kernporen zurück ins Zytoplasma diffundieren muss.

Die passive Diffusion des $\mathrm{Ca}^{2+}$ durch die Kernporen scheint der entscheidende Mechanismus für die $\mathrm{Ca}^{2+}$-Regulation der Kerne der Kardiomyozyten $\mathrm{zu}$ sein. Durch das konstante Verhältnis zwischen dem systolischen $\mathrm{Ca}^{2+}$ des Zellkerns und des Zytoplasmas bei unterschiedlichen Frequenzen, nach Forskolinapplikation und im Postpausenprotokoll kann eine wesentliche Abhängigkeit des nukleären $\mathrm{Ca}^{2+}$ vom zytoplasmatischen $\mathrm{Ca}^{2+}$ beschrieben werden. Dies bedeutet, dass das nukleäre $\mathrm{Ca}^{2+}$ in sehr weiten Bereichen von $\mathrm{Ca}^{2+}$ Konzentrationen durch passive Diffusion durch die Kernporen vom zytoplasmatischen $\mathrm{Ca}^{2+}$ bestimmt wird.

\subsection{Die Kernhülle und die nukleären Tubuli}

In dieser Arbeit wurden von der Kernhülle ausgehende Einstülpungen in den Zellkern beobachtet. Diese werden als nukleäre Tubuli bezeichnet. Auf der dem Nukleoplasma zugewandten Seite der Tubuli befinden sich $\mathrm{Ca}^{2+}$-freisetzende Kanäle (Echevarria et al. 2003; Lui et al. 2003; Lee RK et al. 2006; Schermelleh et al. 2008). Die nukleären Tubuli wurden zwar in einer Vielzahl von Zellen beobachtet, jedoch scheinen sie nicht in allen Zelltypen vorzukommen und auch nicht in allen Zelltypen gleich ausgeprägt zu sein (Bezin et al. 2008). Aus bisher unbekannten Gründen können diese Ausprägungen von kleinen Ausstülpungen bis hin zu komplexen Netzwerken reichen, wobei die Tubuli häufig in der Nähe von Nucleoli lokalisiert sind (Fricker et al. 1997). 
Die Kerntubuli sind Invaginationen der Doppelmembran der Kernhülle (Lui et al. 2003), wobei die Kernhülle selber durch die Verbindung mit dem sarkoplasmatischen Retikulum ebenfalls ein Speicher für $\mathrm{Ca}^{2+}$ ist (Wu et al. 2006).

Auch wenn bisher unter physiologischen Bedingungen noch keine aktive Freisetzung von $\mathrm{Ca}^{2+}$ aus den Kerntubuli in das Nukleoplasma nachgewiesen werden konnte, so konnte unter experimentellen Bedingungen eine Endothelin-1-vermittelte $\mathrm{Ca}^{2+}$-Freisetzung aus den perinukleären $\mathrm{Ca}^{2+}$-Speichern nachgewiesen werden (Kockskämper et al. 2008).

Die hier gemachten Aufnahmen bestätigen die Beobachtungen eines ausgeprägten Netzwerkes von Tubuli im Zellkern der Vorhof- und Ventrikelmyozyten, welches zum Teil den Kern durchzieht. Welche Funktion diese Tubuli haben und ob eine aktive $\mathrm{Ca}^{2+}$ Freisetzung, bei bewiesenem Vorhandensein von dafür notwendigen Strukturen, möglich ist, ist derzeit noch Gegenstand intensiver Forschung. Denkbar ist aber, dass die Tubuli einen wichtigen Beitrag zur lokalen Regulation von $\mathrm{Ca}^{2+}$ im Zellkern von Kardiomyozyten leisten. So konnten an der Außenhülle der Kernhülle $\mathrm{IP}_{3} \mathrm{Rs}$ nachgewiesen werden, welche in enger räumlicher Beziehung zu den T-Tubuli standen, einer Quelle von $\mathrm{IP}_{3}$ und $\mathrm{Ca}^{2+}$ (Escobar et al. 2011). 


\section{Zusammenfassung}

$\mathrm{Ca}^{2+}$ ist für Herzmuskelzellen von essenzieller Bedeutung. Nicht nur für die Kontraktion der Herzmuskelzelle ist es entscheidend, es reguliert auch u.a. die Transkription im Zellkern und ist damit an der Entstehung der Hypertrophie des Herzens beteiligt. Die Regulation des $\mathrm{Ca}^{2+}$ im Zellkern von Kardiomyozyten ist bisher jedoch nur unvollständig verstanden.

In dieser Arbeit ging es um die Charakterisierung der Regulation des nukleären $\mathrm{Ca}^{2+}$ in Kardiomyozyten. Mit dem $\mathrm{Ca}^{2+}$-sensitiven fluoreszierenden Farbstoff Fluo-4 und der 2DKonfokalmikroskopie wurden Messungen elektrisch stimulierter $\mathrm{Ca}^{2+}$-Transienten im Zytoplasma und Zellkern von Kardiomyozyten (Kaninchen, Maus) durchgeführt. Es wurden Änderungen der $\mathrm{Ca}^{2+}$-Transienten nach Änderungen der Stimulationsfrequenz, nach pharmakologischer Beeinflussung mit Forskolin und nach einer definierten Pause der Stimulation registriert. Weiterhin konnte nach längerer Beladung der Zellen mit dem Farbstoff Fluo-4 eine Anfärbung der Kernhülle und der nukleären Tubuli zur Charakterisierung der perinukleären $\mathrm{Ca}^{2+}$-Speicher erreicht werden.

Wichtig für die Untersuchungen waren vor allem die unterschiedlichen Eigenschaften des $\mathrm{Ca}^{2+}$-Transienten im Zellkern und im Zytoplasma. Der Transient des Zellkerns stieg in der Systole langsamer an und erreichte folglich später als der Transient des Zytoplasmas seinen systolischen Wert, der jedoch stets geringer war als der des Zytoplasmas. Weiterhin war der Abfall des $\mathrm{Ca}^{2+}$-Transienten im Zellkern langsamer als im Zytoplasma.

In den Messungen zur Frequenzabhängigkeit des $\mathrm{Ca}^{2+}$-Transienten $(0,3-1,3 \mathrm{~Hz}$ in KaninchenVorhof- und Ventrikelmyozyten; 0,5 bis $4 \mathrm{~Hz}$ in Maus-Ventrikelmyozyten) zeigte sich in allen Zellen ein frequenzabhängiger Anstieg des diastolischen $\mathrm{Ca}^{2+}$ im Zellkern und im Zytoplasma. Das systolische $\mathrm{Ca}^{2+}$ stieg im Zellkern und im Zytoplasma frequenzabhängig nur in den Mausmyozyten an. In allen Zellen wurde bei steigender Frequenz in beiden Kompartimenten ein schnellerer Abfall des $\mathrm{Ca}^{2+}$-Transienten beobachtet, die Zeit bis zum Erreichen des systolischen $\mathrm{Ca}^{2+}$ (TTP) war in den Ventrikelmyozyten in beiden Kompartimenten verkürzt. Unterschiede zwischen Zellkern und Zytoplasma zeigten sich im diastolischen $\mathrm{Ca}^{2+}$ und in der Kinetik des $\mathrm{Ca}^{2+}$-Transienten der Ventrikelmyozyten der Maus. Das diastolische $\mathrm{Ca}^{2+}$ stieg im Zellkern frequenzabhängig stärker an als im Zytoplasma. Die TTP sank im Zellkern zu Beginn stärker ab als im Zytoplasma, im Zellkern fiel die RT50 zu Beginn stärker als im Zytoplasma. 
In der Postpausenmessung zeigte sich im ersten Transienten nach der Pause ein signifikanter Anstieg des diastolischen $\mathrm{Ca}^{2+}$ im Vergleich zur Kontrollmessung bei kontinuierlicher Stimulation. Im Verlauf sank das diastolische $\mathrm{Ca}^{2+}$ bei laufender Stimulation dann wieder, bis auf seinen für die gewählte Frequenz ermittelten Normalwert. Das systolische $\mathrm{Ca}^{2+}$ stieg in den Ventrikelmyozyten der Maus im ersten Transienten nach der Pause an und fiel im nächsten Transienten stark ab, um dann im Verlauf wieder bis zum frequenzabhängigen Normalwert anzusteigen. In den Vorhofmyozyten des Kaninchens konnte der Anstieg nicht beobachtet werden, jedoch waren der Initiale Abfall im zweiten Transienten nach der Pause und der folgende Anstieg des systolischen Transienten hier ebenfalls zu beobachten. Alle beschriebenen Änderungen ließen sich im Zellkern und im Zytoplasma gleichermaßen ohne signifikanten Unterschied zwischen den Kompartimenten beobachten.

Nach Applikation von Forkolin zeigte sich ein Anstieg des systolischen $\mathrm{Ca}^{2+}$ im Zellkern und im Zytoplasma, das diastolische $\mathrm{Ca}^{2+}$ blieb unverändert. Die RT50 fiel nach Forskolingabe in beiden Kompartimenten signifikant ab, während die TTP etwa gleich blieb. Die Forskolinwirkungen waren im Zellkern und Zytoplasma gleich groß.

Nach Anfärbung der intrazellulären $\mathrm{Ca}^{2+}$-Speicher, darunter die Kernhülle, zeigte sich, dass die Kerne der Vorhof- und Ventrikelmyozyten gleich groß waren und dass die Kernhüllen als $\mathrm{Ca}^{2+}$-Speicher fungierten. In beiden Zelltypen wurden Tubuli beobachtet, die in den Kern hineinragten oder diesen ganz durchquerten. Unterschiede zwischen Ventrikel- und Vorhofmyozyten zeigten sich in der Anzahl der Tubuli. So wurden in den Ventrikelymozyten deutlich mehr Tubuli pro Zellkern gefunden.

Unter Berücksichtigung aller Ergebnisse lassen sich wichtige Kernaussagen zusammenfassen: Die Regulation des nukleären $\mathrm{Ca}^{2+}$ scheint im Wesentlichen vom zytoplasmatischen $\mathrm{Ca}^{2+}$ abzuhängen, das passiv durch Diffusion über die Kernporen in den Zellkern gelangt. Dies gilt für einen weiten Bereich systolischer $\mathrm{Ca}^{2+}$-Konzentrationen, wie sie nach Änderungen der Stimulationsfrequenz erreicht wurden. Auch nach Stimulation des cAMP-PKA-Signalweges durch Forskolin scheint die $\mathrm{Ca}^{2+}$-Konzentration des Zellkerns hauptsächlich passiv durch Diffusion über die Kernporen reguliert zu werden. Hinweise auf eine zusätzliche aktive Freisetzung des $\mathrm{Ca}^{2+}$ im Zellkern konnten nicht gefunden werden. Die Kernhülle fungiert als $\mathrm{Ca}^{2+}$-Speicher und besitzt Tubuli, die in den Kern hineinragen. Die Tubuli könnten an der lokalen $\mathrm{Ca}^{2+}$-Regulation des Zellkerns beteiligt sein. 


\section{Literaturverzeichnis}

Alcazar-Roman AR, Wente SR (2008): Inositol polyphosphates: a new frontier for regulating gene expression. Chromosoma 117, 1-13.

Backs J, Olson EN (2006): Control of cardiac growth by histone acetylation/deacetylation. Circ Res $\underline{98}, 15-24$

Badminton MN, Campbell AK, Rembold CM (1996): Differential regulation of nuclear and cytosolic Ca2+ in HeLa cells. J Biol Chem 271, 31210-31214.

Bassani JW, Bassani RA, Bers DM (1994): Relaxation in rabbit and rat cardiac cells: speciesdependent differences in cellular mechanisms. J Physiol 476, 279 -293.

Bassani JW, Yuan W, Bers DM (1995): Fractional SR Ca release is regulated by trigger Ca and SR Ca content in cardiac myocytes. Am J Physiol 268, C1313-C1319.

Berridge MJ, Bootman MD, Roderick HL (2003): Calcium signalling: dynamics, homeostasis and remodelling. Nat Rev Mol Cell Biol 4(7), 517-529.

Bers DM: Excitation-Contraction Coupling and Cardiac Contractile Force. $2^{\text {nd }}$ ed; Kluwer Academic Publishers, Dordrecht 2001.

Bers DM (2002): Cardiac excitation-contraction coupling. Nature 415, 198-205.

Bers DM (2004): Macromolecular complexes regulating ryanodine receptor function. J Mol Cell Cardiol 37, 417-429.

Bers DM (2008): Calcium cycling and signaling in cardiac myocytes. Annu Rev Physiol $\underline{70}$, 23-49. 
Bezin S, Fossier P, Cancela JM (2008): Nucleoplasmic reticulum is not essential in nuclear calcium signalling mediated by cyclic ADPribose in primary neurons. Pflugers Arch $\underline{456}$, $581-586$

Bkaily G, Nader M, Avedanian L, Choufani S, Jacques D, D’Orleans-Juste P, Gobeil F, Chemtob S, Al-Khoury J (2006): G-protein-coupled receptors, channels, and Na+-H+ exchanger in nuclear membranes of heart, hepatic, vascular endothelial, and smooth muscle cells. Can J Physiol Pharmacol $\underline{84}, 431-441$.

Bootman MD, Thomas D, Tovey SC, Berridge MJ, Lipp P (2000): Nuclear calcium signalling. Cell Mol Life Sci $\underline{57}, 371-378$.

Bootman, MD, Collins, TJ, Peppiatt CM, Prothero LS, MacKenzie L, De Smet P, Travers M, Tovey SC, Seo JT, Berridge MJ et al. (2001): Calcium signalling-an overview. Semin Cell Dev Biol 12(1), 3-10.

Bootman MD, Fearnley C, Smyrnias I, MacDonald F, Roderick HL (2009): An update on nuclear calcium signalling. J Cell Sci 122(Pt 14):2337-50.

Bossuyt J, Helmstadter K, Wu X, Clements-Jewery H, Haworth RS, Avkiran M, Martin JL, Pogwizd SM, Bers DM (2008): Ca2+/calmodulin-dependent protein kinase IIdelta and protein kinase D overexpression reinforce the histone deacetylase 5 redistribution in heart failure. Circ Res 102(6), 695-702.

Brehm A, Miska EA, McCance DJ, Reid JL, Bannister AJ, Kouzarides T (1998): Retinoblastoma protein recruits histone deacetylase to repress transcription. Nature 391(6667), 597-601.

Cheng H, Lederer WJ, Cannell MB (1993): Calcium sparks: elementary events underlying excitation-contraction coupling in heart muscle. Science $\underline{262}, 740-4$.

Cheng HY, Pitcher GM, Laviolette SR, Whishaw IQ, Tong KI, Kockeritz LK, Wada T, Joza NA, Crackower M, Goncalves J et al. (2002): DREAM is a critical transcriptional repressor for pain modulation. Cell $\underline{108}, 31-43$. 
Clapham DE (1995): Calcium signaling. Cell 80(2), 259-268.

Clay JR (2009): Determining k channel activation curves from $\mathrm{k}$ channel currents often requires the goldman-hodgkin-katz equation. Front Cell Neurosci $\underline{3}, 20$.

Cocco L, Gilmour RS, Ognibene A, Letcher AJ, Manzoli FA und Irvine RF (1987): Synthesis of polyphosphoinositides in nuclei of Friend cells. Evidence for polyphosphoinositide metabolism inside the nucleus which changes with cell differentiation. Biochem $\mathrm{J}$ 248(3), $765-770$.

Cockcroft S (2006): The latest phospholipase C, PLCeta, is implicated in neuronal function. Trends Biochem Sci $\underline{31}$, 4-7.

Coffey RJ, Hawkey CJ, Damstrup L, Graves-Deal R, Daniel VC, Dempsey PJ, Chinery R, Kirkland SC, DuBois RN, Jetton TL et al. (1997): Epidermal growth factor receptor activation induces nuclear targeting of cyclooxygenase-2, basolateral release of prostaglandins, and mitogenesis in polarizing colon cancer cells. Proc Natl Acad Sci USA 94(2), 657-662.

Cox S, Taylor SS (1994): Holoenzyme interaction sites in the cAMP-dependent protein kinase. Histidine 87 in the catalytic subunit complements serine 99 in the type I regulatory subunit. J Biol Chem 269(36), 22614-22.

Danker T, Shahin V, Schlune A, Schafer C, Oberleithner H (2001): Electrophoretic plugging of nuclear pores by using the nuclear hourglass technique. J Membr Biol 184, 91-99.

Denton RM, McCormack JG (1990): Ca2+ as a second messenger within mitochondria of the heart and other tissues. Annu Rev Physiol 52, 451-66.

Divecha N, Banfic H, Irvine RF (1991): The polyphosphoinositide cycle exists in the nuclei of Swiss 3T3 cells under the control of a receptor (for IGF-I) in the plasma 82 membrane, and stimulation of the cycle increases nuclear diacylglycerol and apparently induces translocation of protein kinase $\mathrm{C}$ to the nucleus. EMBO J 10(11), 3207-3214. 
Dolmetsch RE, Lewis RS, Goodnow CC, Healy JI (1997): Differential activation of transcription factors induced by $\mathrm{Ca} 2+$ response amplitude and duration. Nature $\underline{386}, 855-58$.

Dolmetsch RE, Xu K, Lewis RS (1998): Calcium oscillations increase the efficiency and specificity of gene expression. Nature $\underline{392}, 933-936$.

Dolmetsch RE, Pajvani U, Fife K, Spotts JM, Greenberg ME (2001): Signaling to the nucleus by an L-type calcium channel-calmodulin complex through the MAP kinase pathway. Science 294, 333-339.

Downes CP, Gray A, Lucocq JM (2005): Probing phosphoinositide functions in signaling and membrane trafficking. Trends Cell Biol $\underline{15}, 259-268$.

Echevarria W, Leite MF, Guerra MT, Zipfel WR, Nathanson MH (2003): Regulation of calcium signals in the nucleus by a nucleoplasmic reticulum. Nat Cell Biol 5, 440-446.

Escobar M, Cardenas C, Colavita K, Petrenko NB, Franzini-Armstrong C (2011): Structural evidence for perinuclear calcium microdomains in cardiac myocytes. J Mol Cell Cardiol $\underline{50(3)}, 451-9$.

Faenza I, Bregoli L, Ramazzotti G, Gaboardi G, Follo MY, Mongiorgi S, Billi AM, Manzoli L, Martelli AM, Cocco, L (2008): Nuclear phospholipase C beta1 and cellular differentiation. Front Biosci 13, 2452-2463.

Franzini-Armstrong C, Protasi F, Ramesh V (1999): Shape, size, and distribution of Ca2+ release units and couplons in skeletal and cardiac muscles. Biophys J $\underline{77}, 1528-39$.

Fricker M, Hollinshead M, White N, Vaux D (1997): Interphase Nuclei of Many Mammalian Cell Types Contain Deep, Dynamic, Tubular Membrane-bound Invaginations of the Nuclear Envelope. J Cell Biol 136(3), 531-44.

Genka C, Ishida H, Ichimori K, Hirota Y, Tanaami T, Nakazawa H (1999): Visualization of biphasic $\mathrm{Ca} 2+$ diffusion from cytosol to nucleus in contracting adult rat cardiac myocytes with an ultra-fast confocal imaging system. Cell Calcium 25(3), 199-208. 
Gerasimenko O, Gerasimenko J (2004): New aspects of nuclear calcium signalling. J Cell Sci $\underline{117}, 3087-3094$.

Greber UF, Senior A, Gerace L (1990): A major glycoprotein of the nuclear porecomplex is a membrane-spanning polypeptide with a large lumenal domain and a small cytoplasmic tail. EMBO J $\underline{9}, 1495-1502$.

Gruver CL, DeMayo F, Goldstein MA, Means AR (1993): Targeted developmental overexpression of calmodulin induces proliferative and hypertrophic growth of cardiomyocytes in transgenic mice. Endocrinology $\underline{33}$, 376-88.

Grynkiewicz G, Poenie M, and Tsien RY (1985): A new generation of Ca2+ indicators with greatly improved fluorescence properties. J Biol Chem 260, 3440-3450.

Guatimosim S, Amaya MJ, Guerra MT, Aguiar CJ, Goes AM, Gómez-Viquez NL, Rodrigues MA, Gomes DA, Martins-Cruz J, Lederer WJ, Leite MF (2008): Nuclear Ca2+ regulates cardiomyocyte function. Cell Calcium $\underline{44(2)}, 230-42$.

Hallhuber M, Burkard N, Wu R, Buch MH, Engelhardt S, Hein L, Neyses L, Schuh K, Ritter O (2006): Inhibition of nuclear import of calcineurin prevents myocardial hypertrophy. Circ Res $\underline{99}, 626-635$.

Higazi DR, Fearnley CJ, Drawnel FM, Talasila A, Corps EM, Ritter O, McDonald F, Mikoshiba K, Bootman MD, Roderick HL (2009): Endothelin-1-stimulated InsP3-induced $\mathrm{Ca} 2+$ release is a nexus for hypertrophic signaling in cardiac myocytes. Mol Cell $\underline{33}, 472-482$.

Humbert JP, Matter N, Artault JC, Köppler P, Malviya AN (1996): Inositol 1,4,5trisphosphate receptor is located to the inner nuclear membrane vindicating regulation of nuclear calcium signaling by inositol 1,4,5-trisphosphate. Discrete distribution of inositol phosphate receptors to inner and outer nuclear membranes. J Biol Chem 271(1), 478-85. 
Jong YJ, Kumar V, Kingston AE, Romano C, O’Malley KL (2005): Functional metabotropic glutamate receptors on nuclei from brain and primary cultured striatal neurons: role of transporters in delivering ligand. J Biol Chem $\underline{280}$, 30469-30480.

Kamp TJ, Hell JW (2000): Regulation of cardiac L-type calcium channels by protein kinase A and protein kinase C. Circ Res $\underline{\text { 87(12) }}$, 1095-102.

Kockskämper J, Seidlmeyer L, Walther S, Hellenkamp K, Meier LS, Pieske B (2008): Endothelin-1 enhances nuclear $\mathrm{Ca} 2+$ transients in atrial myocytes through $\operatorname{Ins}(1,4,5) \mathrm{P} 3-$ dependent Ca2+ release from perinuclear Ca2+ stores. J Cell Sci 121(Pt 2), 186-95.

Koppler P, Matter N, Malviya AN (1993): Evidence for stereospecific inositol 1,3,4,5$[3 \mathrm{H}]$ tetrakisphosphate binding sites on rat liver nuclei. Delineating inositol 1,3,4,5tetrakisphosphate interaction in nuclear calcium signaling process. J Biol Chem 268(35), $26248-26252$.

Kramer A, Ludwig Y, Shahin V, Oberleithner H (2007): A pathway separate from the central channel through the nuclear pore complex for inorganic ions and small macromolecules. $\mathrm{J}$ Biol Chem 282, 31437-31443.

Krauss G: Biochemistry of Signal Transduction and Regulation. 2. veränderte Auflage; Wiley-VCH Verlag GmbH \& Co. KGaA, Weinheim 2001.

Lee MA, Dunn RC, Clapham DE, Stehno-Bittel L (1998): Calcium regulation of nuclear pore permeability. Cell Calcium $\underline{23}, 91-101$.

Lee RK, Lui PP, Ngan EK, Lui JC, Suen YK, Chan F, Kong SK. (2006): The nuclear tubular invaginations are dynamic structures inside the nucleus of HeLa cells. Can J Physiol Pharmacol $\underline{84}, 477-486$.

Linseman DA, Bartley CM, Le SS, Laessig TA, Bouchard RJ, Meintzer MK, Li M, Heidenreich KA (2003): Inactivation of the myocyte enhancer factor-2 repressor histone deacetylase- 5 by endogenous $\mathrm{Ca} 2+/$ calmodulin-dependent kinase II promotes depolarizationmediated cerebellar granule neuron survival. J Biol Chem 278, 41472-81. 
Little GH, Saw A, Bai Y, Dow J, Marjoram P, Simkhovich B, Leeka J, Kedes L, Kloner RA, Poizat C (2009): Critical role of nuclear calcium/calmodulin-dependent protein kinase IIdeltaB in cardiomyocyte survival in cardiomyopathy. J Biol Chem 284, 24857-24868.

Ljubojevic S, Walther S, Asgarzoei M, Sedej S, Pieske B, Kockskämper J (2011): In Situ Calibration of Nucleoplasmic versus Cytoplasmic $\mathrm{Ca} 2+$ Concentration in Adult Cardiomyocytes. Biophys J 100(10), 2356-66.

Lui PP, Chan FL, Suen YK, Kwok TT, Kong SK (2003): The nucleus of HeLa cells contains tubular structures for $\mathrm{Ca} 2+$ signaling with the involvement of mitochondria. Biochem Biophys Res Commun $\underline{308}$, 826-833.

Mak DO, Foskett JK (1994): Single-channel inositol 1,4,5-trisphosphate receptor currents revealed by patch clamp of isolated Xenopus oocyte nuclei. J Biol Chem 269(47), 2937529378.

Malviya AN (1994): The nuclear inositol 1,4,5-trisphosphate and inositol 1,3,4,5tetrakisphosphate receptors. Cell Calcium 16(4), 301-313.

Martelli AM, Billi AM, Manzoli L, Faenza I, Aluigi M, Falconi M, Pol AD, Gilmour RS, Cocco L (2000): Insulin selectively stimulates nuclear phosphoinositide-specific phospholipase C (PI-PLC) betal activity through a mitogen-activated protein (MAP) kinase dependent serine phosphorylation. FEBS Lett 486(3), 230-236.

Masterson LR, Yu T, Shi L, Wang Y, Gustavsson M, Mueller MM, Veglia G (2011): cAMPdependent protein kinase A selects the excited state of the membrane substrate phospholamban. J Mol Biol 412(2), 155-64.

McDonough PM, Glembotski CC (1992): Induction of natriuretic factor and myosin light chain-2 gene expression in cultured ventricular myocytes by electrical stimulation. J Biol Chem 267, 11665-68. 
Mermelstein PG, Deisseroth K, Dasgupta N, Isaksen AL, Tsien RW (2001): Calmodulin priming: nuclear translocation of a calmodulin complex and the memory of prior neuronal activity. Proc Natl Acad Sci USA $\underline{98}, 15342-15347$.

Molkentin JD (2004): Calcineurin-NFAT signaling regulates the cardiac hypertrophic response in coordination with the MAPKs. Cardiovasc Res $\underline{63}$, 467-75.

O'Brien EM, Gomes DA, Sehgal S, Nathanson MH (2007): Hormonal regulation of nuclear permeability. J Biol Chem 282, 4210-4217.

Okada M, Ishimoto T, Naito Y, Hirata H, Yagisawa H (2005): Phospholipase Cdelta1 associates with importin beta1 and translocates into the nucleus in a $\mathrm{Ca} 2+-$ dependent manner. FEBS Lett $\underline{579}$, 4949-4954.

Passier R, Zeng H, Frey N, Naya FJ, Nicol RL, McKinsey TA, Overbeek P, Richardson JA, Grant SR, Olson EN (2000): CaM kinase signaling induces cardiac hypertrophy and activates the MEF2 transcription factor in vivo. J Clin Invest 105, 1395-1406.

Quiniou G, Chevalier JM, Barbou F, Bire F, Clementy J (2000): Tachycardia-induced cardiomyopathy, unusual and reversible cause of left ventricular dysfunction: Report of 9 cases. Ann Cardiol Angeiol (Paris) 49(5), 301-308.

Ramesh Iyer V (2008): Ventricular Dysfunction: Tachycardia induced Cardiomyopathy. Indian Pacing Electrophysiol J 8(Suppl. 1), S122-S129.

Rinne A, Kapur N, Molkentin JD, Pogwizd SM, Bers DM, Banach K, Blatter LA (2010): Isoform- and tissue-specific regulation of the $\mathrm{Ca}(2+)$-sensitive transcription factor NFAT in cardiac myocytes and heart failure. Am J Physiol Heart Circ Physiol 298(6), H2001-9.

Rodrigues MA, Gomes DA, Leite MF, Grant W, Zhang L, Lam W, Cheng YC, Bennett AM, Nathanson MH (2007): Nucleoplasmic calcium is required for cell proliferation. J Biol Chem $\underline{282}, 17061-17068$. 
Schermelleh L, Carlton PM, Haase S, Shao L, Winoto L, Kner P, Burke B, Cardoso MC, Agard DA, Gustafsson MG et al. (2008): Subdiffraction multicolor imaging of the nuclear periphery with 3D structured illumination microscopy. Science $\underline{320}$, 1332-1336.

Shahin V, Danker T, Enss K, Ossig R, Oberleithner H (2001): Evidence for Ca2+- and ATPsensitive peripheral channels in nuclear pore complexes. FASEB J $\underline{15}, 1895-1901$.

Shannon TR, Ginsburg KS, Bers DM (2000): Potentiation of fractional SR Ca release by total and free intra-SR Ca concentration. Biophys J $\underline{78}, 334-343$.

Shannon TR, Guo T, Bers DM (2003): Ca2+ scraps: local depletions of free [Ca2+] in cardiac sarcoplasmic reticulum during contractions leave substantial $\mathrm{Ca} 2+$ reserve. Circ Res 93(1), 40-5.

Shinbane JS, Wood MA, Jensen DN, Ellenbogen KA, Fitzpatrick AP, Scheinman MM (1997): Tachycardia-induced cardiomyopathy: A review of animal models and clinical studies. J Am Coll Cardiol 29(4), 709-715.

Shirakawa H, Miyazaki S (1996): Spatiotemporal analysis of calcium dynamics in the nucleus of hamster oocytes. J Physiol 494, 29-40.

Stallings JD, Zeng YX, Narvaez F, Rebecchi MJ (2008): Phospholipase Cdelta1 expression is linked to proliferation, DNA synthesis, and cyclin E levels. J Biol Chem $\underline{283}$, 13992-14001.

Stehno-Bittel L, Lückhoff A, Clapham DE (1995): Calcium release from the nucleus by InsP3 receptor channels. Neuron $\underline{14(1)}, 163-167$.

Stoffler D, Schwarz-Herion K, Aebi U, Fahrenkrog B (2006): Getting across the nuclear pore complex: new insights into nucleocytoplasmic transport. Can J Physiol Pharmacol $\underline{84}$, 499507.

Territo PR, Mootha VK, French SA, Balaban RS (2000): Ca(2+) activation of heart mitochondrial oxidative phosphorylation: role of $\mathrm{F}(0) / \mathrm{F}(1)$-ATPase. Am J Physiol Cell Physiol 278, C423-35. 
Thomas D, Lipp P, Tovey SC, Berridge MJ, Li W, Tsien RY, Bootman MD (2000): Microscopic properties of elementary $\mathrm{Ca} 2+$ release sites in non-excitable cells. Curr Biol $\underline{10}$, 8-15.

Thorogate R, Torok K (2004): Ca2+-dependent and -independent mechanisms of calmodulin nuclear translocation. J Cell Sci 117, 5923-5936.

Thorogate R, Torok K (2007): Role of Ca2+ activation and bilobal structure of calmodulin in nuclear and nucleolar localization. Biochem $\mathrm{J} \underline{402}$, 71-80.

Timpl R, Fujiwara S, Dziadek M, Aumailley M, Weber S, Engel J (1984): Laminin, proteoglycan, nidogen and collagen IV: structural models and molecular interactions. Ciba Found Symp $\underline{108}, 25-43$.

Trafford AW, Diaz ME, Eisner DA (2001): Coordinated control of cell Ca2+ loading and triggered release from the sarcoplasmic reticulum underlies the rapid inotropic response to increased L-type Ca2+ current. Circ Res $\underline{88}, 195-201$.

Umana E, Solares AC, Alpert MA (2003): Tachycardia-Induced Cardiomyopathy. Am J Med $\underline{114}, 51-55$.

Vermassen E, Van Acker K, Annaert WG, Himpens B, Callewaert G, Missiaen L, De Smedt H, Parys JB (2003): Microtubule-dependent redistribution of the type-1 inositol 1,4,5trisphosphate receptor in A7r5 smooth muscle cells. J Cell Sci 116, 1269-1277.

Wei X, Henke VG, Strubing C, Brown EB, Clapham DE (2003): Realtime imaging of nuclear permeation by EGFP in single intact cells. Biophys $\mathrm{J} \underline{84}, 1317-1327$.

Wu X, Bers DM (2006): Sarcoplasmic reticulum and nuclear envelope are one highly interconnected Ca2+ store throughout cardiac myocyte. Circ Res 99(3), 283-291.

Wu X, Bers DM (2007): Free and bound intracellular calmodulin measurements in cardiac myocytes. Cell Calcium $\underline{41}, 353-364$. 
Wu X, Zhang T, Bossuyt J, Li X, McKinsey TA, Dedman JR, Olson EN, Chen J, Brown JH, Bers DM (2006): Local InsP3-dependent perinuclear Ca2+ signaling in cardiac myocyte excitation-transcription coupling. J Clin Invest 116(3), 675-82.

Ye K, Ahn JY (2008): Nuclear phosphoinositide signaling. Front Biosci 13, 540-548.

Zhang T, Brown JH (2004): Role of Ca2+/calmodulin-dependent protein kinase II in cardiac hypertrophy and heart failure. Cardiovasc Res $\underline{63}$, 476-486. 


\section{Teilveröffentlichung der Dissertation}

Ljubojevic S, Walther S, Asgarzoei M, Sedej S, Pieske B, Kockskämper J (2011): In Situ

Calibration of Nucleoplasmic versus Cytoplasmic $\mathrm{Ca} 2+$ Concentration in Adult Cardiomyocytes. Biophys J 100(10), 2356-66. 


\section{Danksagung}

Prof. Dr. rer. nat. Jens Kockskämper danke ich vielmals für die sehr gute und kompetente Betreuung sowie die Geduld, welche er bei jeder meiner Fragen und den Korrekturen dieser Arbeit hatte. Dank seiner fachlich und menschlich kompetenten Führung konnte diese Arbeit abgeschlossen werden.

Der gesamten Arbeitsgruppe von Prof. Dr. med. Pieske danke ich für die stets freundlichen und kompetenten Ratschläge und Gespräche.

Meiner Mitdoktorandin Shelia Khan danke ich für die Hilfe bei der Einarbeitung in die Methodik und die stets freundliche und bemühte Art. 


\section{Curriculum Vitae}

Ich wurde am 27.06.1981 als erster von drei Söhnen von Malek Mohammad Asgarzoei und Maleka Besmellah in Kabul (Afghanistan) geboren. Im Februar 1982 flüchteten meine Eltern mit mir vor dem Einmarsch der Sowjetunion nach Deutschland.

Von 1987 bis 1991 besuchte ich die Lohberg-Grundschule in Göttingen, im Anschluss besuchte ich die Berthold-Brecht-Orientierungsstufe in Göttingen von 1991 bis 1993.

Es folgte der Besuch des Hainberggymnasiums in Göttingen von 1993 bis zum Erhalt der allgemeinen Hochschulreife 2000.

Im Dezember 2000 begann ich meinen Zivildienst im Universitäts-Klinikum Göttingen in der Pflege. Zum Wintersemester 2001 konnte ich dann mit dem Medizinstudium in Göttingen beginnen, welches ich erfolgreich im Juni 2009 abschließen konnte. Während dieser Zeit begann ich im September 2006 mit meiner Doktorarbeit in der Kardiologie.

Seit 2009 bin ich im Klinikum Bielefeld als Assistenzarzt in der Kardiologie und internistischen Intensivmedizin beschäftigt. 